\title{
Interventions for implementation of thromboprophylaxis in hospitalized patients at risk for venous thromboembolism (Review)
}

Kahn SR, Morrison DR, Diendéré G, Piché A, Filion KB, Klil-Drori AJ, Douketis JD, Emed J, Roussin A, Tagalakis V, Morris M, Geerts W

Kahn SR, Morrison DR, Diendéré G, Piché A, Filion KB, Klil-Drori AJ, Douketis JD, Emed J, Roussin A, Tagalakis V, Morris M, Geerts W.

Interventions for implementation of thromboprophylaxis in hospitalized patients at risk for venous thromboembolism. Cochrane Database of Systematic Reviews 2018, Issue 4. Art. No.: CD008201.

DOI: 10.1002/14651858.CD008201.pub3.

www.cochranelibrary.com 
TABLE OF CONTENTS

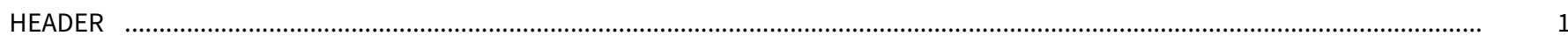

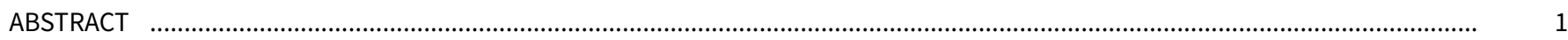

PLAIN LANGUAGE SUMMARY

SUMMARY OF FINDINGS

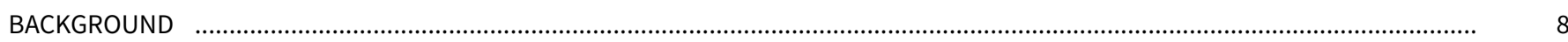

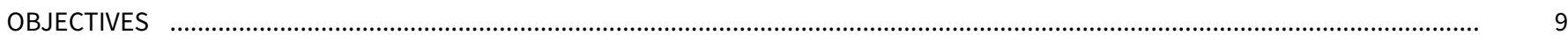

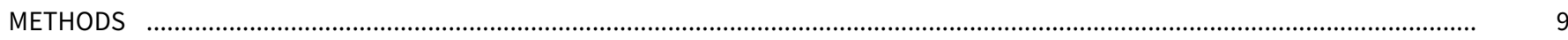

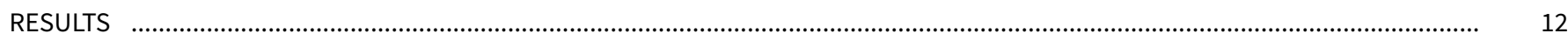

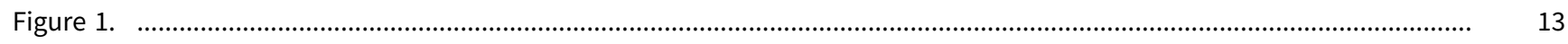

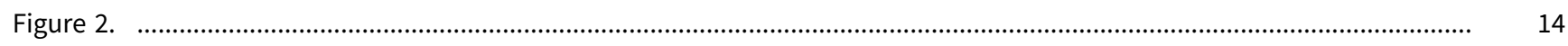

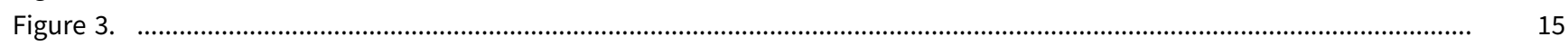

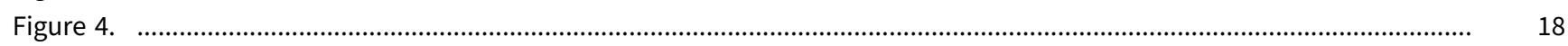

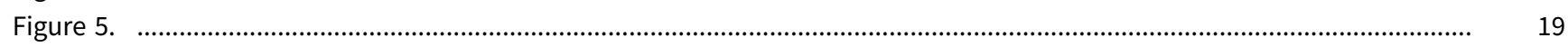

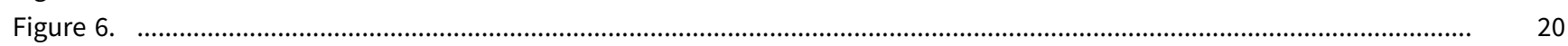

Figure 7.

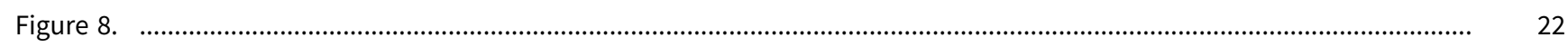

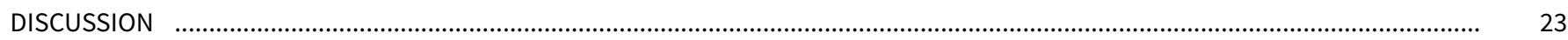

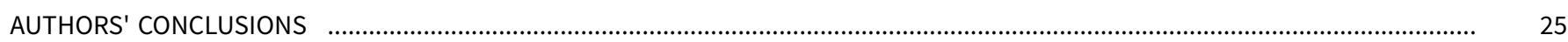

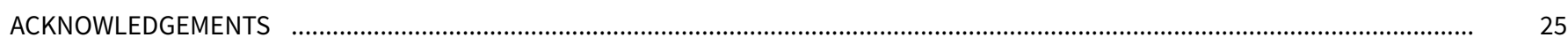

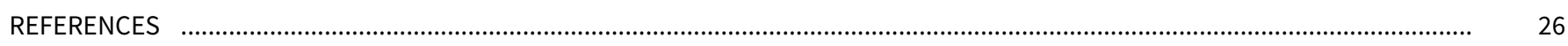

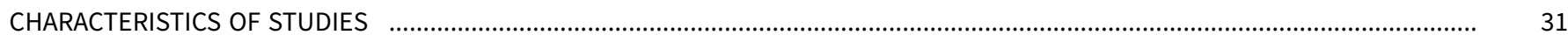

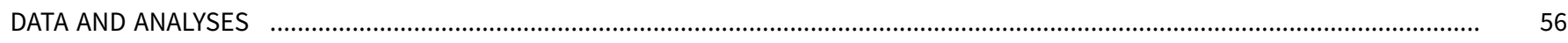

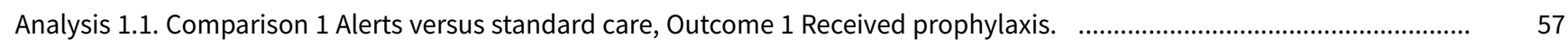

Analysis 1.2. Comparison 1 Alerts versus standard care, Outcome 2 Received appropriate prophylaxis. $\quad$..................................... 57

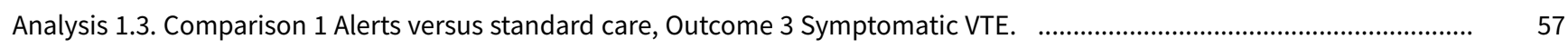

Analysis 2.1. Comparison 2 Multifaceted interventions versus standard care or another intervention, Outcome 1 Received 58 prophylaxis (unadjusted).

Analysis 2.2. Comparison 2 Multifaceted interventions versus standard care or another intervention, Outcome 2 Received prophylaxis (adjusted).

Analysis 2.3. Comparison 2 Multifaceted interventions versus standard care or another intervention, Outcome 3 Received prophylaxis (adjusted) sensitivity analysis: applied lowest ICC from other trials.

Analysis 2.4. Comparison 2 Multifaceted interventions versus standard care or another intervention, Outcome 4 Received prophylaxis (adjusted) sensitivity analysis: applied mean ICC from other trials.

Analysis 2.5. Comparison 2 Multifaceted interventions versus standard care or another intervention, Outcome 5 Received prophylaxis (adjusted) sensitivity analysis: applied highest ICC from trials.

ADDITIONAL TABLES

APPENDICES

WHAT'S NEW

CONTRIBUTIONS OF AUTHORS

DECLARATIONS OF INTEREST

SOURCES OF SUPPORT

DIFFERENCES BETWEEN PROTOCOL AND REVIEW

INDEX TERMS 
[Intervention Review]

\section{Interventions for implementation of thromboprophylaxis in hospitalized patients at risk for venous thromboembolism}

Susan R Kahn1,2,3, David R Morrison², Gisèle Diendéré2, Alexandre Piché4, Kristian B Filion²,5, Adi J Klil-Drori², James D Douketis6 ${ }^{2}$ Jessica Emed $^{7}$, André Roussin 8 , Vicky Tagalakis 2,3 , Martin Morris ${ }^{9}$, William Geerts 10

1Department of Epidemiology, Biostatistics and Occupational Health, McGill University, Montreal, Canada. ${ }^{2}$ Centre for Clinical Epidemiology and Community Studies, SMBD-Jewish General Hospital, McGill University, Montreal, Canada. ${ }^{3}$ Division of Internal Medicine and Department of Medicine, McGill University, Montreal, Canada. ${ }^{4}$ Department of Mathematics and Statistics, McGill University, Montreal, Canada. ${ }^{5}$ Departments of Medicine and of Epidemiology, Biostatistics and Occupational Health, McGill University, Montreal, Canada. ${ }^{6}$ Department of Medicine, McMaster University and St. Josephs Hospital, Hamilton, Canada. ${ }^{7}$ Department of Nursing, Jewish General Hospital, Montreal, Canada. ${ }^{8}$ Department of Medicine, University of Montreal and Thrombosis Canada, Montreal, Canada. ${ }^{9}$ Schulich Library of Physical Sciences, Life Sciences and Engineering, McGill University, Montreal, Canada. ${ }^{10}$ Department of Medicine, Sunnybrook Health Sciences Centre, University of Toronto, Toronto, Canada

Contact address: Susan R Kahn, Department of Epidemiology, Biostatistics and Occupational Health, McGill University, Montreal, Canada. Susan.Kahn@mcgill.ca.

Editorial group: Cochrane Vascular Group

Publication status and date: New search for studies and content updated (no change to conclusions), published in Issue 4, 2018.

Citation: Kahn SR, Morrison DR, Diendéré G, Piché A, Filion KB, Klil-Drori AJ, Douketis JD, Emed J, Roussin A, Tagalakis V, Morris M, Geerts W. Interventions for implementation of thromboprophylaxis in hospitalized patients at risk for venous thromboembolism. Cochrane Database of Systematic Reviews 2018, Issue 4. Art. No.: CD008201. DOI: 10.1002/14651858.CD008201.pub3.

Copyright @ 2018 The Cochrane Collaboration. Published by John Wiley \& Sons, Ltd.

\section{A B S T R A C T}

\section{Background}

Venous thromboembolism (VTE) is a leading cause of morbidity and mortality in hospitalized patients. While numerous randomized controlled trials (RCTs) have shown that the appropriate use of thromboprophylaxis in hospitalized patients at risk for VTE is safe, effective, and cost-effective, thromboprophylaxis remains underused or inappropriately used. Our previous review suggested that system-wide interventions, such as education, alerts, and multifaceted interventions were more effective at improving the prescribing of thromboprophylaxis than relying on individual providers' behaviors. However, 47 of the 55 included studies in our previous review were observational in design. Thus, an update to our systematic review, focused on the higher level of evidence of RCTs only, was warranted.

\section{Objectives}

To assess the effects of system-wide interventions designed to increase the implementation of thromboprophylaxis and decrease the incidence of VTE in hospitalized adult medical and surgical patients at risk for VTE, focusing on RCTs only.

\section{Search methods}

Our research librarian conducted a systematic literature search of MEDLINE Ovid, and subsequently translated it to CENTRAL, PubMed, Embase Ovid, BIOSIS Previews Ovid, CINAHL, Web of Science, the Database of Abstracts of Reviews of Effects (DARE; in the Cochrane Library), NHS Economic Evaluation Database (EED; in the Cochrane Library), LILACS, and clinicaltrials.gov from inception to 7 January 2017. We also screened reference lists of relevant review articles. We identified 12,920 potentially relevant records.

\section{Selection criteria}

We included all types of RCTs, with random or quasi-random methods of allocation of interventions, which either randomized individuals (e.g. parallel group, cross-over, or factorial design RCTs), or groups of individuals (cluster RCTs (CRTs)), which aimed to increase the use of prophylaxis or appropriate prophylaxis, or decrease the occurrence of VTE in hospitalized adult patients. We excluded observational 
studies, studies in which the intervention was simply distribution of published guidelines, and studies whose interventions were not clearly described. Studies could be in any language.

\section{Data collection and analysis}

We collected data on the following outcomes: the number of participants who received prophylaxis or appropriate prophylaxis (as defined by study authors), the occurrence of any VTE (symptomatic or asymptomatic), mortality, and safety outcomes, such as bleeding. We categorized the interventions into alerts (computer or human alerts), multifaceted interventions (combination of interventions that could include an alert component), educational interventions (e.g. grand rounds, courses), and preprinted orders (written predefined orders completed by the physician on paper or electronically). We meta-analyzed data across RCTs using a random-effects model. For CRTs, we pooled effect estimates (risk difference (RD) and risk ratio (RR), with 95\% confidence interval (CI), adjusted for clustering, when possible. We pooled results if three or more trials were available for a particular intervention. We assessed the certainty of the evidence according to the GRADE approach.

\section{Main results}

From the 12,920 records identified by our search, we included $13 \mathrm{RCTs}$ ( $\mathrm{N}=35,997$ participants) in our qualitative analysis and $11 \mathrm{RCTs}$ ( $\mathrm{N}$ $=33,207$ participants) in our meta-analyses.

Primary outcome: Alerts were associated with an increase in the proportion of participants who received prophylaxis (RD $21 \%, 95 \% \mathrm{Cl}$ $15 \%$ to $27 \%$; three studies; 5057 participants; $I^{2}=75 \%$; low-certainty evidence). The substantial statistical heterogeneity may be in part explained by patient types, type of hospital, and type of alert. Subgroup analyses were not feasible due to the small number of studies included in the meta-analysis.

Multifaceted interventions were associated with a small increase in the proportion of participants who received prophylaxis (cluster-adjusted RD 4\%, 95\% Cl 2\% to 6\%; five studies; 9198 participants; $\mathrm{I}^{2}=0 \%$; moderate-certainty evidence). Multifaceted interventions with an alert component were found to be more effective than multifaceted interventions that did not include an alert, although there were not enough studies to conduct a pooled analysis.

Secondary outcomes: Alerts were associated with an increase in the proportion of participants who received appropriate prophylaxis (RD $16 \%, 95 \% \mathrm{Cl} 12 \%$ to $20 \%$; three studies; 1820 participants; $\mathrm{I}^{2}=0$; moderate-certainty evidence). Alerts were also associated with a reduction in the rate of symptomatic VTE at three months (RR $64 \%, 95 \%$ Cl 47\% to $86 \%$; three studies; 5353 participants; $\left.\right|^{2}=15 \%$; lowcertainty evidence). Computer alerts were associated with a reduction in the rate of symptomatic VTE, although there were not enough studies to pool computer alerts and human alerts results separately.

\section{Authors' conclusions}

We reviewed RCTs that implemented a variety of system-wide strategies aimed at improving thromboprophylaxis in hospitalized patients. We found increased prescription of prophylaxis associated with alerts and multifaceted interventions, and increased prescription of appropriate prophylaxis associated with alerts. While multifaceted interventions were found to be less effective than alerts, a multifaceted intervention with an alert was more effective than one without an alert. Alerts, particularly computer alerts, were associated with a reduction in symptomatic VTE at three months, although there were not enough studies to pool computer alerts and human alerts results separately.

Our analysis was underpowered to assess the effect on mortality and safety outcomes, such as bleeding.

The incomplete reporting of relevant study design features did not allow complete assessment of the certainty of the evidence. However, the certainty of the evidence for improvement in outcomes was judged to be better than for our previous review (low- to moderate-certainty evidence, compared to very low-certainty evidence for most outcomes). The results of our updated review will help physicians, hospital administrators, and policy makers make practical decisions about adopting specific system-wide measures to improve prescription of thromboprophylaxis, and ultimately prevent VTE in hospitalized patients.

\section{PLAIN LANGUAGE SUMMARY}

Interventions to increase the use of measures to prevent the development of blood clots in hospitalized medical and surgical patients

\section{What is the aim of this review?}

The aim of this Cochrane review was to find out if system-wide interventions increased the use of measures to prevent blood clots (thromboprophylaxis), and decreased the incidence of blood clots (venous thromboembolism) in hospitalized adult medical and surgical patients at risk for this problem.

\section{Key messages}


Providing system-wide interventions, particularly alerts, to doctors and other healthcare professionals probably improves the use of thromboprophylaxis or appropriate thromboprophylaxis, and decreases the number of symptomatic blood clots (clots showing symptoms) at three months. However, the certainty of the evidence was rated as moderate or low, thus more high-quality studies examining the effectiveness of system-wide interventions are needed to confirm the findings of this review.

\section{What was studied in this review?}

Blood clots that occur in the leg veins (deep vein thrombosis) or in the lung circulation (pulmonary embolism) are together known as venous thromboembolism (VTE). VTE is a potential complication for patients who have been hospitalized for medical or surgical reasons. These complications lengthen hospital stay and are a leading cause of death and long-term disability. Risk factors for VTE include hospitalization for surgical or medical illness, cancer, trauma or immobilization, medications, such as oral contraceptives or hormone replacement therapy, and pregnancy or postpartum. Other risk factors are older age, obesity, previous blood clots, and family history of blood clots.

Thromboprophylaxis involves the administration of small doses of anticoagulant (i.e. blood thinning) medications, such as heparin, low molecular weight heparin, or oral blood thinners, or the application of physical measures, such as graduated compression stockings or sequential compression devices. In the USA, thromboprophylaxis has been ranked as the number one strategy to improve patient safety in hospitals, and interventions to improve the implementation of thromboprophylaxis were recently ranked as a top-10 patient safety strategy that demanded action.

While thromboprophylaxis is safe and can prevent VTE in various patient groups at risk for these complications, it remains underused or inappropriately used. We looked at two different ways to measure thromboprophylaxis use: received prophylaxis (did the patient receive any thromboprophylaxis?), and received appropriate prophylaxis (did the patient receive prophylaxis that was appropriate for them?). We considered prophylaxis to be appropriate if the study authors did.

\section{What are the main results of this review?}

We did a systematic review of randomized controlled trials (trials in which people are randomly put into one of two or more treatment groups) that tested various system-wide interventions, which aimed to increase the use of thromboprophylaxis in hospitalized patients. Our search found 13 relevant studies; two could not be pooled with the others because they did not report data in which we were interested. We included 11 studies, with a total of 33,207 participants, in our analyses. Our review showed that interventions using alerts seemed to be the most reliable way to increase the use of thromboprophylaxis.

Combined data showed that:

- Computer or human alerts increased the number of participants who received thromboprophylaxis by $21 \%$ (three studies, 5057 participants, low-certainty evidence).

- Alerts increased the number of participants who received appropriate thromboprophylaxis by $16 \%$ (three studies, 1820 participants, moderate-certainty evidence).

- Alerts decreased the relative rate of symptomatic VTE at three months by 36\% (three studies, 5353 participants, low-certainty evidence). - Multifaceted interventions were associated with only a modest $4 \%$ increase in the prescription of thromboprophylaxis (five studies, 9198 participants, moderate-certainty evidence).

- While not directly compared to each other, alerts, whether computer or human alerts, appeared to be more effective than multifaceted interventions.

- While not directly compared to each other, computer alerts may have been more effective than human alerts for increasing appropriate thromboprophylaxis and reducing symptomatic VTE.

\section{How up to date is the review?}

We searched for studies that had been published up to 7 January 2017. 


\begin{tabular}{|c|c|c|c|c|c|c|c|}
\hline \multirow{14}{*}{ 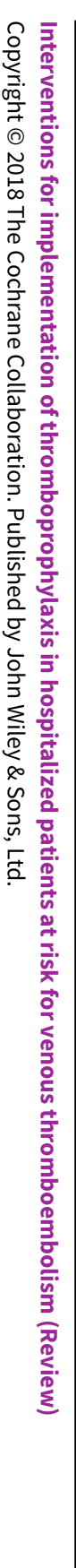 } & \multicolumn{7}{|c|}{$\begin{array}{l}\text { S U M M A R Y O F F I N D I N G S } \\
\text { Summary of findings for the main comparison. Computer or human alerts interventions versus standard care }\end{array}$} \\
\hline & \multicolumn{7}{|c|}{ Computer or human alerts compared with standard care for VTE prophylaxis. } \\
\hline & \multicolumn{7}{|c|}{$\begin{array}{l}\text { Patient or population: adult medical and surgical patients at risk for VTE } \\
\text { Settings: hospital } \\
\text { Intervention: automatic reminder systems, such as computer alerts or human alerts, designed to increase the implementation of thromboprophylaxis and/or decrease the } \\
\text { incidence of symptomatic or asymptomatic VTE } \\
\text { Comparison: standard care (no intervention) }\end{array}$} \\
\hline & \multirow[t]{3}{*}{ Outcomes } & \multicolumn{2}{|c|}{$\begin{array}{l}\text { Illustrative comparative } \\
\text { risks }^{\star}(95 \% \mathrm{CI})\end{array}$} & \multirow[t]{3}{*}{ Measures of effect (RD, RR) $\left(95 \% \mathrm{Cl} ; \mathrm{I}^{2}\right)$} & \multirow[t]{3}{*}{$\begin{array}{l}\text { No of Participants } \\
\text { (studies) }\end{array}$} & \multirow{3}{*}{$\begin{array}{l}\text { Quality of the } \\
\text { evidence } \\
\text { (GRADE) }\end{array}$} & \multirow[t]{3}{*}{ Comments } \\
\hline & & $\begin{array}{l}\text { Assumed } \\
\text { risk }^{\star}\end{array}$ & $\begin{array}{l}\text { Correspond- } \\
\text { ing risk }\end{array}$ & & & & \\
\hline & & $\begin{array}{l}\text { Control } \\
\text { group }\end{array}$ & $\begin{array}{l}\text { Intervention } \\
\text { group }\end{array}$ & & & & \\
\hline & \multirow{6}{*}{$\begin{array}{l}\text { Received prophylaxis }{ }^{\star \star} \\
\text { (Follow-up: } 3 \text { months) }\end{array}$} & \multicolumn{2}{|c|}{ Study population } & \multirow[t]{6}{*}{ RD 0.21 ( 0.15 to $0.27 ; 75 \%)$} & \multirow{6}{*}{$\begin{array}{l}5057 \\
\text { (3 studies) }\end{array}$} & \multirow{6}{*}{$\begin{array}{l}\oplus \oplus \ominus \ominus \\
\text { Low } 1\end{array}$} & \\
\hline & & 178 per 1000 & $\begin{array}{l}390 \text { per } 1000 \\
(335 \text { to } 454)\end{array}$ & & & & \\
\hline & & \multicolumn{2}{|c|}{ Low risk population } & & & & \\
\hline & & 145 per 1000 & $\begin{array}{l}\mathbf{3 1 8} \text { per } \mathbf{1 0 0 0} \\
(273 \text { to } 370)\end{array}$ & & & & \\
\hline & & \multicolumn{2}{|c|}{ High risk population } & & & & \\
\hline & & 357 per 1000 & $\begin{array}{l}782 \text { per } 1000 \\
(671 \text { to } 910)\end{array}$ & & & & \\
\hline & \multirow{2}{*}{$\begin{array}{l}\text { Received appropriate } \\
\text { prophylaxis } \\
\text { (Follow-up: } 36 \text { hours } \\
\text { to } 18 \text { months) }\end{array}$} & \multicolumn{2}{|c|}{ Study population } & \multirow[t]{2}{*}{ RD 0.16 ( 0.12 to $0.20 ; 0 \%)$} & \multirow{2}{*}{$\begin{array}{l}1820 \\
\text { ( } 3 \text { studies) }\end{array}$} & \multirow{2}{*}{\multicolumn{2}{|c|}{$\begin{array}{l}\oplus \oplus \oplus \ominus \\
\text { Moderate }^{2}\end{array}$}} \\
\hline & & 305 per 1000 & $\begin{array}{l}\mathbf{4 6 0} \text { per } 1000 \\
(305 \text { to } 616)\end{array}$ & & & & \\
\hline
\end{tabular}




\begin{tabular}{|c|c|c|c|c|c|}
\hline & Low risk pop & ation & & & \\
\hline $\begin{array}{l}\bar{F} \\
0 \\
0 \\
\tilde{0} \\
0 \\
0\end{array}$ & 175 per 1000 & $\begin{array}{l}\text { 249 per } \mathbf{1 0 0 0} \\
\text { (175 to } 354)\end{array}$ & & & \\
\hline & High risk pop & ation & & & \\
\hline 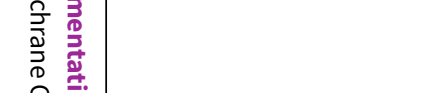 & 663 per 1000 & $\begin{array}{l}\mathbf{9 4 1} \text { per } 1000 \\
\text { (663 to } 1000)\end{array}$ & & & \\
\hline Symptomatic VTE & Study popula & & RR 0.64 ( 0.47 to $0.86 ; 15 \%)$ & 5353 & $\oplus \oplus \odot \ominus$ \\
\hline (Follow-up: 3 months) & 56 per 1000 & $\begin{array}{l}36 \text { per } 1000 \\
\text { (26 to } 48)\end{array}$ & & & \\
\hline 童 & Low risk pop & ation & & & \\
\hline 产产 & 29 per 1000 & $\begin{array}{l}19 \text { per } 1000 \\
\text { (14 to } 25)\end{array}$ & & & \\
\hline 年 & High risk pop & ation & & & \\
\hline . & 82 per 1000 & $\begin{array}{l}\mathbf{5 2} \text { per } \mathbf{1 0 0 0} \\
\text { (39 to } 71)\end{array}$ & & & \\
\hline
\end{tabular}

${ }^{*}$ Control risk was used as assumed risk (baseline risk), due to lack of well-designed observational studies that measure this in detail to be presented as baseline risk for the population. The corresponding risk (and its 95\% confidence interval) is based on the assumed risk in the comparison group and the relative effect of the intervention (and its $95 \% \mathrm{Cl})$.

** Clustered trials did not provide sufficient data (intraclass correlation (ICC) or adjusted confidence intervals) for us to pool cluster adjusted estimates.

Cl: confidence interval; I': statistical index of heterogeneity; RD: risk difference; RR: risk ratio; VTE: venous thromboembolism

GRADE Working Group grades of evidence

High quality: Further research is very unlikely to change our confidence in the estimate of effect.

Moderate quality: Further research is likely to have an important impact on our confidence in the estimate of effect and may change the estimate.

Low quality: Further research is very likely to have an important impact on our confidence in the estimate of effect and is likely to change the estimate.

Very low quality: We are very uncertain about the estimate.

1 We downgraded the level of certainty of evidence from high to low based on the following reasons: serious study limitations (quasi-random sequence generation in $1 / 3$ RCTs, no blinding of outcome assessment in 1/3 RCTs, selective reporting of safety outcomes in 1/3 RCTs. Random sequence generation, allocation concealment, blinding of participants and personnel, and other potential biases were unclear in most studies). No indirectness of evidence; some inconsistency of pooled results; no imprecision of pooled results; and undetected publication bias. 
2 We downgraded the level of certainty of evidence from high to moderate based on the following reasons: serious study limitations (no blinding of participants and personnel in 2/3 RCTs, incorrect analysis that did not account for the clustered nature of the data in 1/3 RCTs. Random sequence generation, allocation concealment, blinding of outcome assessment, incomplete outcome data, selective reporting, and other potential biases were unclear in most studies). No indirectness of evidence; no inconsistency and imprecision of pooled RD results; and undetected publication bias.

3 We downgraded the level of certainty of evidence from high to low based on the following reasons: serious study limitations (quasi-random sequence generation in $1 / 3$ RCTs, selective reporting of safety outcomes in $1 / 3$ RCTs. Random sequence generation, allocation concealment, blinding of participants and personnel, and other potential biases were unclear in most studies). No indirectness of evidence, no inconsistency of pooled RR results, some imprecision of pooled results related to the small number of events, and undetected publication bias.

\section{Summary of findings 2. Multifaceted interventions versus standard care or another intervention}

Multifaceted interventions compared with standard care or another type of intervention for VTE prophylaxis.

Patient or population: adult medical and surgical patients at risk for VTE

Settings: hospital

Intervention: multifaceted interventions (combination of interventions that may include education, audit and feedback, and alert), designed to trigger need for thromboprophylaxis

Comparison: standard care (no intervention) or another type of intervention*

\begin{tabular}{|c|c|c|c|c|c|c|}
\hline \multirow[t]{3}{*}{ Outcomes } & \multicolumn{2}{|c|}{$\begin{array}{l}\text { Illustrative comparative } \\
\text { risks }^{\star \star}(95 \% \mathrm{Cl})\end{array}$} & \multirow{3}{*}{$\begin{array}{l}\text { Absolute } \\
\text { effect (RD) } \\
\left(95 \% \mathrm{Cl} ; \mathrm{I}^{2}\right)\end{array}$} & \multirow{3}{*}{$\begin{array}{l}\text { No of Partici- } \\
\text { pants } \\
\text { (studies) }\end{array}$} & \multirow{3}{*}{$\begin{array}{l}\text { Quality of the } \\
\text { evidence } \\
\text { (GRADE) }\end{array}$} & \multirow[t]{3}{*}{ Comments } \\
\hline & $\begin{array}{l}\text { Assumed } \\
\text { risk }^{\star \star}\end{array}$ & $\begin{array}{l}\text { Correspond- } \\
\text { ing risk }\end{array}$ & & & & \\
\hline & $\begin{array}{l}\text { Control } \\
\text { group }\end{array}$ & $\begin{array}{l}\text { Intervention } \\
\text { group }\end{array}$ & & & & \\
\hline \multirow{4}{*}{$\begin{array}{l}\text { Received pro- } \\
\text { phylaxis } \\
\text { (Unadjusted; Fol- } \\
\text { low-up: } 2 \text { to } 4 \\
\text { months) }\end{array}$} & \multicolumn{2}{|c|}{ Study population } & \multirow{4}{*}{$\begin{array}{l}\text { RD } \mathbf{0 . 0 3}(0.00 \\
\text { to } 0.05 ; 64 \%)\end{array}$} & \multirow{4}{*}{$\begin{array}{l}26,330 \\
\text { (5 studies) }\end{array}$} & \multirow{4}{*}{$\begin{array}{l}\oplus \oplus \oplus \ominus \\
\text { Moderate }\end{array}$} & \multirow{4}{*}{$\begin{array}{l}\text { Clustered trials did not provide sufficient data (intraclass cor- } \\
\text { relation (ICC) or adjusted confidence intervals) for us to pool } \\
\text { cluster-adjusted estimates } \\
\text { Length of follow-up was not specified in one study (Labarere } \\
\text { 2007) }\end{array}$} \\
\hline & 526 per 1000 & $\begin{array}{l}\mathbf{5 5 8} \text { per } \mathbf{1 0 0 0} \\
(526 \text { to } 594)\end{array}$ & & & & \\
\hline & \multicolumn{2}{|c|}{ Low risk population } & & & & \\
\hline & 299 per 1000 & $\begin{array}{l}317 \text { per } 1000 \\
\text { (299 to } 338)\end{array}$ & & & & \\
\hline
\end{tabular}




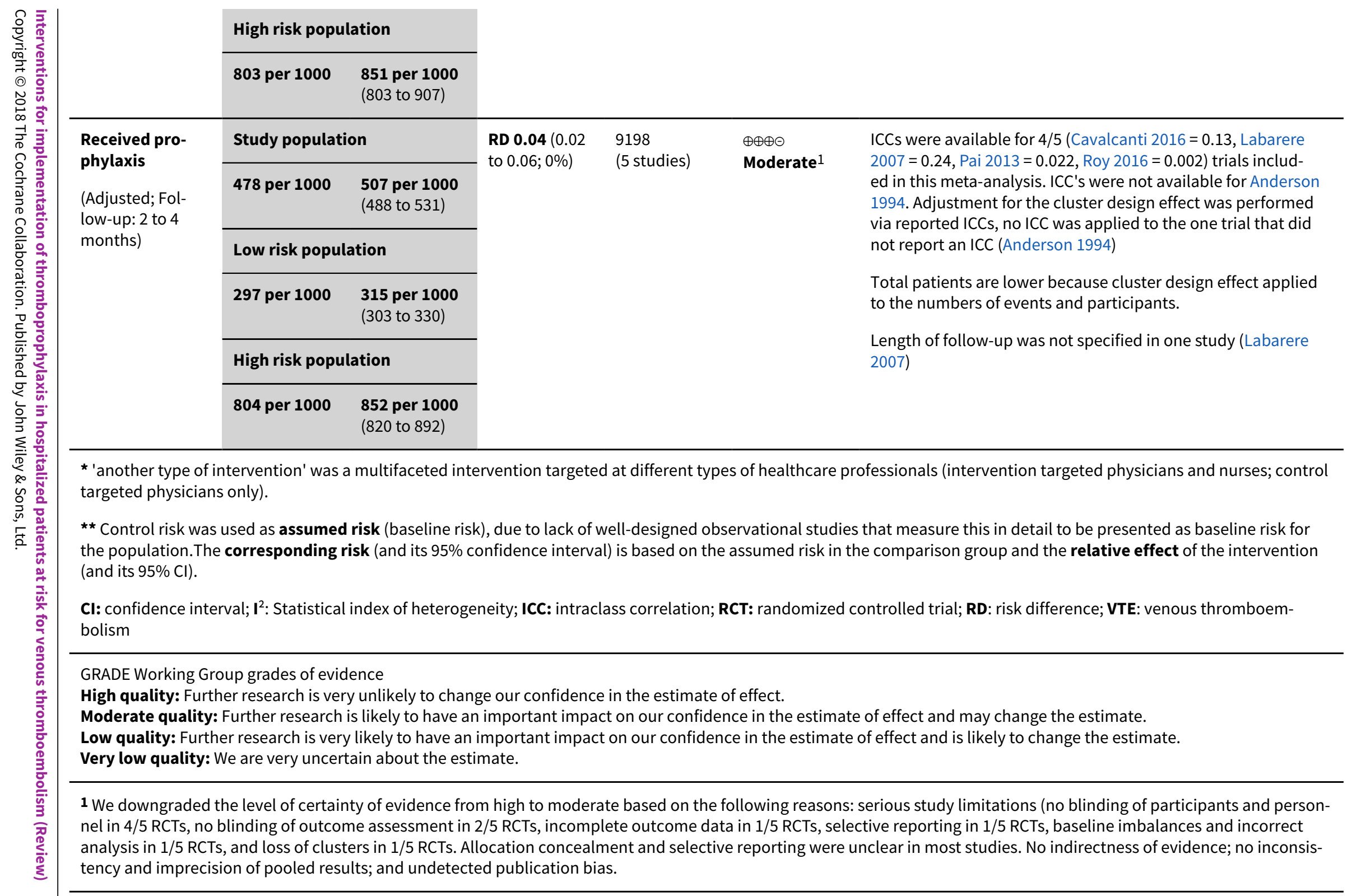




\section{B A C K G R O U N D}

Venous thromboembolism (VTE), which includes deep venous thrombosis (DVT) and pulmonary embolism (PE), is a frequent complication in hospitalized patients, a leading cause of increased costs and length of stay in hospitalized patients, and the leading cause of preventable death in hospital (Fernandez 2015; Heit 2016; Lancet Haematology 2015; Raskob 2014; Wendelboe 2016). The overall annual incidence of VTE is similar in Western Europe, North America, Australia, and southern Latin America, with annual rates ranging from 0.75 to 2.69 per 1000 individuals (Raskob 2014).

Postoperative VTE is a common complication, and a leading cause of mortality and morbidity in hospitalized surgical patients (Heit 2015; Jacobs 2017; Kim 2015). Indeed, among more than seven million patients discharged from 944 acute care hospitals in the USA postoperative VTE was the second most common complication, the second most common cause of excess length of stay, and the third most common cause of excess mortality and costs (Zhan 2003). PE and DVT are recognized as the most frequent preventable causes of hospital death and disability in low-, middle-, and high-income countries combined ( $\mathrm{J}$ ha 2013), and preventing VTE has been ranked as number one of 79 strategies aimed to improve patient safety in hospitals (Shojania 2001).

Hospital-acquired VTE, occurring during hospitalization or within the three months after hospitalization, has been shown to underlie more than $50 \%$ of all cases of the population burden of VTE (Anderson 2007; Heit 2001; Heit 2002; Noboa 2006; Raskob 2016; Spencer 2007). A USA population-based study reported that hospital-acquired DVT occurs in $1.3 \%$ of hospital admissions, and PE occurs in $0.4 \%$ of hospital admissions (Stein 2005). About $60 \%$ of all VTE events occur as a result of a current or recent hospital admission, mainly for surgery (24\%), or medical illness (22\%; Heit 2002). Risk factors for hospital-acquired VTE are well-characterized and include surgery, acute medical illness, cancer and cancer therapy, trauma, immobilization, central venous catheters, previous history of VTE, older age, and obesity (Anderson 2003; Barbar 2017; Dobromirski 2012). Almost all hospitalized patients have at least one risk factor for VTE, and approximately $40 \%$ have three or more risk factors (Anderson 2003; Kucher 2005a; NICE 2015).

There is irrefutable evidence from numerous randomized clinical trials, conducted over the past three decades, that the appropriate use of primary thromboprophylaxis in target groups of hospitalized medical and surgical patients at elevated risk for VTE is safe, effective, and cost-effective in reducing DVT and PE (Bozarth 2013; Bozzato 2012; Geerts 2008; Hansrani 2017; Shirvanian 2015; Streiff 2012). Since 1986, many clinical practice guidelines have systematically reviewed and synthesized the evidence from these trials, and strongly recommended the use of thromboprophylaxis in hospitalized patients at risk for VTE (Falck-Ytter 2012; Farge 2016; Geerts 2008; Gould 2012; Jacobs 2012; Kahn 2012; Liew 2017; NICE 2015; Nicolaides 2013; Qaseem 2011). Some have explicitly recommended that hospitals should develop a formal strategy that addresses VTE prevention, ideally in the form of a written, active hospital-wide thromboprophylaxis policy (Beckman 2016; Geerts 2008; Geerts 2009; Maynard 2016).

Notwithstanding the publication of more than 20 practice guidelines since 1986 recommending the use of thromboprophylaxis, audits conducted in numerous countries, in various groups of hospitalized patients, show that thromboprophylaxis continues to be un- derutilized or utilized inappropriately (Adamali 2013; Akinbobuyi 2016; Al-Hameed 2014; Dobesh 2010; Farfan 2016; Geahchan 2016; Golian 2016; Hibbert 2016; Kahn 2007; Kakkar 2010; Kerbauy 2013; Khoury 2011; Kim 2016; Randelli 2016; Schleyer 2011; Stein 2011; Vazquez 2014). Furthermore, population-based data have not shown a reduction in the overall incidence of VTE over time (Alotaibi 2016; Heit 2016; Raskob 2014), nor have they consistently shown an important reduction in the number of deaths from $\mathrm{PE}$ in hospitalized patients diagnosed with PE (Bikdeli 2016; de Miguel-Díez 2014; Jiménez 2016; Minges 2015; Stein 2012; Tsai 2012). The increasing number of patients diagnosed with PE may also artificially offset recent reports of reduced PE mortality (Konstantinides 2016). Hence, it is clear that a gap exists between the available evidence and the systematic implementation of this evidence into clinical practice.

In the last few years, in an effort to reduce preventable mortality and morbidity in hospital settings, there has been an increased focus on the best ways to systematically improve compliance with VTE prophylaxis recommendations (e.g. National Institute for Health and Clinical Excellence, UK; The Joint Commission and National Quality Forum, USA; Canadian Patient Safety Institute, Canada). As a consequence, reducing the rates of VTE in hospitalized patients has been identified as an urgent public health priority, and researchers have begun to address this issue from a healthcare provider systems perspective. In 2013, in a critical review of the evidence supporting various strategies to improve patient safety, interventions to improve prophylaxis for VTE were classified as strongly encouraged patient safety practices that were ready for adoption (Shekelle 2013a; Shekelle 2013b). Various types of system-wide interventions have been proposed in an attempt to improve the prescription of thromboprophylaxis in hospitalized patients (Amin 2009; Lau 2014; Maynard 2016; Schünemann 2004; Tooher 2005). Examples of system-wide interventions that have been evaluated to date include: passive strategies, such as simple distribution of guidelines, audit and feedback (e.g. review of performance), and the use of passive reminders, such as preprinted orders (e.g. written, predefined orders, which can be completed by the physician on paper or electronically); active strategies, such as the use of automatic reminder systems that include alerts (e.g. human alerts, by a trained nurse, pharmacist, or staff member; or computer, electronic alerts); multifaceted approaches that combine different types of interventions (e.g. combination of education, audit and feedback, and alerts); educational approaches, which focus on the teaching and learning process by organizing educational events (e.g. grand rounds, self-administered courses).

\section{Description of the condition}

Venous thromboembolism (VTE) is a condition in which a blood clot forms in a vein. It most commonly occurs in the deep veins of the legs; this is called deep venous thrombosis (DVT). The blood clot may dislodge from its site of origin and travel to the lungs; this phenomenon is called pulmonary embolism (PE).

\section{Description of the intervention}

Various pharmacologic (e.g. anticoagulant or 'blood thinner' medications) and mechanical (e.g. compression devices) interventions are used for primary prophylaxis (prevention) of VTE. System-wide interventions are those that attempt to reach one or more components of the healthcare provider system as a whole. These can include alerts (e.g. computer alerts or human alerts), multifaceted interventions (e.g. combination of education, audit and feedback, 
and alerts), educational interventions (e.g. grand rounds, self-administered courses), and preprinted orders (e.g. written predefined orders that can be completed by the physician on paper or electronically).

\section{How the intervention might work}

These system-wide interventions, by reaching one or more components of the healthcare provider system as a whole, might help to improve the prescription of thromboprophylaxis (e.g. pharmacologic or mechanical modalities, or both) in hospitalized medical and surgical patients at risk of VTE.

\section{Why it is important to do this review}

In our previous Cochrane review, we assessed the effectiveness of various system-wide interventions, designed to increase the implementation of thromboprophylaxis in hospitalized medical and surgical patients at risk for VTE (Kahn 2013). However, as 47 of the 55 included studies were observational in design, the risk of bias was substantial and the certainty of evidence for improvement in outcomes was very low. Since 2013, many new trials, but no relevant systematic reviews with meta-analyses have been published; therefore, an update of our systematic review focused solely on randomized controlled trials (RCTs) was warranted.

This updated review of data from RCTs included new studies, and addressed the effectiveness of various system-wide interventions, designed to increase the use of thromboprophylaxis, and decrease the risk of VTE in hospitalized medical and surgical patients at risk for VTE.

This review aimed to help identify the most effective system-wide interventions for thromboprophylaxis. These interventions could be implemented to help clinicians and other healthcare professionals improve the use of appropriate thromboprophylaxis in hospitalized medical and surgical patients at risk of VTE, and thereby reduce morbidity and mortality from this preventable complication of hospitalization.

\section{OB JECTIVES}

The objective of this review was to assess the effects of system-wide interventions, designed to increase the implementation of thromboprophylaxis, decrease the incidence of VTE in hospitalized adult medical and surgical patients at risk for VTE, or both, focusing on randomized controlled trials (RCTs) only.

We assessed effectiveness in terms of:

1. Increase in the proportion of participants who received prophylaxis (RP)

2. Increase in the proportion of participants who received appropriate prophylaxis (RAP)

3. Decrease in the proportion of participants who developed any VTE (i.e. all, symptomatic, asymptomatic VTE; proximal, distal, or any DVT; PE, or fatal PE)

4. Decrease in the proportion of participants who developed symptomatic VTE (i.e. all VTE; proximal, distal, or any DVT; PE, or fatal PE)

5. Decrease in the proportion of participants who develop asymptomatic VTE (detected by systematic screening of participants who did not have symptoms of DVT or PE)
6. Decrease in the number of deaths (all-cause mortality, sudden death)

7. Safety of the intervention (e.g. frequency of bleeding or other complications)

\section{METHODS}

\section{Criteria for considering studies for this review}

\section{Types of studies}

We considered all RCTs that included a control group, and evaluated the effectiveness of one or more system-wide interventions designed to increase the implementation of thromboprophylaxis in hospitalized adult medical or surgical patients at risk for VTE. Thus, we considered parallel group RCTs, cross-over RCTs, factorial design RCTs, cluster-randomized controlled trials (CRTs), and quasi-RCTs (QRCTs, e.g. those using pseudo-randomization methods, such as even or odd date of birth). We accepted control group comparisons such as no intervention, an existing policy, or another type of intervention. We considered studies and abstracts in any language.

\section{Types of participants}

Depending on the study design, participants could include hospitalized adult medical or surgical inpatients, their physicians, residents, or nurses, or in the case of CRTs, the cluster unit (e.g. ward, hospital, physician practice).

\section{Types of interventions}

Interventions included any strategy targeted at individuals or clustered units that aimed to increase the use of thromboprophylaxis in hospitalized patients at risk for VTE, decrease the rate of symptomatic or asymptomatic VTE, or both. Examples of interventions included alerts, multifaceted interventions, educational interventions, and preprinted paper or electronic orders.

We excluded studies in which the intervention was a simple distribution of published guidelines, and studies in which the intervention was not clearly described.

\section{Types of outcome measures}

\section{Primary outcomes}

- Increase in the proportion of participants who received prophylaxis (RP). Prophylaxis could be either pharmacologic or mechanical

\section{Secondary outcomes}

- Increase in the proportion of participants who received appropriate prophylaxis (RAP). The definition of appropriate prophylaxis was that used by the respective study authors

- Decrease in the proportion of participants who developed any VTE (i.e. all, symptomatic, asymptomatic; any, proximal, distal, DVT; PE, fatal PE)

- Decrease in the proportion of participants who developed symptomatic VTE (all VTE; any, proximal, distal DVT; PE, fatal PE)

- Decrease in the proportion of participants who developed asymptomatic VTE (detected by systematic screening of participants who did not have symptoms of DVT or PE) 
- Decrease in the number of deaths (all-cause mortality, sudden death)

- Safety of the intervention, e.g. frequency of clinically relevant bleeding (major hemorrhage, minor hemorrhage), or other complications

We included studies if the study design, population, and intervention were clearly described, if data were provided separately by intervention group and for VTE outcomes, and if VTE was diagnosed using objective, accepted diagnostic criteria.

\section{Search methods for identification of studies}

\section{Electronic searches}

A research librarian (author MM), trained in systematic review searching, created a comprehensive, systematic search strategy to identify RCTs that assessed interventions designed to increase the use of thromboprophylaxis, decrease the incidence of VTE in hospitalized patients, or both. We developed the strategy for MEDLINE Ovid, and subsequently translated it to the Cochrane Central Register of Controlled Trials (CENTRAL; 2017, Issue 1) in the Cochrane Library, PubMed, Embase Ovid, BIOSIS Previews Ovid, CINAHL (Cumulative Index to Nursing and Allied Health Literature), Web of Science, the Database of Abstracts of Reviews of Effects (DARE; 2017, Issue 1) in the Cochrane Library, the NHS Economic Evaluation Database (EED; 2017, Issue 1) in the Cochrane Library, LILACS (Latin American and Caribbean Health Sciences Literature), and clinicaltrials.gov. We have set out the search strategies in Appendix 1; Appendix 2; Appendix 3; Appendix 4; Appendix 5; Appendix 6; Appendix 7; Appendix 8. They comprised a combination of Medical Subject Headings (MeSH) or their equivalent (where available), keywords, truncations, and Boolean operators. We searched the databases from inception to 28 July 2015. We updated the searches monthly until 7 January 2017.

We applied no language restrictions.

\section{Searching other resources}

We handsearched the reference lists of relevant retrieved studies, including narrative and systematic reviews, to find additional potentially relevant studies.

\section{Data collection and analysis}

\section{Selection of studies}

Two review authors independently reviewed titles, abstracts, and full-texts of each study, and indicated on a Study Eligibility Form if the study should be included, excluded, or if they were undecided. Disagreements regarding study inclusion were resolved by discussion between the two review authors, and if necessary, by involving a third independent review author. All studies marked 'undecided' by one review author were discussed further between the two review authors, and then deemed included or excluded.

\section{Data extraction and management}

Two review authors independently extracted data from the included articles. The data obtained for each study were entered in duplicate into two identical databases, which were designed by Information Management Services of the Lady Davis Institute in Montréal, Canada. They compared the two databases for inaccuracies, and corrected any data entry errors. If agreement on the data en- tered for a given data field could not be reached between the two extractors, they consulted a third extractor. They populated a third, final database, with the final adjudicated data. They extracted the following information on participants, intervention, comparator, outcome, setting (i.e. PICOS) from each study (if available), using a standardized data extraction form (one form per study), based on the Cochrane EPOC data collection template.

1. RCT design: parallel group, cross-over, cluster, or factorial design

2. Randomization procedure, unit of randomization and analysis

3. Study period, years of enrolment, year of publication, duration and completeness of follow-up

4. Cluster unit, intracluster correlation (ICC) if applicable

5. Study setting (hospital, or center characteristics): number of centers, university-affiliated hospital, community hospital, physician practice, type of healthcare system (public versus private), departments included

6. Physician characteristics: number of physicians, physician specialties

7. Patient characteristics: patient types (medical, surgical, trauma, other), inclusion and exclusion criteria, number of patients screened and included, average age, percent male, comorbidities and individual VTE risk profile; (e.g. age, sex, cancer patient, cardiac patient)

8. Description of intervention (active and control arms): type of intervention (alerts, multifaceted interventions, educational interventions, preprinted orders, other), intervention components (alert, no alert), type of alert (computer alert, human alert)

9. Control group characteristics: control intervention, timing of control intervention (before or concurrent with intervention group)

10.VTE prophylaxis used in the study: pharmacologic (type, dose), mechanical

11.Was appropriateness of prophylaxis assessed? How was appropriateness of prophylaxis defined?

12. Method of VTE screening, diagnosis, or both

13. Outcomes, raw data, effect estimates

a. Number, proportion of participants who received prophylaxis (RP)

b. Number, proportion of participants who received appropriate prophylaxis (RAP)

c. Number, proportion of participants who developed any VTE (all, symptomatic, asymptomatic VTE; any, proximal, distal, DVT; PE, fatal PE)

d. Number, proportion of participants who developed symptomatic VTE (all VTE; any, proximal, distal DVT; PE, fatal PE)

e. Number, proportion of participants who developed asymptomatic VTE (all VTE; any, proximal, distal DVT; PE, fatal PE)

f. Number, proportion of deaths (e.g. all-cause mortality, sudden death)

g. Number, proportion of participants who developed complications possibly related to the intervention (e.g. major bleeding, minor bleeding, thrombocytopenia)

h. Effect estimate and variance estimates for these outcomes where raw data were unavailable

14.Risk of bias: we also extracted information on methodological quality and potential biases for each study, as described in the 
following section. We constructed tables of characteristics that described study data and methodological quality (i.e. 'Risk of bias' tables) for each study.

\section{Assessment of risk of bias in included studies}

Two review authors independently assessed the risk of bias of each study, using a component approach rather than summarizing internal study quality in an overall score. We used Cochrane's tool to assess the risk of bias (Higgins 2011). We assessed all items listed as other potential sources of bias (section 8.15.1), including the design-specific risks of bias for CRTs (section 16.3.2) and multiple intervention studies (section 16.5.3; Higgins 2011). We resolved disagreements by discussion among co-authors. We assessed the following potential sources of bias and rated them as high risk, low risk, or unclear risk of bias (ROB): allocation (selection bias), blinding (performance bias and detection bias), incomplete outcome data (attrition bias), selective reporting (reporting bias), and other potential sources of bias.

\section{For all studies:}

1. Was there selection bias (biased allocation to interventions) due to inadequate generation of a randomized sequence?

2. Was there selection bias (biased allocation to interventions) due to inadequate concealment of allocations prior to assignment?

3. Was there performance bias due to knowledge of the allocated interventions by participants and personnel during the study?

4. Was there detection bias due to knowledge of the allocated interventions by outcome assessors?

5. Was there attrition bias due to amount, nature, or handling of incomplete outcome data?

6. Was there reporting bias due to selective outcome reporting?

7. Were there other biases due to problems not covered previously in the risk of bias selection?

a. If CRT, was there recruitment bias?

b. If CRT, was there baseline imbalance?

c. If CRT, was there loss of clusters?

d. If CRT, was there incorrect analysis?

e. If CRT, was there lack of comparability with individually randomized trials?

f. If multi-intervention study, were data presented for each of the groups to which participants were randomized?

g. If multi-intervention study, were reports of the study free of suggestion of selective reporting of comparisons of intervention arms for some outcomes?

h. Any other potential biases

We assessed and incorporated the overall ROB for each of the included studies in our analysis. Although the use of summative scores was not encouraged in the Cochrane Handbook of Systematic Reviews for Interventions (section 8.7), we elected to assign quantitative scores for ROB for all included studies using a simple system (Higgins 2011). For each of the seven ROB domains, a negative score $(-1)$ was assigned for each high ROB response, a score of zero was assigned for each unclear ROB response, and a positive score was assigned for each low ROB response. Summary scores of less than -1 were considered as high ROB, summary scores of 0 were considered as unclear ROB, and summary scores of greater than +1 were considered low ROB (Table 1).
We removed studies that were considered at high overall ROB as part of a sensitivity analysis (see sensitivity analysis), as we considered that these studies might be associated with an under- or overestimation of intervention effect, although the magnitude of this bias was difficult to quantify.

\section{Measures of treatment effect}

We grouped and analyzed studies by type of intervention, type of study design, and type of outcome. For the primary outcome (RP) and the secondary outcome (RAP), we summarized the effects of the intervention using the risk difference (RD), which provides an absolute measure of effect. We also summarized the relative effects using the risk ratio (RR). We examined $\mathrm{I}^{2}$ values for both absolute and relative effect measures, and found that using absolute measures did not systematically introduce statistical heterogeneity. For the secondary outcomes VTE, mortality, and safety outcomes (which had a much lower rate of occurrence, and for which absolute rates varied widely depending on the population studied and definition used), we summarized the relative effects using the risk ratio (RR). For CRTs, we preferentially used effect estimates for which the variance had been adjusted, to account for the clustered nature of the data, either by including appropriate cluster-adjusted estimates reported in the individual studies, or by conducting an approximate adjustment for the cluster design effect, as advised in the Cochrane Handbook of Systematic Reviews for Interventions (section 16.3; Higgins 2011). Where this was not possible, we used unadjusted effect estimates. It should be noted that the variance for these unadjusted effect estimates may in fact be greater, and therefore these results should be interpreted with some caution. We presented the treatment effects with $95 \%$ confidence intervals (Cls)

\section{Unit of analysis issues}

For studies evaluating more than one intervention, we followed the recommendations in the Cochrane Handbook of Systematic Reviews for Interventions (section 16.5.4; Higgins 2011). One of the included studies had two separate intervention groups, which fell into two different intervention categories, with a common control group (Anderson 1994). We compared each intervention group to the control group, and performed meta-analysis with the control group and each intervention group. Four of the 10 CRTs reported an ICC for the cluster design effect in their analyses (Cavalcanti 2016; Labarere 2007; Pai 2013; Roy 2016). For the six CRTs that did not, we estimated an ICC for each trial based on the ICCS (average, minimum, maximum) of the four trials that did, and performed sensitivity analysis as recommended in the Cochrane Handbook of Systematic Reviews for Interventions (section 16.3; Higgins 2011). Adjustment for the clustered design was only feasible for the metaanalysis of multifaceted interventions.

\section{Dealing with missing data}

We contacted three original investigators to request missing data (Chapman 2011; Dexter 2001; Hinchey 2010). One investigator provided additional data (Dexter 2001), and two either did not respond, or were unable to provide the requested data (Chapman 2011; Hinchey 2010). We were able to calculate the missing data for Chapman 2011, but were unable to do so for Hinchey 2010, thus, we decided to exclude the data from this trial in the quantitative analysis. We did not use statistical methods to impute missing values or model missing data. 


\section{Assessment of heterogeneity}

We estimated the amount of statistical heterogeneity that was present using the $\mathrm{I}^{2}$ statistic, and had planned to investigate clinical and methodological sources of heterogeneity via subgroup analysis and meta-regression. The $\mathrm{I}^{2}$ statistic determines the percentage of the variability in the effect estimate that is above and beyond what is expected through sampling error (i.e. chance). We considered values greater than $50 \%$ to suggest important statistical heterogeneity. We also performed the $\mathrm{Chi}^{2}$ test for heterogeneity to assess whether the observed differences in between-study results were compatible with chance alone, whereby a $\mathrm{P}<0.05$ to $<0.1$ suggested significant heterogeneity, with the recognition that this is a low-power test $\left(\mathrm{Chi}^{2}\right.$ results are derived from the $\mathrm{I}^{2}$ statistic, and are shown in forest plots).

\section{Assessment of reporting biases}

We graphed and visually examined funnel plots centered around the pooled studies effect (either RD or RR) to assess the potential for publication bias. However, we only presented these in the Appendices as we believed that these could be misleading: given the small number of trials that could be meta-analyzed in this review, we were underpowered (less than 10 studies) to distinguish chance from real asymmetry (Higgins 2011). Indeed, many other factors can contribute to asymmetry of the funnel plot, such as selective outcome reporting, differences in methodological quality among studies, poor methodological quality leading to spuriously inflated effects in smaller studies, true heterogeneity, artefact, and chance (Egger 1997; Higgins 2011). Cumulative meta-analyses were also planned but not performed, due to the small number of included trials.

\section{Data synthesis}

Where there were sufficient data ( $\geq 3$ studies), we calculated a summary statistic for each intervention category (alerts, multifaceted interventions, educational interventions, and preprinted orders) and associated outcome, using a random-effects model to pool RD (outcomes RP and RAP) or RR (outcomes VTE, mortality, and safety). When we could not pool studies, we tabulated them and presented them descriptively in the summary results tables (which also included the corresponding meta-analyses).

\section{'Summary of findings' table}

We summarized the main findings of our review in two 'Summary of findings' tables, and drew conclusions about the certainty of the evidence for each intervention category (alerts and multifaceted interventions), and each outcome (received prophylaxis, received appropriate prophylaxis, and VTE) that we were able to meta-analyze (Summary of findings for the main comparison; Summary of findings 2). Two review authors independently assessed the certainty of the evidence using the GRADE approach and GRADEpro GDT software (GRADEpro GDT; Guyatt 2011). We used the five GRADE considerations (risk of bias, indirectness of evidence, inconsistency of results, imprecision of results, and publication bias) to assess the evidence according to the methods and recommendations in the
Cochrane Handbook of Systematic Reviews for Interventions (sections $8.5,11.5$, and 12.2), and rated the certainty of the evidence as high, moderate, low, or very low (Higgins 2011). We provided detailed explanations in the footnotes of the 'Summary of findings' tables, and made comments to help summarize our decisions during the GRADE assessment where necessary. We also used plain language statements to report these findings throughout the review.

\section{Subgroup analysis and investigation of heterogeneity}

We had planned subgroup analyses on patient types (medical versus surgical, type of surgery), patient characteristics (VTE risk profile, e.g. sex, age, cancer, comorbidities), physician specialty, and type of healthcare system (public versus private, university-affiliated versus community hospitals). We also had planned to address heterogeneity in each meta-analysis by considering clinical and methodological sources of heterogeneity across studies, such as variation in study design (e.g. CRTs versus non-CRTs), patient characteristics, type of intervention, intervention components (alert versus no alert), type of alert (computer alert versus human alert), control group, definition of study outcome, differing duration and completeness of study follow-up, and type of analysis (e.g. measure of effect such as RD, RR). However, due to the small number of trials in each meta-analysis, we were unable to perform subgroup analysis or meta-regression.

\section{Sensitivity analysis}

We performed an influence analysis, in which we assessed the degree to which excluding single studies, one by one, influenced the magnitude, precision, and direction of the summary results.

Ten of the included trials in this review were CRTs. Where possible, we used the ICC reported by the authors to account for the clustered nature of the data (Fiero 2016). In the analysis of trials that evaluated multifaceted interventions, all of which were CRTs, four of five trials reported an ICC (Cavalcanti 2016; Labarere 2007; Pai 2013; Roy 2016). As a sensitivity analysis, we applied the lowest, the mean, and the highest ICC among these four trials to the one trial that did not report an ICC (Anderson 1994).

To investigate whether methodological quality impacted our results, as a sensitivity analysis, we removed the high ROB trial (see Assessment of risk of bias in included studies, above) from the meta-analysis of trials that evaluated an alerts intervention (Garcia 2009).

Finally, to assess the robustness of our results to our choice of metaanalytic model, we conducted sensitivity analyses using a fixed-effect approach.

\section{RES U LTS}

\section{Description of studies}

\section{Results of the search}

Figure 1 displays the flow diagram of study selection. All the articles identified were in English. 


\section{Figure 1. Study flow diagram.}

1 record identified from other sources, updated search from 28 July 2015 to 7 January 2017
12,919 records identified via our search strategy (up to 28 July 2015):

Cochrane Library (total 342; CENTRAL (291), Cochrane Methods (1). CDSR (31), DARE (7), NHSEED (12)), MEDLINE (2927), Embase (4056), CINAHL (1260), LILACS (101), Pubmed (147), Web of Science (3547), Biosis (344), clinicaltrials.gov (195)

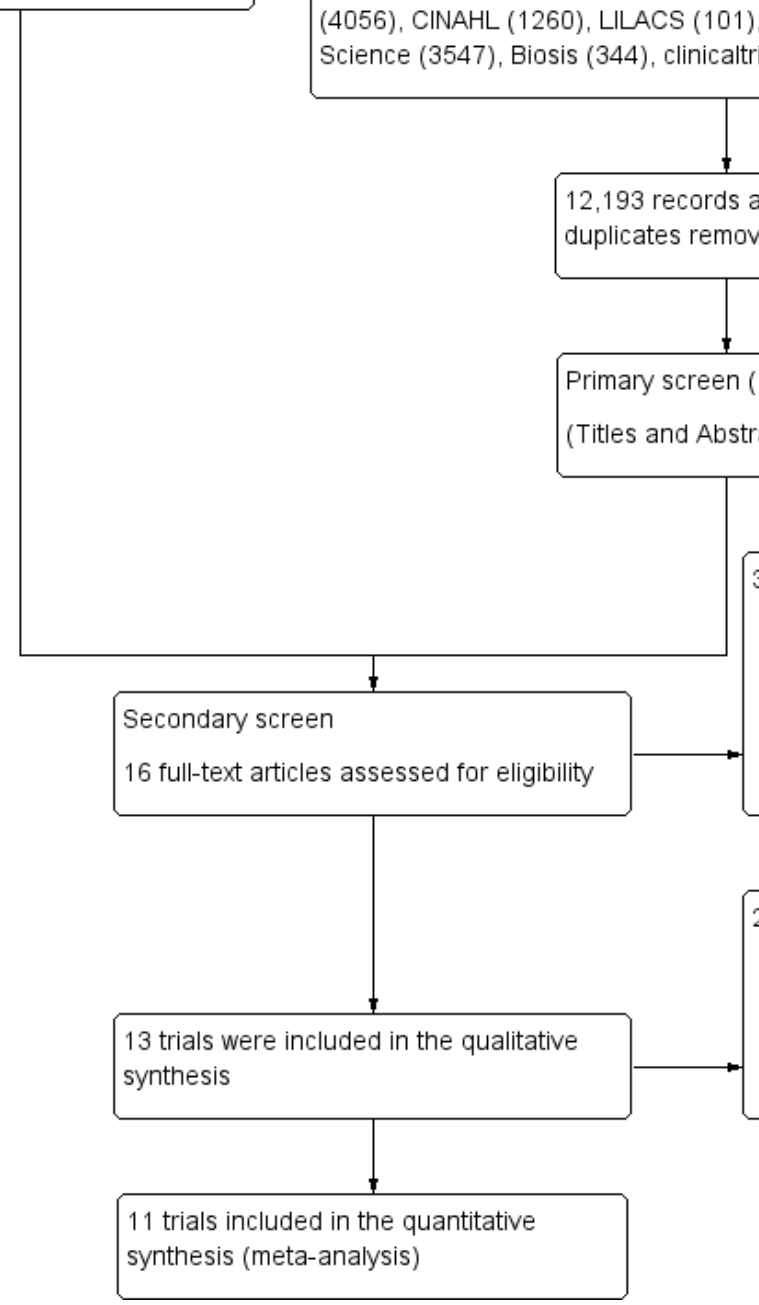

12,178 records excluded after primary screen

3 full-text articles excluded:

1. Intervention did not aim to increase the use of prophylaxis decrease the proportion of symptomatic or asymptomatic $\operatorname{VTE}(\mathrm{N}=1)$

2. Non-randomized controlled trial $(N=1)$

3. Patient population was outpatients $(N=1)$

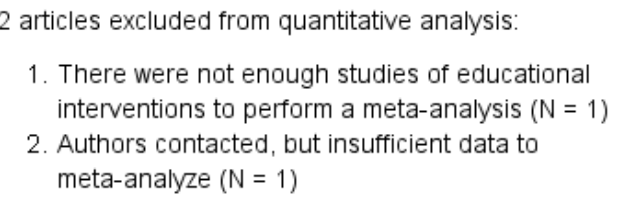

1. There were not enough studies of educational interventions to perform a meta-analysis $(N=1)$

2. Authors contacted, but insufficient data to meta-analyze $(\mathrm{N}=1)$

\section{Included studies}

We included 13 randomized controlled trials (RCTs) in our systematic review (Anderson 1994; Cavalcanti 2016; Chapman 2011; Dexter 2001; Fontaine 2006; Garcia 2009; Hinchey 2010; Kucher 2005; Labarere 2007; Overhage 1996; Pai 2013; Piazza 2009; Roy 2016; see Characteristics of included studies), three of which were quasi-randomized controlled trials (QRCTs; Garcia 2009; Hinchey 2010; Kucher 2005). We included 11 trials in the meta-analysis. We did not included one trial in the meta-analysis due to missing outcome data (Hinchey 2010). We did not include another trial in the meta-analysis because there were no other studies assessing a similar intervention (educational interventions alone; Fontaine 2006).

Ten included studies were cluster-randomized controlled trials (CRTs; Anderson 1994; Cavalcanti 2016; Dexter 2001; Fontaine 2006; Garcia 2009; Hinchey 2010; Labarere 2007; Overhage 1996; Pai 2013; Roy 2016), one of which was a study with more than one independent intervention group (Anderson 1994). There were no cross-over or factorial design RCTs, or RCTs that compared multiple dependent intervention arms to a common reference group (e.g. study with intervention groups, and hence participants, in common, leading to correlated comparisons).

Six studies evaluated an alerts intervention, which used automatic reminder systems to support health care providers' decisions (Chapman 2011; Dexter 2001; Garcia 2009; Kucher 2005; Overhage 1996; Piazza 2009). Of these, three evaluated a computer alert as a reminder (Dexter 2001; Kucher 2005; Overhage 1996), and three evaluated a human alert, using a person, such as a trained nurse, pharmacist, or staff member, to provide a reminder (Chapman 2011; Garcia 2009; Piazza 2009). Six studies evaluated multifaceted interventions that combined different types of system-wide interventions, such as education, audit and feedback, and alert (Anderson 1994; Cavalcanti 2016; Hinchey 2010; Labarere 2007; Pai 2013; Roy 2016), one of which included an alert component (Roy 2016). One study evaluated an educational intervention that used a hospital-administered course with self-assessment examinations (Anderson 1994), and one study evaluated a preprinted orders intervention using predefined anticoagulant prescription forms as a passive reminder (Fontaine 2006). 


\section{Excluded studies}

We excluded three RCTs that failed to meet our eligibility criteria (Marini 2014; Nendaz 2010; Piazza 2013; see Characteristics of excluded studies). One was excluded because the aim of the study was not to increase the use of prophylaxis, decrease the proportion of symptomatic venous thromboembolism (VTE), or decrease the proportion of asymptomatic VTE (Marini 2014), one study was a non-randomized controlled trial (controlled before-and-after study design; Nendaz 2010), and one study was excluded because the intervention was directed to outpatients (Piazza 2013).
Details of studies excluded in the previous version of the review and details of non-randomized studies previously classed as included studies can be found in Kahn 2013.

\section{Risk of bias in included studies}

The 'Risk of bias' tables for each study are shown in the 'Characteristics of included studies' table. Figure 2 and Figure 3 show a summary of the risks of bias in the included studies, as judged by the review authors.

\section{Figure 2. Summary of risk of bias: review authors' judgements about each 'Risk of bias' item presented as percentages across all included studies}

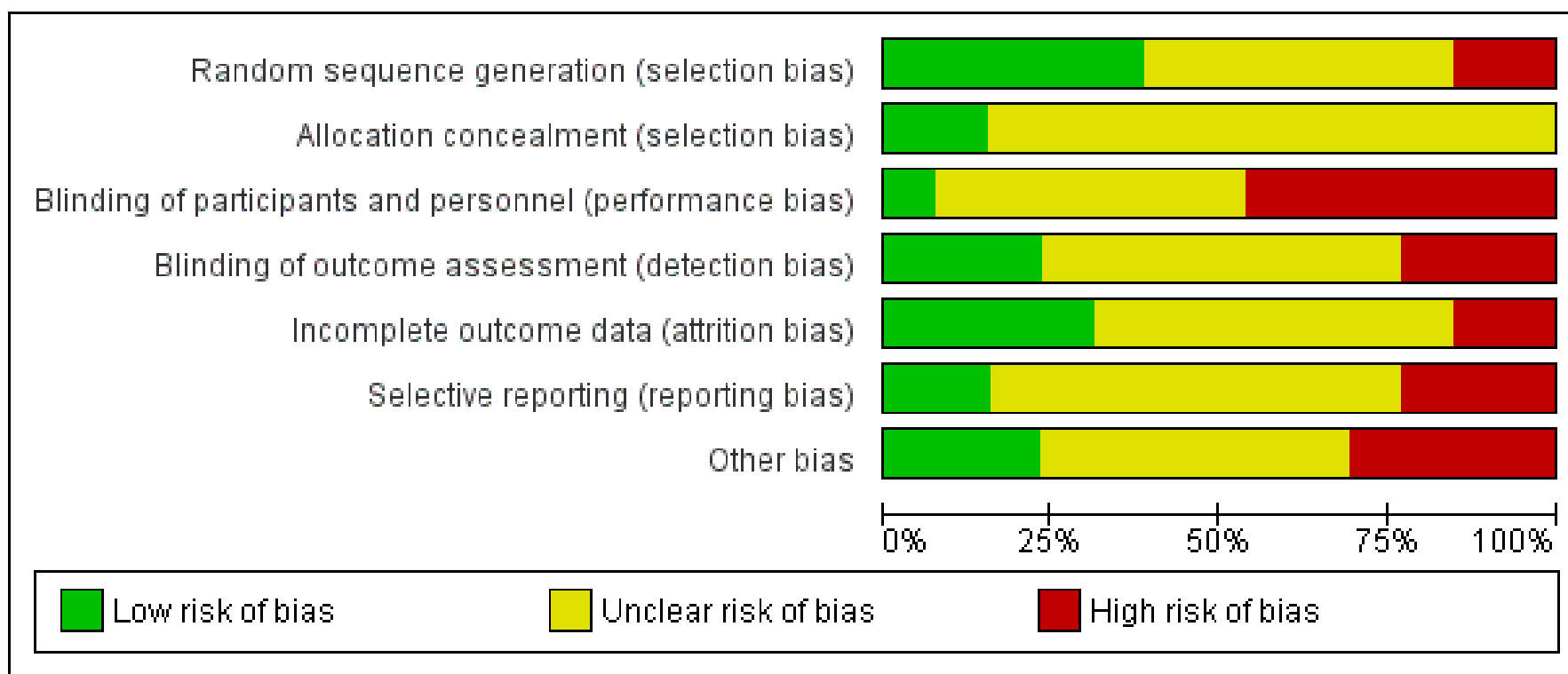


Figure 3. Summary of risk of bias: review authors' judgements about each 'Risk of bias' item for each included study

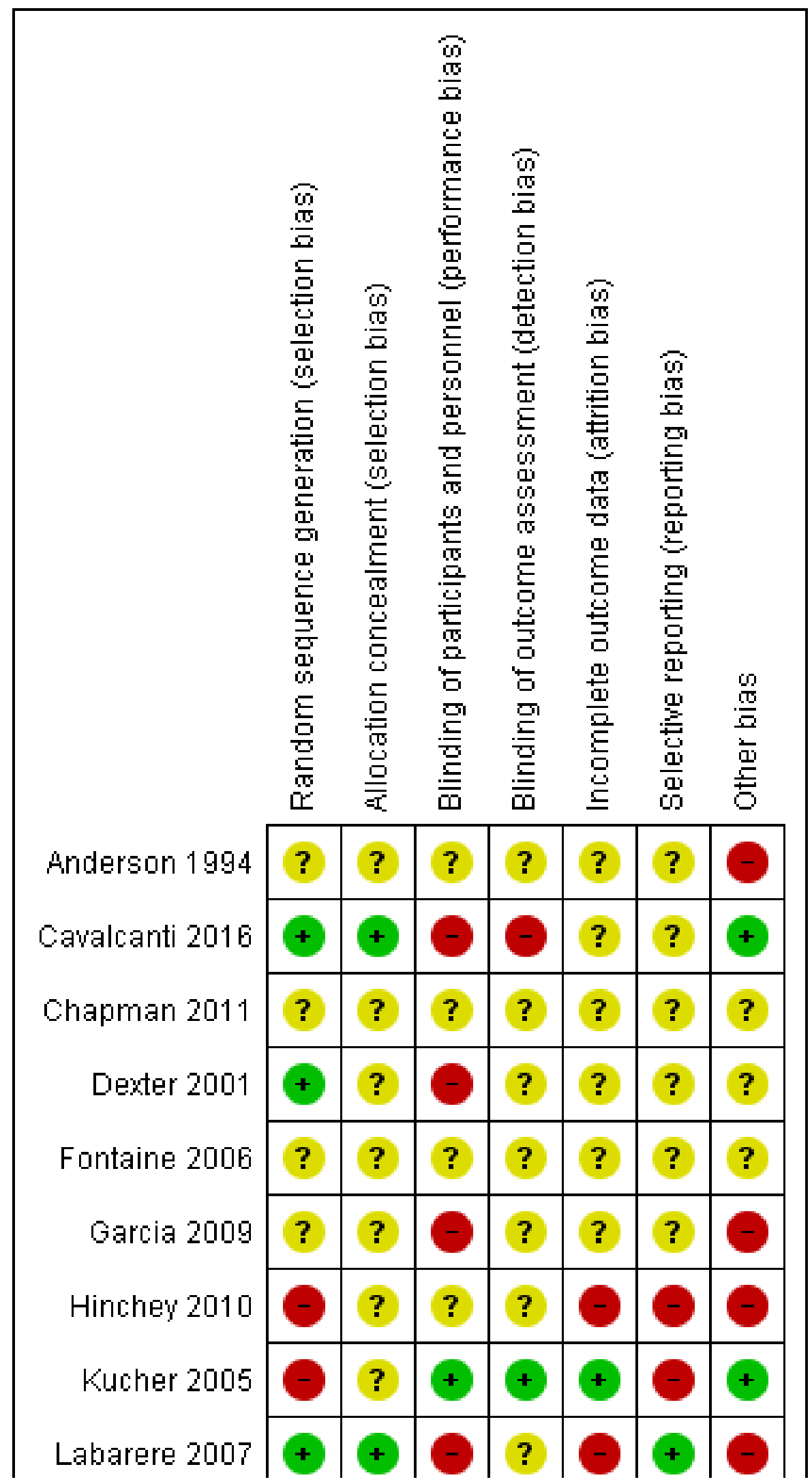


Figure 3. (Continued)

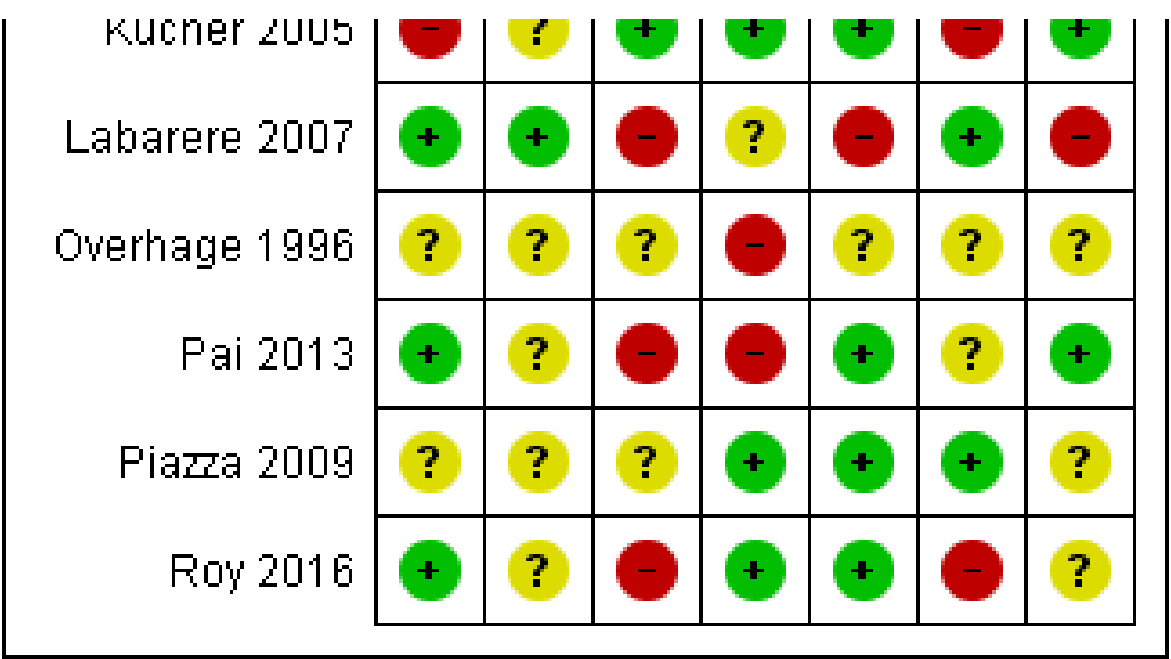




\section{Allocation}

In this updated review, the extent of allocation concealment was clearly reported in two studies (Cavalcanti 2016; Labarere 2007), and unclear in 11 studies (Anderson 1994; Chapman 2011; Dexter 2001; Fontaine 2006; Garcia 2009; Hinchey 2010; Kucher 2005; Overhage 1996; Pai 2013; Piazza 2009; Roy 2016). Sequence generation was clearly reported in five studies (Cavalcanti 2016; Dexter 2001; Labarere 2007; Pai 2013; Roy 2016), unclear in six studies (Anderson 1994; Chapman 2011; Fontaine 2006; Garcia 2009; Overhage 1996; Piazza 2009), and inadequate in two studies (Hinchey 2010; Kucher 2005). While sequence generation was clear in Labarere 2007, some unblinding may have occurred during the course of the study as knowledge of the allocated interventions may not have been adequately prevented.

\section{Blinding}

For most studies, there was an unclear or high risk of performance and detection bias as a result of lack of, or inadequate blinding of study participants or outcome assessors. Only one study demonstrated adequate blinding of participants and assessors (Kucher 2005).

\section{Incomplete outcome data}

Of the 13 studies included in our review, two were judged to have a high risk of bias due to incomplete outcome data (Hinchey 2010; Labarere 2007), seven had an unclear risk of bias due to incomplete outcome data (Anderson 1994; Cavalcanti 2016; Chapman 2011; Dexter 2001; Fontaine 2006; Garcia 2009; Overhage 1996), and four had a low risk of bias related to completeness of outcome data (Kucher 2005; Pai 2013; Piazza 2009; Roy 2016).

\section{Selective reporting}

In two studies, there was a low risk of bias related to completeness of outcome reporting (Labarere 2007; Piazza 2009), and in eight studies, there was uncertainty regarding selective outcome reporting (Anderson 1994; Cavalcanti 2016; Chapman 2011; Dexter 2001; Fontaine 2006; Garcia 2009; Overhage 1996; Pai 2013). We judged three studies to have a high risk of bias due to selective outcome reporting for the following reasons: 1 ) not reporting on safety outcomes (bleeding, heparin induced thrombocytopenia, etc.) at all time points related to outcome assessment, when this was stated as a study objective (Kucher 2005); 2) not reporting on all types of thromboprophylaxis (e.g. mechanical) when increasing the rate of thromboprophylaxis was stated as a study objective (Roy 2016); and 3) not clearly reporting rates or raw data for primary and secondary analysis when improving adherence rates for deep vein thrombosis (DVT) prophylaxis was stated as a study objective (Hinchey 2010).

\section{Other potential sources of bias}

In three studies, there was a low risk of bias due to other potential sources of bias (Cavalcanti 2016; Kucher 2005; Pai 2013), while six were judged to have an unclear risk of bias (Chapman 2011; Dexter 2001; Fontaine 2006; Overhage 1996; Piazza 2009; Roy 2016). Four studies were judged to have a high risk of bias, mainly for not accounting for the clustered study design in the analysis (Anderson 1994; Garcia 2009; Hinchey 2010; Labarere 2007).

\section{Effects of interventions}

See: Summary of findings for the main comparison Computer or human alerts interventions versus standard care; Summary of findings 2 Multifaceted interventions versus standard care or another intervention

Studies were grouped for meta-analysis based on intervention type (alerts and multifaceted interventions) and outcome (received prophylaxis, received appropriate prophylaxis, and symptomatic venous thromboembolism (VTE)).

For the interventions educational interventions and preprinted orders, and the outcomes mortality and safety outcomes, there were not enough studies to pool data across trials. Summary of findings for the main comparison summarizes the results from the meta-analyses conducted for alerts for the primary outcome, received prophylaxis and the secondary outcomes, received appropriate prophylaxis and symptomatic VTE and corresponds to the forest plots described below. Summary of findings 2 summarizes the results from the meta-analyses conducted for the multifaceted interventions, for the primary outcome, received prophylaxis. Table 2 presents a sensitivity analysis that attempted to account for the clustered designs of the trials included in the meta-analysis for multifaceted interventions. Additional tables Table 3; Table 4; Table 5; Table 6; Table 7; Table 8 summarize the results for each outcome by intervention and show the results of meta-analyses if there were $\geq 3$ studies or the results of individual studies if there were fewer than 3 studies. All funnel plots are shown in Appendix 9.

\section{Alerts versus standard care}

\section{Primary outcome}

\section{Received prophylaxis}

We were able to pool three studies that examined alerts interventions (Kucher 2005; Overhage 1996; Piazza 2009). Among the studies pooled, 451/2534 (17.8\%) participants randomized to the control groups, which received standard care, and 1003/2523 (39.7\%) participants randomized to the intervention groups, received prophylaxis.

The meta-analysis showed that more participants received prophylaxis in the intervention groups than in the control groups (risk difference (RD) 0.21 ; $95 \%$ confidence interval $(\mathrm{Cl}) 0.15$ to $0.27 ; 3$ studies; 5057 participants; Analysis 1.1; Figure 4; low-certainty evidence). 
Figure 4. Funnel plot of comparison: 1 Alerts versus standard care, outcome: 1.1 Received prophylaxis.

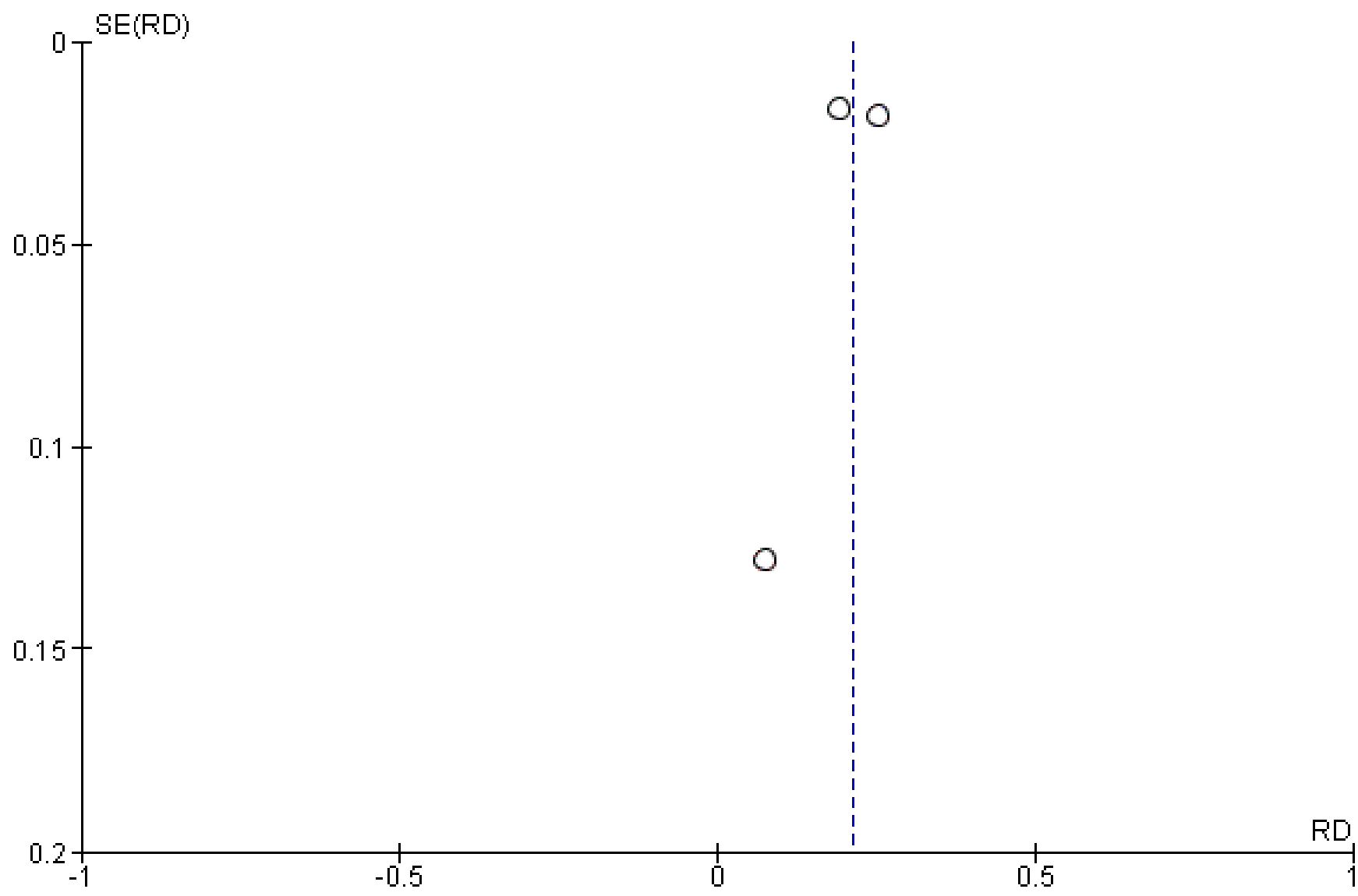

There was important heterogeneity between studies $\left(I^{2}=75 \%\right)$. The influence analysis showed that Kucher 2005 was highly influential on the confidence interval, and its omission resulted in an increased variance (Appendix 10). There may have been additional variance due to the clustered design of Overhage 1996. The confidence interval of Overhage 1996 overlapped one (i.e. the null) in Analysis 1.1. While the point estimate was not affected by its omission in the influence analysis, the confidence interval in the main analysis might have been wider if clustering had been adequately accounted for in the analysis. Unfortunately, this trial did not provide sufficient data (ICC or adjusted CIs) for us to pool cluster-adjusted estimates.

\section{Secondary outcomes}

\section{Received appropriate prophylaxis}

We were able to assess the number of participants who received appropriate prophylaxis in three of the trials that examined alerts (Chapman 2011; Dexter 2001; Garcia 2009). Among the studies pooled, $279 / 914$ (30.5\%) participants in the standard care (control) groups and 419/906 (46.2\%) participants in the intervention groups received appropriate prophylaxis.

The meta-analysis showed that alerts were associated with more participants who received appropriate prophylaxis (RD 0.16, 95\% $\mathrm{Cl} 0.12$ to 0.20 ; 3 studies; 1820 participants; Analysis 1.2; Figure 5 ; moderate-certainty evidence). There was no heterogeneity between studies $\left(I^{2}=0 \%\right)$. 
Figure 5. Funnel plot of comparison: 1 Alerts versus standard care, outcome: 1.2 Received appropriate prophylaxis.

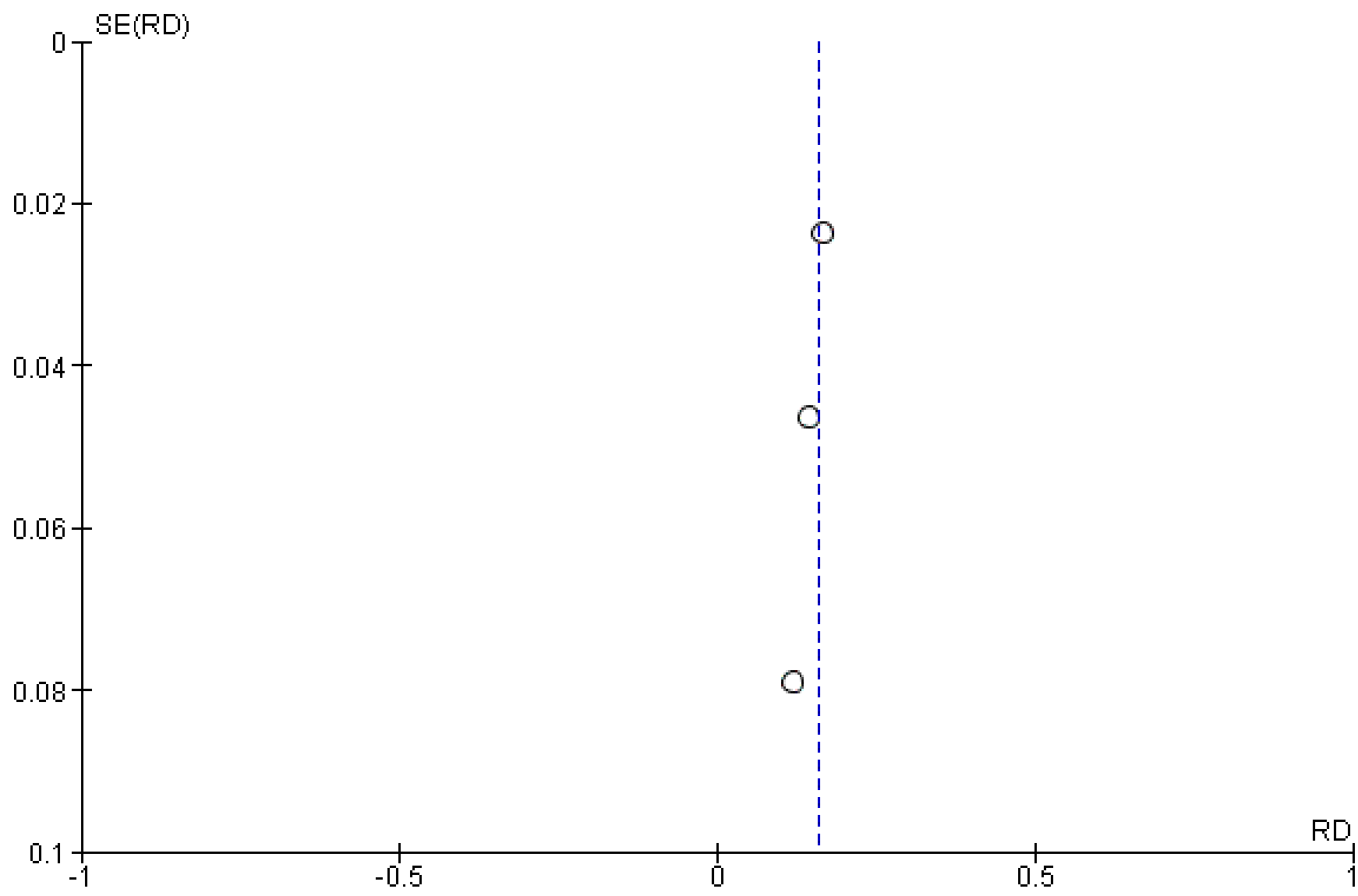

The influence analysis showed that none of the studies had a substantial influence on the pooled effect. A sensitivity analysis removing the trial with a high risk of bias did not substantially impact the point estimate (Garcia 2009; Appendix 10). There may have been additional variance contributed to the main analysis by the clustered designs of Dexter 2001 and Garcia 2009); unfortunately, these trials did not provide sufficient data (ICC or adjusted confidence intervals) for us to pool cluster-adjusted estimates.

\section{Venous thromboembolism (VTE)}

Three alerts studies reported on the presence of symptomatic VTE at 90 days post-intervention (Chapman 2011; Kucher 2005; Piazza 2009). Among the studies pooled, there were $149 / 2678$ (5.6\%) participants in the control (standard care) groups and 94/2675 (3.5\%) participants in the intervention groups who developed VTE.

The meta-analysis showed that alerts were associated with a decrease in the risk of VTE (risk ratio (RR) $0.64,95 \% \mathrm{Cl} 0.47$ to 0.86 ; three studies; 5353 participants; Analysis 1.3; Figure 6; low-certainty evidence). 
Figure 6. Funnel plot of comparison: 1 Alerts versus standard care, outcome: 1.3 Symptomatic VTE.

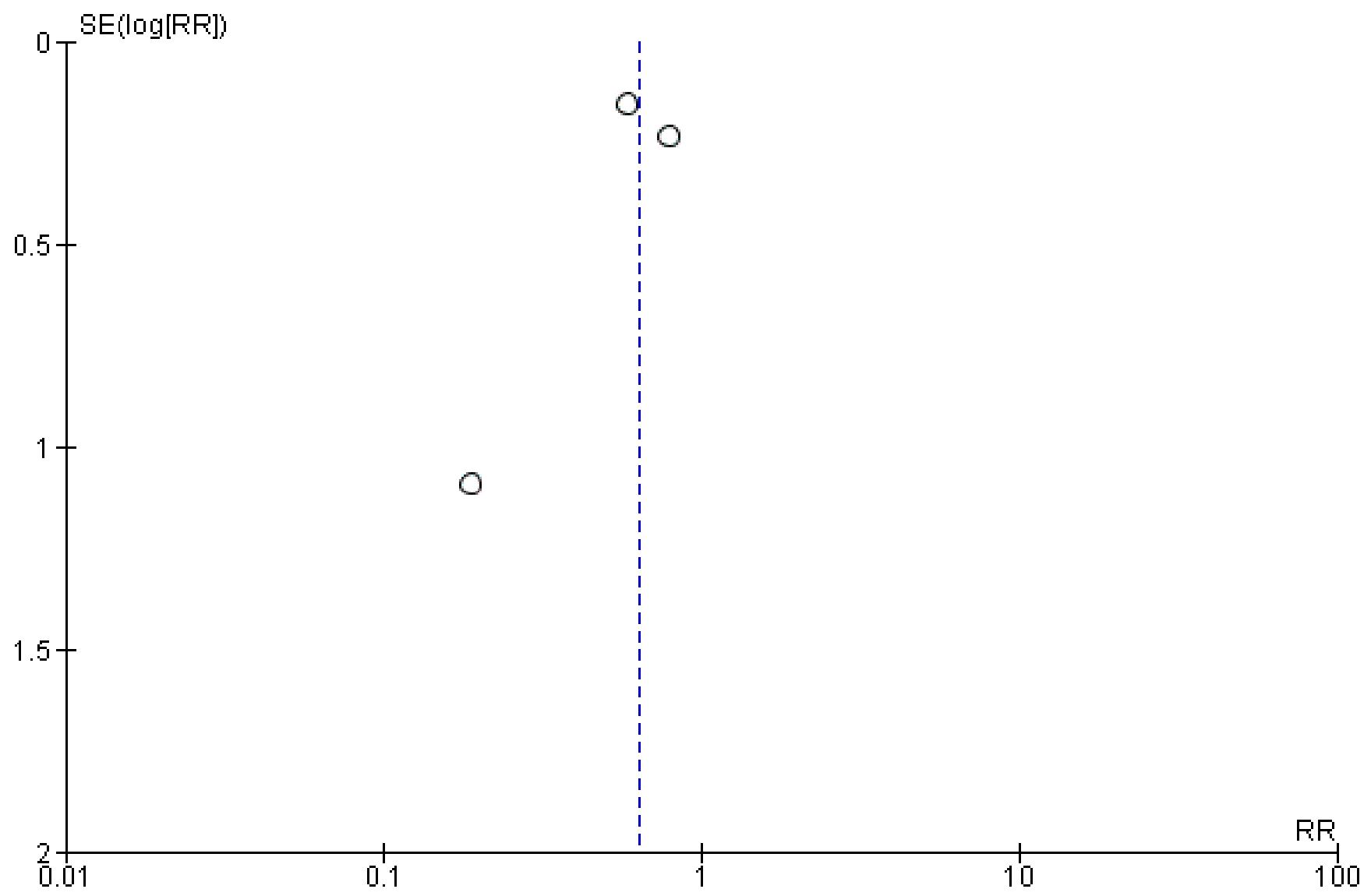

There was low heterogeneity between studies $\left(I^{2}=15 \%\right)$. The influence analysis showed that omitting Kucher 2005 from the analysis increased the variance and moved the point estimate towards the null (Appendix 10).

Any VTE, asymptomatic VTE and their components DVT and PE were not reported by the included studies.

\section{Mortality and safety outcomes}

Two studies reported mortality and safety outcomes (all-cause mortality, major bleeding) related to the use of alerts interventions (Kucher 2005; Piazza 2009). However, there was insufficient evidence to show that there were any clear differences between groups with regards to these outcomes (Table 3). Kucher 2005 also reported on the safety outcome of minor bleeding, which did not appear to differ in frequency between the intervention and control groups.

\section{Results according to the type of alert}

\section{Computer alerts}

See Table 4

Two studies found that more participants in the computer alerts groups received prophylaxis, over those who received standard care (Kucher 2005; Overhage 1996); however, only the Kucher 2005 study showed a clear difference between the computer alerts and standard care groups. Overhage 1996 did not report an ICC for the cluster design effect, thus, the effect estimate was not adjusted for the clustered nature of the data.

One computer alerts study reported the outcome received appropriate prophylaxis and showed that more participants received appropriate prophylaxis in the group that received computer alerts over those who received standard care (Dexter 2001).

One computer alerts study reported the outcome VTE and showed a decrease in the risk of developing VTE in the group that received computer alerts over those who received standard care (Kucher 2005). Mortality and safety outcomes are reported in Table 4.

\section{Human alerts}

See Table 5

One human alerts study reported the outcome received prophylaxis and showed that more participants received prophylaxis in the group that received human alerts, over those who received standard care (Piazza 2009). Two studies reported that there were more participants who received appropriate prophylaxis in the group that received human alerts than in the standard care group (Chapman 2011; Garcia 2009); however, only the Chapman 2011 study showed a clear difference between the human alerts and standard care groups (Table 5). Garcia 2009 did not report an ICC for the cluster design effect, thus the effect estimate was not adjusted for the clustered nature of the data. 
The two studies that examined human alerts found there was no clear difference between the human alerts and standard care groups in the number of participants who developed VTE (Chapman 2011; Piazza 2009; Table 5). Mortality and safety outcomes are reported in Table 5.

\section{Multifaceted interventions versus standard care or another intervention}

\section{Primary outcome}

\section{Received prophylaxis}

Across the five cluster-randomized trials (CRTs), 6690/12722 $(52.6 \%)$ participants randomized to the control groups (standard care or another intervention) and 7493/13608 (55.1\%) partici- pants randomized to the intervention groups (multifaceted interventions) received prophylaxis (Anderson 1994; Cavalcanti 2016; Labarere 2007; Pai 2013; Roy 2016).

Without adjusting for clustering, the meta-analysis showed a small increase in the proportion of participants who received prophylaxis in the intervention groups ( $\mathrm{RD} 0.03,95 \% \mathrm{Cl} 0.00$ to $0.05 ; 5$ studies; 26,330 participants; Analysis 2.1; Figure 7; moderate-certainty evidence). There was significant heterogeneity between studies $\left(I^{2}\right.$ $=64 \%$ ) when we did not account for clustering. When we adjusted for the cluster design effect with reported ICCs, the point estimate moved slightly away from the null, and remained significant (RD 0.04, 95\% Cl 0.02 to 0.06; 5 studies; 9198 participants; Analysis 2.2; Figure 8; moderate-certainty evidence), and the $\mathrm{I}^{2}$ decreased to $0 \%$.

Figure 7. Funnel plot of comparison: 2 Multifaceted interventions versus standard care or another intervention, outcome: 2.1 Received prophylaxis (unadjusted).

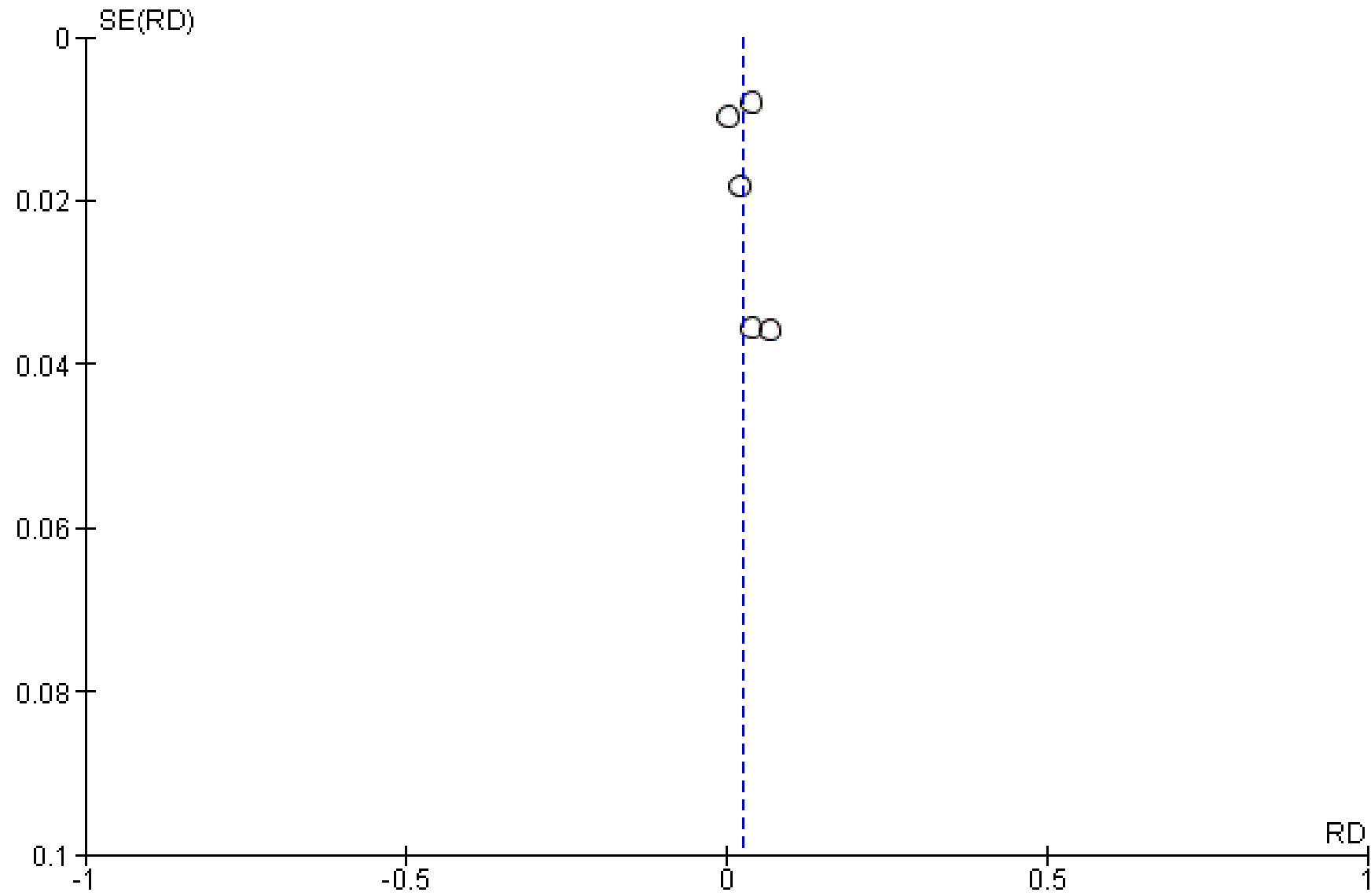


Figure 8. Funnel plot of comparison: 2 Multifaceted interventions versus standard care or another intervention, outcome: 2.2 Received prophylaxis (adjusted).

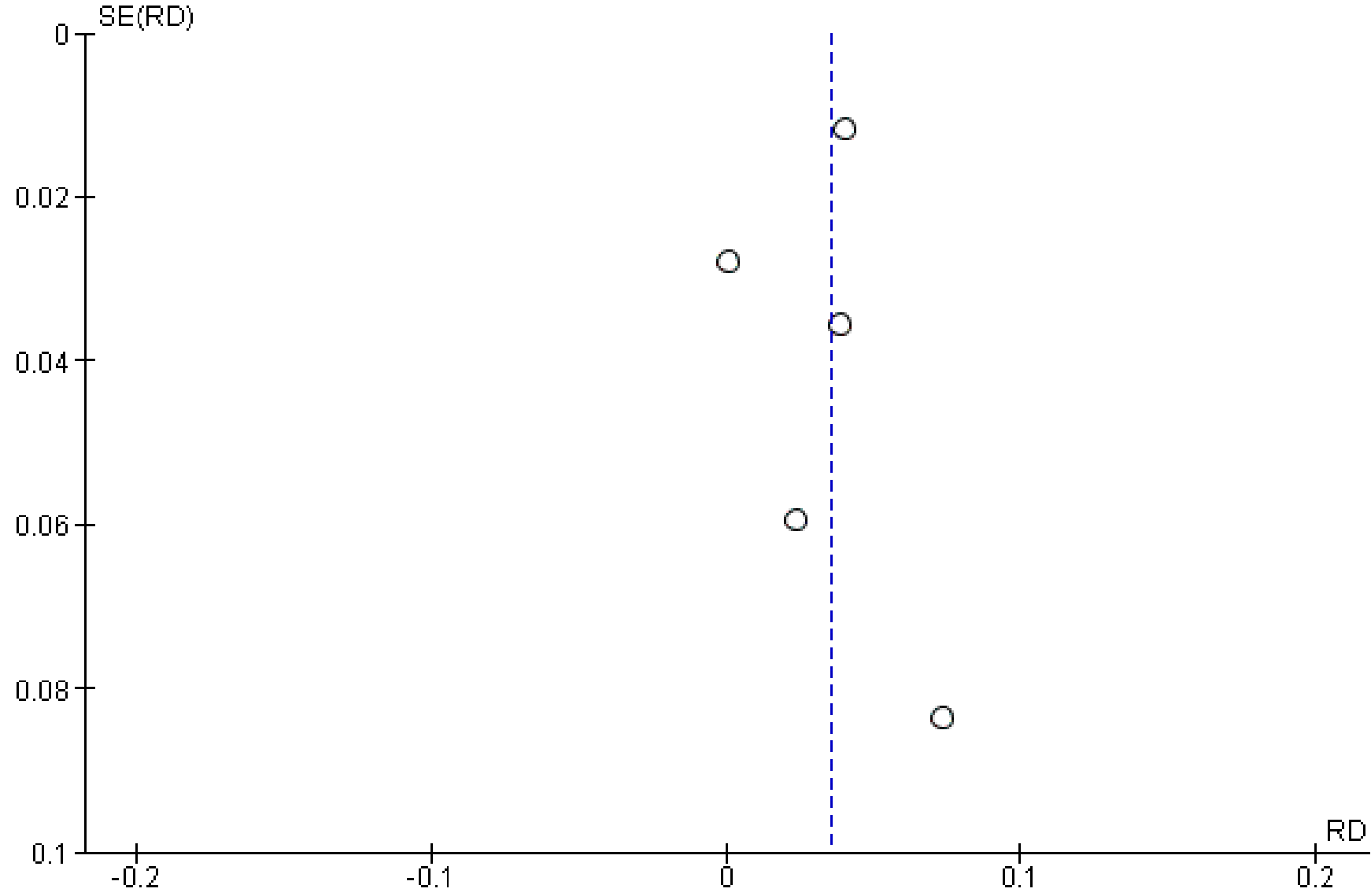

In the analysis of studies with multifaceted interventions, four of five trials reported an ICC. As a sensitivity analysis, we applied the lowest (Analysis 2.3), the mean (Analysis 2.4), and the highest ICC (Analysis 2.5) among these four trials to the one trial that did not report an ICC (Anderson 1994). All of these analyses showed similar point estimates and similar variance (Table 2).

The influence analysis showed that omitting the Roy 2016 trial from the adjusted analysis, the one multifaceted interventions study that included an alert component, was associated with a decrease in the pooled RD to $0.02(95 \% \mathrm{Cl}-0.02$ to 0.06$)$, with the result no longer significant (Appendix 10).

The study by Labarere 2007 was different from the other studies, in that it used an intervention (combination of educational session, dissemination of educational material, audit and feedback) as the control group. Therefore, the effect of multifaceted interventions may have been greater than what was found in our meta-analysis. However, when we removed Labarere 2007 from the adjusted analysis, as part of a sensitivity analysis, the point estimate of the main analysis was not affected Appendix 10).

\section{Secondary outcomes}

\section{Received appropriate prophylaxis}

Two studies of multifaceted interventions reported on the outcome received appropriate prophylaxis (Pai 2013; Roy 2016; Table 6). Pai
2013 showed a 3\% increase in the intervention group for those who received appropriate prophylaxis $(95 \% \mathrm{Cl}-0 \%$ to $6 \%)$, while Roy 2016 showed a $2 \%$ increase in the intervention group for received appropriate prophylaxis (95\% $\mathrm{Cl} 1 \%$ to $3 \%)$.

\section{Venous thromboembolism (VTE)}

Two studies of multifaceted interventions also reported one or more VTE outcomes (symptomatic VTE, symptomatic DVT, symptomatic PE, and asymptomatic DVT), however, we found no clear differences between the multifaceted interventions and control groups in these studies (Labarere 2007; Roy 2016; Table 6).

\section{Mortality and safety outcomes}

Three studies of multifaceted interventions reported one or more mortality and safety outcomes (all-cause mortality, sudden death, major bleeding, and thrombocytopenia; Cavalcanti 2016; Labarere 2007; Roy 2016) (Table 6); we found no clear differences between multifaceted interventions and control groups in these studies.

\section{Multifaceted interventions components}

All multifaceted intervention studies evaluated an educational intervention combined with other types of interventions (distribution of guidelines, audit and feedback, preprinted orders, and reminders). One multifaceted interventions study included an alert component. Roy 2016 evaluated a computer alert (computer-based 
clinical decision support system and computerized reminders) along with educational lectures, posters, and pocket cards, and showed a $4 \%$ increase in participants who received prophylaxis and a $2 \%$ increase in participants who received appropriate prophylaxis (Table 6). However, the computer alert component of the intervention was implemented in only two of the 14 intervention group centers. Thus, the overall effect of this multifaceted intervention might have been smaller than expected.

Among the four multifaceted trials that did not involve an alert component, all reported the number of participants who received prophylaxis, and we found no clear difference between groups (Anderson 1994; Cavalcanti 2016; Labarere 2007; Pai 2013; Analysis 2.1; Analysis 2.2; Figure 7; Figure 8). Cavalcanti 2016 evaluated a multifaceted intervention that included a reminder via SMS messages, sent one to three times a week, to ensure follow-through with daily checklist adherence and goals of care, along with daily multidisciplinary rounds. We found that this reminder component was not similar to the other alerts in our analysis, in that the timing of the alert was not at the point of prescription, but rather a general reminder to complete checklists that targeted a broad spectrum of care processes, including thromboprophylaxis.

\section{Educational interventions}

Anderson 1994 studied two types of interventions, an educational (continuing medical education) program and a multifaceted intervention (continuing medical education in association with a quality assurance program), and compared each to a control group. They reported a $4 \%$ increase $(95 \% \mathrm{Cl}-3 \%$ to $11 \%)$ in the number of participants who received prophylaxis in the multifaceted intervention group, and a $2 \%$ decrease $(95 \% \mathrm{Cl}-9 \%$ to $5 \%)$ in the number of participants who received prophylaxis in the educational intervention group (Table 7).

\section{Preprinted orders}

One study evaluated the use of preprinted orders, based on written thromboprophylaxis prescription aids, and reported a $5 \%$ decrease $(95 \% \mathrm{Cl}-12 \%$ to $2 \%)$ in the number of participants who received prophylaxis, compared to the group whose caregivers did not use preprinted orders (Fontaine 2006; Table 8). Due to the passive form of dissemination of this intervention, we did not consider it to be an alert intervention.

\section{DISCUSSION}

\section{Summary of main results}

Venous thromboembolism (VTE) is a leading, potentially preventable, cause of morbidity and mortality in hospitalized patients. We included 13 RCTs, which implemented a variety of system-wide interventions aimed at improving thromboprophylaxis rates in many settings and patient populations. Among the 11 RCTs $(\mathrm{N}=33,207$ participants) that we included in our quantitative analyses, we found improvements in the prescription of thromboprophylaxis associated with alerts (received prophylaxis: 3 studies; 5057 participants; low-certainty evidence; received appropriate prophylaxis: 3 studies; 1820 participants; moderate-certainty evidence), and multifaceted interventions (5 studies; 9198 participants; moderate-certainty evidence). However, multifaceted interventions appeared to be less effective overall than alerts. Due to a lack of studies, we were unable to assess if multifaceted interventions that included an alert component were more effective than those that did not include an alert. We also found that in studies that reported the development of symptomatic VTE, the risk of symptomatic VTE was reduced with the use of alerts, particularly with computer alerts ( 3 studies; 5353 participants; low-certainty evidence). However, there were not enough studies to pool results for computer alerts and human alerts separately.

Strengths of our review were that we considered studies, published in any language, with randomized designs (randomized, cluster-randomized, and quasi-randomized), which studied various interventions, settings, and patient populations. Our review was based on a peer reviewed protocol and followed current Cochrane methodological standards: we screened the reference lists of all included studies as well as narrative and systematic reviews identified by the literature searches in an attempt to identify additional studies; two review authors independently made decisions about study eligibility, assessed for risk of bias, extracted data, and conducted the analyses.

\section{Overall completeness and applicability of evidence}

Eight studies did not report on the appropriateness of prophylaxis as an outcome. Seven studies did not report relevant clinical outcomes, such as VTE and bleeding.

\section{Quality of the evidence}

Our systematic approach to searching the literature, study selection, and data extraction followed the guidance of the Cochrane Handbook for Systematic Reviews of Interventions (Higgins 2011). The risk of bias of the included studies was variable (Figure 2; Figure 3). Moderate- or low-certainty evidence supported the effectiveness of alerts interventions to increase thromboprophylaxis and decrease the incidence of symptomatic or asymptomatic VTE in hospitalized adult medical and surgical patients at risk for VTE, according to the GRADE approach (Summary of findings for the main comparison). We downgraded the certainty of the evidence from high to low for the outcome 'received prophylaxis' because of serious risk of bias in the RCTs, and inconsistency in the pooled results (unexplained statistical heterogeneity). We downgraded the certainty of the evidence from high to moderate for the outcome 'received appropriate prophylaxis' because of serious risk of bias in the included RCTs. We downgraded the certainty of the evidence from high to low for the outcome 'symptomatic VTE' because of serious risk of bias in included RCTs, and imprecision of results, related to the small number of VTE events (less than 300). We could not assess the presence of publication bias because we had fewer than 10 included studies. However, despite the fact that all analyses were underpowered to distinguish chance from real asymmetry, there was nearly a symmetrical distribution of individuals trials around the pooled estimate of effect in each meta-analysis, particularly for the outcome received appropriate prophylaxis.

Moderate-certainty evidence supported the effectiveness of multifaceted interventions to increase thromboprophylaxis and decrease the incidence of symptomatic or asymptomatic VTE in hospitalized adult medical and surgical patients at risk for VTE, according to the GRADE approach (Summary of findings 2). We downgraded the certainty of the evidence from high to moderate for the outcome 'received prophylaxis', because of serious risk of bias in included RCTs. We could not assess the presence of publication bias, because we had fewer than 10 included studies. However, despite the fact that the analysis was underpowered to distinguish chance 
from real asymmetry, there was a symmetrical distribution of individuals trials around the pooled estimate of effect.

The incomplete reporting of many included studies did not allow complete assessment of relevant study design features, such as sequence generation, allocation concealment, blinding of participants and personnel, blinding of outcome assessment, incomplete outcome data, selective reporting, and other potential sources of bias. Thus, the risk of bias of included studies was high. Ten of the included trials were of cluster design. While we were able to account for clustering using the reported ICC where available, in many cases, the ICC was not provided in the study report, leading to $\mathrm{Cls}$ that may have been narrower than if clustering had been adequately accounted for.

\section{Potential biases in the review process}

\section{Search strategy}

Our full literature search was last performed 7 January 2017. We searched databases from inception to 28 July 2015. Our research librarian updated the same search monthly 7 January 2017, when we closed our database. Any studies published subsequent to this date will be considered in future updates of this review. Despite the efforts made to conduct the most rigorous, sensitive and comprehensive search possible, it is nonetheless possible that we may have missed some studies.

\section{Screening}

We believe that there was low potential for bias in our screening process. Our process was very inclusive and we only eliminated studies that were not RCTs, or RCTs that did not evaluate interventions that aimed to increase the use of thromboprophylaxis, or appropriate thromboprophylaxis, or decrease the rate of VTE. Furthermore, screening of abstracts and article records was done in duplicate and any study identified as being potentially relevant by either review author was included in the full-text stage of study selection.

\section{Data extraction}

The data extraction form used in this review was designed to capture data on a variety of outcomes, and all data were extracted independently by two review authors. Therefore it is unlikely that we missed any data if they were reported in the article itself. We contacted the authors of four studies to obtain missing data, but were able to obtain additional data for only two of these (Cavalcanti 2016; Dexter 2001). The 'Risk of bias' assessment presented in this review was based solely on the data that were presented in the individual articles and data received through correspondence with the two authors.

\section{Analysis}

For our meta-analysis, we used between-group risk differences (alerts interventions studies), unadjusted for clustering, because ICCs were only provided for 4/10 CRTs. For the analysis of multifaceted interventions studies, we adjusted the risk differences using the ICCS reported, according to the methods in the Cochrane Handbook of Systematic Reviews of Interventions (Higgins 2011). Six of the cluster design trials in our review did not report ICCS; as a result, there is a potential of artificially narrow confidence intervals around the risk differences in the pooled unadjusted estimates. Fi- nally, the outcome 'received prophylaxis' may be an imperfect surrogate for 'received appropriate prophylaxis'.

To assess the robustness of our results using a random-effects model, we conducted sensitivity analyses using a fixed-effect approach (results not shown).

\section{Agreements and disagreements with other studies or reviews}

In our previous Cochrane Review that included 47 observational studies and eight RCTs, we found improvements in the prescription of thromboprophylaxis or appropriate thromboprophylaxis associated with the use of alerts, multifaceted interventions, and educational interventions (Kahn 2013). Multifaceted interventions with an alert component were found to be more effective than alerts alone or education alone. We did not find any clear difference in the pooled effect of these interventions on VTE, mortality, or safety outcomes. However, in that review, the overall magnitude of effects was small, precision was low, heterogeneity across studies was considerable, the risk of bias in included studies was substantial, and the overall certainty of evidence was very low.

This updated review improved upon prior meta-analyses conducted in this area, as it was restricted to RCTs, found less widely differing estimates (i.e. heterogeneity) across studies, and more precision of the estimates of effect (i.e. narrower confidence intervals), due to reduced between-study variance. We showed lower risk of bias in included studies, and higher certainty of evidence for improvement in outcomes.

There have been seven other previous systematic reviews of this topic, which were less methodologically rigorous than our review, and are now outdated. Tooher's systematic review of 30 studies published between 1996 and 2003, concluded that passive dissemination of guidelines was unlikely to improve VTE prophylaxis prescribing practice, and that multiple active strategies used together, which incorporated methods to remind clinicians to assess patients for DVT risk, and aided with the selection of appropriate prophylaxis, were likely to achieve better outcomes (Tooher 2005). Three subsequent, less comprehensive narrative reviews that searched the literature up to 2006 drew similar conclusions (Amin 2009; Amin 2012; Michota 2007). A systematic review of articles published between 1996 and 2008, on methods to improve prophylaxis and decrease VTE events in hospitalized patients came to similar conclusions, namely, that interventions that were active, rather than passive, appeared to be more effective (Mahan 2010).

In Adams's narrative review of 23 studies published up to 2010, which investigated the effectiveness of computer-based clinical decision-support systems to improve rates of thromboprophylaxis, computerized systems were associated with substantial improvements in the prescribing of appropriate prophylaxis and reductions in VTE events, particularly in hospitalized medical patients (Adams 2012). Lau 2014 was a narrative review that included 16 studies, published between 2001 and 2012, of different types of interventions, aimed to improve prescription of VTE prophylaxis in hospitalized patients. They too found that passive mandatory tools and education alone were less effective at improving the use of VTE prophylaxis than active strategies, like information technology tools, such as alerts and computer-based clinical decision-support systems. A subsequent overview review of 60 systematic reviews of interventions aimed at improving patient safety in hospitals and pub- 
lished up to 2015, concluded that alerts, education, real-time audit and feedback, and multifaceted interventions improved appropriate administration of thromboprophylaxis, but did not effectively reduce VTE events in hospital (Zegers 2016). This review included two of the previously noted systematic and narrative reviews (Kahn 2013; Lau 2014).

The most recent systematic review of the effectiveness of computer-based clinical decision-support systems to increase adherence to international (American College of Chest Physicians guidelines) and local thromboprophylaxis guidelines, and to decrease the rate of VTE events in hospitalized surgical patients, included 11 studies published between 1991 and 2016 (Borab 2017). This review, which included only observational studies, concluded that the use of computer-based clinical decision-support systems was associated with an increased rate of ordering appropriate thromboprophylaxis, and a reduced rate of postoperative VTE.

\section{AUTHORS' CONCLUSIONS}

\section{Implications for practice}

The findings of this review provided low- to moderate-certainty evidence to support the use of specific system-wide interventions to improve the prescription of thromboprophylaxis, and decrease the incidence of symptomatic VTE in hospitalized adult medical and surgical patients at risk for VTE. From 11 RCTs with data available for meta-analysis, we found improvements in rates of prescription of prophylaxis associated with alerts (computer alerts or human alerts) and multifaceted interventions (e.g. combination of education, audit and feedback, and alert); and improvements in the rates of appropriate prescription of prophylaxis and reductions in the rate of symptomatic VTE at three months associated with alerts. Multifaceted interventions appeared to be less effective (as suggested by the smaller pooled risk differences) than alerts.

Based on risk differences and risk ratios, computer alerts may be more effective than human alerts, for appropriate prescription of prophylaxis and symptomatic VTE at three months. However, due to a lack of studies, we were unable to provide pooled estimates for the direct comparison of computer alerts versus human alerts.

Our analysis was underpowered to assess the effect on mortality and safety outcomes, such as bleeding.

Our findings provide support for the tenet that system-wide interventions to improve the use of VTE prophylaxis are effective, particularly computer and human alerts that are well integrated into the clinical workflow. We hope that the results of our review will help physicians and other healthcare practitioners, hospital administrators, and policy makers make practical decisions tailored to their own settings about adoption of specific system-wide measures to improve prevention of VTE in hospitalized patients. VTE prevention quality initiative programs could also benefit from our findings.

\section{Implications for research}

Several questions remained unresolved regarding the effectiveness of system-wide interventions to increase the implementation of thromboprophylaxis in hospitalized medical and surgical patients at risk for VTE, as well as how best to implement them. While most of the interventions we reviewed were effective at increasing rates of prophylaxis or appropriate prophylaxis, research is needed to understand why such interventions do not have a larger effect on the prescribing of prophylaxis. More studies should report the more clinically relevant outcome of appropriate prophylaxis. Research is also needed to better understand how these interventions affect clinical outcomes such as VTE, mortality, and safety outcomes such as bleeding.

Even within a specific type of intervention (e.g. computer alerts; human alerts), there was variability in the design of the intervention, leaving uncertainty about which design may be optimal. Further research into the targeting of patients and clinicians for VTE prophylaxis education upon admission is also needed. As one-third of the studies in our review were performed at single centers, which can limit the generalizability of results, we believe that additional multi-centre randomized controlled trials are justified in an area like this, where there is currently a void in high quality research, and where the potential impact on both health and future cost savings could be great. Direct evaluations of costs of the implementation of computer-based clinical decision-support systems are still lacking, as are studies of comparative cost-effectiveness of various system-wide interventions. In one study, use of a computer-based clinical decision support system reduced proxy measures of cost for inpatient VTE (Fillmore 2013), and in another, use of an electronic alert system at a hospital in Spain reduced the incidence of VTE and led to net cost savings (Lecumberri 2011).

\section{ACK N O WLEDGEMENTS}

Dr Kahn holds a Tier 1 Canada Research Chair in Venous Thromboembolism. Dr Kahn, Dr Tagalakis, Ms Emed, Dr Roussin, and Dr Geerts are investigators of the CanVECTOR Network (CIHR funding reference CDT-142654). Dr Klil-Drori is supported by a CanVECTOR fellowship award. Dr Filion is supported by a Junior II salary support award from the Fonds de recherche du Québec - Santé (Quebec Foundation for Health Research).

This review was funded by a Canadian Institutes for Health Research Knowledge Synthesis Grant (\#141001) and a Canadian Institutes for Health Research Foundation Grant to Dr Kahn (\# 143346). 


\section{RE F E R E N C E S}

\section{References to studies included in this review}

Anderson 1994 \{published data only\}

Anderson FA Jr, Wheeler HB, Goldberg RJ, Hosmer DW, Forcier A, Patwardhan NA. Changing clinical practice. Prospective study of the impact of continuing medical education and quality assurance programs on use of prophylaxis for venous thromboembolism. Archives of Internal Medicine 1994;154(6):669-77. [PMID: 8129501]

\section{Cavalcanti 2016 \{published data only\}}

Cavalcanti AB, Bozza FA, Machado FR, Salluh JI, Campagnucci VP, Vendramim P, et al. Effect of a quality improvement intervention with daily round checklists, goal setting, and clinician prompting on mortality of critically ill patients: a randomized clinical trial. JAMA 2016;315(14):1480-90. [DOI: 10.1001/jama.2016.3463]

\section{Chapman 2011 \{published data only (unpublished sought but not used)\}}

Chapman NH, Lassere MN, Clarke M, Chong BH. Guidelines for venous thromboembolism (VTE) prevention in hospitalised medical patients: a validation study pilot. Journal of Thrombosis and Haemostasis 2011;9(2):654. [Available from dx.doi.org/10.1111/j.1538-7836.2011.04380_3.x (accessed 17 July 2017)]

\section{Dexter 2001 \{published and unpublished data\}}

Dexter PR, Perkins S, Overhage JM, Maharry K, Kohler RB, McDonald CJ. A computerized reminder system to increase the use of preventive care for hospitalized patients. New England Journal of Medicine 2001;345(13):965-70. [DOI: 10.1056/ NEJMsa010181]

\section{Fontaine 2006 \{published data only\}}

Fontaine A, Mahé I, Bergmann JF, Fiessinger JN, Dhote R, Cohen $\mathrm{P}$, et al. Effectiveness of written guidelines on the appropriateness of thromboprophylaxis prescriptions for medical patients: a prospective randomized study. Journal of Internal Medicine 2006;260(4):369-76. [DOI: 10.1111/ j.1365-2796.2006.01699.x]

\section{Garcia 2009 \{published data only\}}

Garcia DA, Highfill J, Finnerty K, Varoz E, McConkey S, Hutchinson $\mathrm{K}$, et al. A prospective, controlled trial of a pharmacy-driven alert system to increase thromboprophylaxis rates in medical inpatients. Blood Coagulation and Fibrinolysis 2009;20(7):541-5. [DOI: 10.1097/MBC.0b013e32832d6cfc]

\section{Hinchey 2010 \{published data only (unpublished sought but not used)\}}

Hinchey JA, Shephard T, Tonn ST, Ruthazer R, Herman RC, Selker HP, et al. The stroke practice improvement network: a quasi-experimental trial of a multifaceted intervention to improve quality. Journal of Stroke and Cerebrovascular Diseases 2010;19(2):130-7. [DOI: 10.1016/ j.jstrokecerebrovasdis.2009.03.016]
Kucher 2005 \{published data only\}

Kucher N, Koo S, Quiroz R, Cooper JM, Paterno MD, Soukonnikov B, et al. Electronic alerts to prevent venous thromboembolism among hospitalized patients. New England Journal of Medicine 2005;352(10):969-77. [DOI: 10.1056/ NEJMoa041533]

Paterno MD, Cina JL, Goldhaber SZ, Kucher N. Preventing DVT and PE in hospitalized patients: improving a successful electronic alert. AMIA Annual Symposium Proceedings 2006:1058. [PMCID: PMC1839306]

\section{Labarere 2007 \{published data only\}}

Labarere J, Bosson JL, Sevestre MA, Sellier E, Richaud C, Legagneux A. Intervention targeted at nurses to improve venous thromboprophylaxis. International Journal for Quality in Health Care 2007;19(5):301-8. [DOI: 10.1093/intqhc/mzm034]

\section{Overhage 1996 \{published data only\}}

Overhage JM, Tierney WM, McDonald CJ. Computer reminders to implement preventive care guidelines for hospitalized patients. Archives of Internal Medicine 1996;156(14):1551-6. [PMID: 8687263 ]

\section{Pai 2013 \{published data only\}}

Pai M, Lloyd NS, Cheng J, Thabane L, Spencer FA, Cook DJ, et al. Strategies to enhance venous thromboprophylaxis in hospitalized medical patients (SENTRY): a pilot cluster randomized trial. Implementation Science 2013;8:1. [DOI: 10.1186/1748-5908-8-1]

\section{Piazza 2009 \{published data only\}}

Piazza G, Rosenbaum EJ, Pendergast W, Jacobson JO, Pendleton RC, McLaren GD, et al. Physician alerts to prevent symptomatic venous thromboembolism in hospitalized patients. Circulation 2009;119(16):2196-201. [DOI: 10.1161/ CIRCULATIONAHA.108.841197]

\section{Roy 2016 \{published data only\}}

Roy PM, Rachas A, Meyer G, Le Gal G, Durieux P, El Kouri D, et al. Multifaceted intervention to prevent venous thromboembolism in patients hospitalized for acute medical illness: a multicenter cluster-randomized trial. PLoS One 2016;11(5):e0154832. [DOI: 10.1371/journal.pone.0154832]

\section{References to studies excluded from this review}

\section{Marini 2014 \{published data only\}}

Marini BL, Funk K, Kraft MD, Fong JM, Naanos R, Stout SM, et al. The effects of an informational video on patient knowledge, satisfaction and compliance with venous thromboembolism prophylaxis: a pilot study. Patient Education and Counseling 2014;96(2):264-7. [DOI: 10.1016/j.pec.2014.05.008]

\section{Nendaz 2010 \{published data only\}}

Nendaz MR, Chopard P, Lovis C, Kucher N, Asmis LM, Dörffler J, et al. Adequacy of venous thromboprophylaxis in acutely ill medical patients (IMPART): multisite comparison of 
different clinical decision support systems. Journal of Thrombosis and Haemostasis 2010;8(6):1230-4. [DOI: 10.1111/ j.1538-7836.2010.03817.x]

\section{Piazza 2013 \{published data only\}}

Piazza G, Anderson FA, Ortel TL, Cox MJ, Rosenberg DJ, Rahimian S, et al. Randomized trial of physician alerts for thromboprophylaxis after discharge. American Journal of Medicine 2013;126(5):435-42. [DOI: 10.1016/ j.amjmed.2012.09.020]

\section{Additional references}

\section{Adamali 2013}

Adamali H, Suliman AM, Zaid H, O'Donoghue E, Burke A, Suliman AW, et al. A national house-staff audit of medical prophylaxis in medical patients for the prevention of venous thromboembolism (PREVENT-VTE). Irish Medical Journal 2013;106(10):302-5.

\section{Adams 2012}

Adams P, Riggio JM, Thomson L, Brandell-Marino R, Merli G. Clinical decision support systems to improve utilization of thromboprophylaxis: a review of the literature and experience with implementation of a computerized physician order entry program. Hospital Practice (1995) 2012;40(3):27-39.

\section{Akinbobuyi 2016}

Akinbobuyi O, Shalders L, Nokes T. Ensuring timely thromboprophylaxis on a medical assessment unit. British Medical Journal Quality Improvement Reports 2016;5(1):u212414.w4934.

\section{Al-Hameed 2014}

Al-Hameed F, Al-Dorzi HM, Aboelnazer E. The effect of a continuing medical education program on venous thromboembolism prophylaxis utilization and mortality in a tertiary-care hospital. Thrombosis Journal 2014;12:9.

\section{Alotaibi 2016}

Alotaibi GS, Wu C, Senthilselvan A, McMurtry MS. Secular trends in incidence and mortality of acute venous thromboembolism: The AB-VTE population-based study. American Journal of Medicine 2016;129(8):879.e19-25.

\section{Amin 2009}

Amin AN, Deitelzweig SB. Optimizing the prevention of venous thromboembolism: recent quality initiatives and strategies to drive improvement. The Joint Commission Journal on Quality and Patient Safety 2009;35(11):558-64.

\section{Amin 2012}

Amin AN, Deitelzweig SB. Strategies to optimize the prevention of venous thromboembolism: process improvement practices. Journal of Clinical Outcomes Management 2012;19(3):117-24.

\section{Anderson 2003}

Anderson FA Jr, Spencer FA. Risk factors for venous thromboembolism. Circulation 2003;107(23):19-16.

\section{Anderson 2007}

Anderson FA Jr, Zayaruzny M, Heit JA, Fidan D, Cohen AT. Estimated annual numbers of US acute-care hospital patients at risk for venous thromboembolism. American Journal of Hematology 2007;82(9):777-82.

\section{Barbar 2017}

Barbar S, Prandoni P. Scoring systems for estimating risk of venous thromboembolism in hospitalized medical patients. Seminars in Thrombosis and Hemostasis 2017;43(5):460-8.

\section{Beckman 2016}

Beckman MG, Abe K, Barnes K, Bartman B, Brady PJ, Hooper WC. Strategies and partnerships toward prevention of healthcare-associated venous thromboembolism. Journal of Hospital Medicine 2016;11(Suppl 2):S5-7.

\section{Bikdeli 2016}

Bikdeli B, Wang Y, Minges KE, Desai NR. Hospitalizations, therapies, and outcomes of pulmonary embolism in medicare beneficiaries: trends are similar to Europe. Journal of the American College of Cardiology 2016;67(21):2559-60.

\section{Borab 2017}

Borab ZM, Lanni MA, Tecce MG, Pannucci CJ, Fischer JP. Use of computerized clinical decision support systems to prevent venous thromboembolism in surgical patients: a systematic review and meta-analysis. JAMA Surgery 2017;152(7):638-45.

\section{Bozarth 2013}

Bozarth AL, Bajaj N, Abdeljalil A. A review of venous thromboembolism prophylaxis for hospitalized medical patients. Hospital Practice (1995) 2013;41(3):60-9.

\section{Bozzato 2012}

Bozzato S, Galli L, Ageno W. Thromboprophylaxis in surgical and medical patients. Seminars in Respiratory and Critical Care Medicine 2012;33(2):163-75.

\section{de Miguel-Díez 2014}

de Miguel-Díez J, Jiménez-García R, Jiménez D, Monreal M, Guijarro R, Otero R, et al. Trends in hospital admissions for pulmonary embolism in Spain from 2002 to 2011. European Respiratory Journal 2014;44(4):942-50.

\section{Dobesh 2010}

Dobesh P. The importance of appropriate prophylaxis for the prevention of venous thromboembolism in at-risk medical patients. International Journal of Clinical Practice 2010;64(11):1554-62.

\section{Dobromirski 2012}

Dobromirski M, Cohen AT. How I manage venous thromboembolism risk in hospitalized medical patients. Blood 2012;120(8):1562-9.

\section{Egger 1997}

Egger M, Smith GD, Schneider M, Minder C. Bias in meta-analysis detected by a simple, graphical test. BMJ 1997;315(7109):62934. 


\section{Falck-Ytter 2012}

Falck-Ytter Y, Francis CW, Johanson NA, Curley C, Dahl OE, Schulman S, et al. Prevention of VTE in orthopedic surgery patients: antithrombotic therapy and prevention of thrombosis, 9th ed: American College of Chest Physicians evidence-based clinical practice guidelines. Chest 2012;141(2):e278S-325S.

\section{Farfan 2016}

Farfan M, Bautista M, Bonilla G, Rojas J, Llinás A, Navas J. Worldwide adherence to ACCP guidelines for thromboprophylaxis after major orthopedic surgery: a systematic review of the literature and meta-analysis. Thrombosis Research 2016;141:163-70.

\section{Farge 2016}

Farge D, Bounameaux H, Brenner B, Cajfinger F, Debourdeau P, Khorana AA, et al. International clinical practice guidelines including guidance for direct oral anticoagulants in the treatment and prophylaxis of venous thromboembolism in patients with cancer. Lancet Oncology 2016;17(10):e452-66.

\section{Fernandez 2015}

Fernandez MM, Hogue S, Preblick R, Kwong WJ. Review of the cost of venous thromboembolism. ClinicoEconomics and Outcomes Research 2015;7:451-62.

\section{Fiero 2016}

Fiero MH, Huang S, Oren E, Bell ML. Statistical analysis and handling of missing data in cluster randomized trials: a systematic review. Trials 2016;17:72.

\section{Fillmore 2013}

Fillmore CL, Bray BE, Kawamoto K. Systematic review of clinical decision support interventions with potential for inpatient cost reduction. BMC Medical Informatics and Decision Making 2013;13:135

\section{Geahchan 2016}

Geahchan N, Basile M, Tohmeh M, DIONYS registry. Venous thromboembolism prophylaxis in patients undergoing abdominal and pelvic cancer surgery: adherence and compliance to ACCP guidelines in DIONYS registry. Springerplus 2016;5(1):1541.

\section{Geerts 2008}

Geerts WH, Bergqvist D, Pineo GF, Heit JA, Samama CM, Lassen MR, et al. Prevention of venous thromboembolism: American College of Chest Physicians Evidence-Based Clinical Practice Guidelines (8th Edition). Chest 2008;133(6):381S-453S.

\section{Geerts 2009}

Geerts W. Prevention of venous thromboembolism: a key patient safety priority. Journal of Thrombosis and Haemostasis 2009;7(Suppl 1):1-8.

\section{Golian 2016}

Golian M, Moussa M, White C, Aletta G, Koley L, Seifer C. Venous thromboembolism prophylaxis on a cardiology in-patient unit: a surprising result?. Canadian Journal of Cardiology 2016;32(2):256-8.

\section{Gould 2012}

Gould MK, Garcia DA, Wren SM, Karanicolas PJ, Arcelus JI, Heit JA, et al. Prevention of VTE in non-orthopedic surgical patients: antithrombotic therapy and prevention of thrombosis, 9th ed: American College of Chest Physicians evidence-based clinical practice guidelines. Chest 2012;141(Suppl 2):e227S-77S.

\section{GRADEpro GDT [Computer program]}

McMaster University (developed by Evidence Prime). GRADEpro GDT. Version accessed 20 July 2017. Hamilton (ON): McMaster University (developed by Evidence Prime), 2015.

\section{Guyatt 2011}

Guyatt GH, Oxman AD, Schünemann HJ, Tugwell P, Knottnerus A. GRADE guidelines: a new series of articles in the Journal of Clinical Epidemiology. Journal of Clinical Epidemiology 2011;64(4):380-2.

\section{Hansrani 2017}

Hansrani V, Khanbhai M, McCollum C. The prevention of venous thromboembolism in surgical patients. Advances in Experimental Medicine and Biology 2017;906:1-8.

\section{Heit 2001}

Heit JA, Melton LJ 3rd, Lohse CM, Petterson TM, Silverstein MD, Mohr DN, et al. Incidence of venous thromboembolism in hospitalized patients vs community residents. Mayo Clinic Proceedings 2001;76(11):1102-10.

\section{Heit 2002}

Heit JA, O'Fallon WM, Petterson TM, Lohse CM, Silverstein MD, Mohr DN, et al. Relative impact of risk factors for deep vein thrombosis and pulmonary embolism: a population-based study. Archives of Internal Medicine 2002;162(11):1245-8.

\section{Heit 2015}

Heit JA. Epidemiology of venous thromboembolism. Nature Reviews Cardiology 2015;12(8):464-74.

\section{Heit 2016}

Heit JA, Spencer FA, White RH. The epidemiology of venous thromboembolism. Journal of Thrombosis and Thrombolysis 2016;41(1):3-14.

\section{Hibbert 2016}

Hibbert PD, Hannaford NA, Hooper TD, Hindmarsh DM, Braithwaite J, Ramanathan SA, et al. Assessing the appropriateness of prevention and management of venous thromboembolism in Australia: a cross-sectional study. BMJ Open 2016;6(3):e008618.

\section{Higgins 2011}

Higgins JPT, Green S (editors). Cochrane Handbook for Systematic Reviews of Interventions version 5.1.0 (updated March 2011). The Cochrane Collaboration, 2011. Available from handbook.cochrane.org.

\section{Jacobs 2012}

Jacobs JJ, Mont MA, Bozic KJ, Della Valle CJ, Goodman SB, Lewis CG, et al. American Academy of Orthopaedic Surgeons clinical practice guideline on: preventing venous 
thromboembolic disease in patients undergoing elective hip and knee arthroplasty. Journal of Bone and Joint Surgery. American Volume 2012;94(8):746-7.

\section{Jacobs 2017}

Jacobs B, Pannucci C. Scoring systems for estimating risk of venous thromboembolism in surgical patients. Seminars in Thrombosis and Hemostasis 2017;43(5):449-59.

\section{Jha 2013}

Jha AK, Larizgoitia I, Audera-Lopez C, Prasopa-Plaizier N, Waters H, Bates DW. The global burden of unsafe medical care: analytic modelling of observational studies. BMJ Quality \& Safety 2013;22(10):809-15.

\section{Jiménez 2016}

Jiménez D, de Miguel-Díez J, Guijarro R, Trujillo-Santos J, Otero R, Barba R, et al. Trends in the management and outcomes of acute pulmonary embolism: analysis from the RIETE registry. Journal of the American College of Cardiology 2016;67(2):162-70.

\section{Kahn 2007}

Kahn SR, Panju A, Geerts W, Pineo GF, Desjardins L, Turpie AG, et al. Multicenter evaluation of the use of venous thromboembolism prophylaxis in acutely ill medical patients in Canada. Thrombosis Research 2007;119(2):145-55.

\section{Kahn 2012}

Kahn SR, Lim W, Dunn AS, Cushman M, Dentali F, Akl EA, et al. Prevention of VTE in nonsurgical patients: antithrombotic therapy and prevention of thrombosis, 9th ed: American College of Chest Physicians evidence-based clinical practice guidelines. Chest 2012;141(2 Suppl):e195S-226S.

\section{Kakkar 2010}

Kakkar AK, Cohen AT, Tapson VF, Bergmann JF, Goldhaber SZ, Deslandes B, et al. Venous thromboembolism risk and prophylaxis in the acute care hospital setting (ENDORSE survey): findings in surgical patients. Annals of Surgery 2010;251(2):230-8

\section{Kerbauy 2013}

Kerbauy MN, de Moraes FY, Kerbauy LN, Conterno Lde O, El-Fakhouri S. Venous thromboprophylaxis in medical patients: an application review. Revista da Associação Médica Brasileira (1992) [Journal of the Brazilian Medical Association] 2013;59(3):258-64.

\section{Khoury 2011}

Khoury H, Welner S, Kubin M, Folkerts K, Haas S. Disease burden and unmet needs for prevention of venous thromboembolism in medically ill patients in Europe show underutilisation of preventive therapies. Thrombosis and Haemostasis 2011;106(4):600-8.

\section{Kim 2015}

Kim JY, Khavanin N, Rambachan A, McCarthy RJ, Mlodinow AS, De Oliveria GS Jr, et al. Surgical duration and risk of venous thromboembolism. JAMA Surgery 2015;150(2):110-7.

\section{Kim 2016}

Kim PS, Gasparis AP, ProbeckK, Elitharp D, Tassiopoulos A, Labropoulos N. Accuracy of venous thromboembolism assessment and compliance to prophylaxis in a tertiary care center. Phlebology 2016;31(8):541-5.

\section{Konstantinides 2016}

Konstantinides SV. Trends in pulmonary embolism outcomes: are we really making progress?. Journal of the American College of Cardiology 2016;67(2):171-3.

\section{Kucher 2005a}

Kucher N, Tapson VF, Goldhaber SZ, DVT FREE Steering Committee. Risk factors associated with symptomatic pulmonary embolism in a large cohort of deep vein thrombosis patients. Thrombosis and Haemostasis 2005;93(3):494-8.

\section{Lancet Haematology 2015}

The Lancet Haematology. Thromboembolism: an under appreciated cause of death. Lancet Haematology 2015;2(10):e393.

\section{Lau 2014}

Lau BD, Haut ER. Practices to prevent venous thromboembolism: a brief review. BMJ Quality \& Safety 2014;23(3):187-95

\section{Lecumberri 2011}

Lecumberri R, Panizo E, Gomez-Guiu A, Varea S, GarciaQuetglase E, Serrano M, et al. Economic impact of an electronic alert system to prevent venous thromboembolism in hospitalised patients. Journal of Thrombosis and Haemostasis 2011;9(6):1108-15.

\section{Liew 2017}

Liew NC, Alemany GV, Angchaisuksiri P, Bang SM, Choi G, DE Silva DA, et al. Asian venous thromboembolism guidelines: updated recommendations for the prevention of venous thromboembolism. International Angiology 2017;36(1):1-20.

\section{Mahan 2010}

Mahan CE, Spyropoulos AC. Venous thromboembolism prevention: a systematic review of methods to improve prophylaxis and decrease events in the hospitalized patient. Hospital Practice 2010;38(1):97-108.

\section{Maynard 2016}

Maynard G. Preventing hospital-associated venous thromboembolism: a guide for effective quality improvement, 2nd ed. Rockville, MD: Agency for Healthcare Research and Quality; AHRQ Publication No. 16-0001-EF 2016.

\section{Michota 2007}

Michota F. Bridging the gap between evidence and practice in venous thromboembolism prophylaxis: the quality improvement process. Journal of General Internal Medicine 2007;22(12):1762-70.

\section{Minges 2015}

Minges KE, Bikdeli B, Wang Y, Kim N, Curtis JP, Desai MM, et al. National trends in pulmonary embolism hospitalization 
rates and outcomes for adults aged $\geq 65$ years in the United States (1999 to 2010). American Journal of Cardiology 2015;116(9):1436-42.

\section{NICE 2015}

National Institute for Health and Clinical Excellence. Venous thromboembolism: reducing the risk of venous thromboembolism (deep vein thrombosis and pulmonary embolism) in inpatients undergoing surgery (last updated: June 2015). www.nice.org.uk/guidance/CG92 (accessed 19 July 2017):1-60.

\section{Nicolaides 2013}

Nicolaides A, Fareed J, Kakkar AK, Comerota AJ, Goldhaber SZ, Hull $R$, et al. Prevention and treatment of venous thromboembolism international consensus statement (guidelines according to scientific evidence). Clinical and Applied Thrombosis/Hemostasis 2013;19(2):116-8.

\section{Noboa 2006}

Noboa S, Mottier D, Oger E, EPI-GETBO study group. Estimation of a potentially preventable fraction of venous thromboembolism: a community-based prospective study. Journal of Thrombosis and Haemostasis 2006;4(12):2720-2.

\section{Qaseem 2011}

Qaseem A, Chou R, Humphrey LL, Starkey M, Shekelle P, Clinical Guidelines Committee of the American College of Physicians. Venous thromboembolism prophylaxis in hospitalized patients: a clinical practice guideline from the American College of Physicians. Annals of Internal Medicine 2011;155(9):625-32.

\section{Randelli 2016}

Randelli F, Cimminiello C, Capozzi M, Bosco M, Cerulli G, GIOTTO Investigators. Real life thromboprophylaxis in orthopedic surgery in Italy. Results of the GIOTTO study. Thrombosis Research 2016;137:103-7.

\section{Raskob 2014}

Raskob GE, Angchaisuksiri P, Blanco AN, Büller H, Gallus A, Hunt BJ, et al. Thrombosis: a major contributor to global disease burden. Seminars in Thrombosis and Hemostasis 2014;40(7):724-35.

\section{Raskob 2016}

Raskob GE, Angchaisuksiri P, Blanco AN, Buller H, Ddungu H, Hunt BJ, et al. Venous thromboembolism: a call for risk assessment in all hospitalised patients. Thrombosis and Haemostasis 2016;116(5):777-9.

\section{Schleyer 2011}

Schleyer AM, Schreuder AB, Jarman KM, Logerfo JP, Goss JR. Adherence to guideline-directed venous thromboembolism prophylaxis among medical and surgical inpatients at 33 academic medical centers in the United States. American Journal of Medical Quality 2011;26(3):174-80.

\section{Schünemann 2004}

Schünemann HJ, Cook D, Grimshaw J, Liberati A, Heffner J, Tapson V, et al. Antithrombotic and thrombolytic therapy: from evidence to application: The Seventh ACCP Conference on Antithrombotic and Thrombolytic Therapy. Chest 2004;126(Suppl 3):688S-96S.

\section{Shekelle 2013a}

Shekelle PG, Wachter RM, Pronovost PJ, Schoelles K, McDonald KM, Dy SM, et al. Making health care safer II: an updated critical analysis of the evidence for patient safety practices. Publication No. 13-E001-EF. www.ahrq.gov/research/ findings/evidence-based-reports/ptsafetyuptp.html (accessed 19 July 2017):1-945.

\section{Shekelle 2013b}

Shekelle PG, Pronovost PJ, Wachter RM, McDonald KM, Schoelles K, Dy SM, et al. The top patient safety strategies that can be encouraged for adoption now. Annals of Internal Medicine 2013;158(5 Pt 2):365-8.

\section{Shirvanian 2015}

Shirvanian S, Tapson VF. Venous thromboembolism: identifying patients at risk and establishing prophylaxis. Current Medical Research and Opinion 2015;31(12):2297-311.

\section{Shojania 2001}

Shojania KG, Duncan BW, McDonald KM, Wachter RM, Markowitz AJ. Making health care safer: a critical analysis of patient safety practices. Evidence Report/Technology Assessment, No. 43. archive.ahrq.gov/clinic/ptsafety (accessed 19 June 2017):i-x, 1-668.

\section{Spencer 2007}

Spencer FA, Lessard D, Emery C, Reed G, Goldberg RJ. Venous thromboembolism in the outpatient setting. Archives of Internal Medicine 2007;167(14):1471-5.

\section{Stein 2005}

Stein PD, Beemath A, Olson RE. Trends in the incidence of pulmonary embolism and deep venous thrombosis in hospitalized patients. American Journal of Cardiology 2005;95(12):1525-6.

\section{Stein 2011}

Stein PD, Matta F, Dalen JE. Is the campaign to prevent VTE in hospitalized patients working?. Chest 2011;139(6):1317-21.

\section{Stein 2012}

Stein PD, Matta F, Alrifai A, Rahman A. Trends in case fatality rate in pulmonary embolism according to stability and treatment. Thrombosis Research 2012;130(6):841-6.

\section{Streiff 2012}

Streiff MB, Lau BD. Thromboprophylaxis in non surgical patients. Hematology. American Society of Hematology. Education Program 2012;2012(1):631-7.

\section{Tooher 2005}

Tooher R, Middleton P, Pham C, Fitridge R, Rowe S, Babidge W, et al. A systematic review of strategies to improve prophylaxis for venous thromboembolism in hospitals. Annals of Surgery 2005;241(3):397-415. 


\section{Tsai 2012}

Tsai J, Grosse SD, Grant AM, Hooper CW, Atrash HK. Trends in in-hospital deaths among hospitalizations with pulmonary embolism. Archives of Internal Medicine 2012;172(12):960-1.

\section{Vazquez 2014}

Vazquez F, Watman R, Tabares A, Gumpel C, Baldessari E, Vilaseca AB. Risk of venous thromboembolic disease and adequacy of prophylaxis in hospitalized patients in Argentina: a multicentric cross-sectional study. Thrombosis Journal 2014;12:15

\section{Wendelboe 2016}

Wendelboe AM, Raskob GE. Global burden of thrombosis: epidemiologic aspects. Circulation Research 2016;118(9):1340-7.

\section{Zegers 2016}

Zegers M, Hesselink G, Geense W, Vincent C, Wollersheim H. Evidence-based interventions to reduce adverse events in hospitals: a systematic review of systematic reviews. BMJ Open 2016;6(9):e012555.

\section{CHARACTERISTICS OF STUDIES}

Characteristics of included studies [ordered by study ID]

\section{Zhan 2003}

Zhan C, Miller MR. Excess length of stay, charges, and mortality attributable to medical injuries during hospitalization. JAMA 2003;290(14):1868-74

\section{References to other published versions of this review Kahn 2010}

Kahn SR, Morrison DR, Emed J, Tagalakis V, Shrier I. Interventions for implementation of thromboprophylaxis in hospitalized medical and surgical patients at risk for venous thromboembolism. Cochrane Database of Systematic Reviews 2010, Issue 1. [DOI: 10.1002/14651858.CD008201]

\section{Kahn 2013}

Kahn SR, Morrison DR, Cohen JM, Emed J, Tagalakis V, Roussin A, et al. Interventions for implementation of thromboprophylaxis in hospitalized medical and surgical patients at risk for venous thromboembolism. Cochrane Database of Systematic Reviews 2013, Issue 7. [DOI: 10.1002/14651858.CD008201.pub2]

\section{Anderson 1994}

\begin{tabular}{|c|c|}
\hline Methods & $\begin{array}{l}\text { - } \text { RCT } \\
\text { - } \text { Cluster } \\
\text { - Unit of randomization: groups of } 5 \text { hospitals } \\
\text { - Unit of analysis: patient } \\
\text { - Study period: } 1985 \text { to } 1989\end{array}$ \\
\hline Participants & $\begin{array}{l}\text { - USA } \\
\text { - } 15 \text { centers } \\
\text { - Departments not reported } \\
\text { - Medical, surgical, and trauma/ER patients } \\
\text { - Inclusion criteria: randomly selected patients thought to be at increased risk for VTE: } \geq 50 \text {, hospitalized } \\
\text { at least } 6 \text { days, primary discharge diagnosis associated with VTE or any age hospitalized at least } 6 \text { days } \\
\text { for major trauma, or hip or leg fracture } \\
\text { - Exclusion criteria: specialists unlikely to be involved in the decision to provide prophylaxis for ve- } \\
\text { nous thromboembolism were excluded, e.g. radiologists, pathologists, anesthesiologists, pediatri- } \\
\text { cians, and oral surgeons } \\
\text { - N included: phase } 1 \text { - pre intervention phase ( } 466 \text { (group 1), } 679 \text { (group 2), } 702 \text { (group 3)); phase } 2 \text { - } \\
\text { post intervention phase ( } 342 \text { (group } 1 \text { ), } 513 \text { (group 2), } 456 \text { (group 3)) } \\
\text { - Age (mean): } 70 \text { (group } 1 \text { ), } 70 \text { (group 2), } 68 \text { (group 3) } \\
\text { - Male \%: } 47 \text { (group 1), } 48 \text { (group 2), } 49 \text { (group 3) } \\
\text { - Control group: observed for } 1 \text { year and } 6 \text { months before the intervention, with a 1-year and 6-month } \\
\text { gap inbetween; same types of patients (department, hospital) as the intervention group }\end{array}$ \\
\hline Interventions & $\begin{array}{l}\text { - Aimed at doctors } \\
\text { - Use of two interventions: educational and multifaceted intervention } \\
\text { - Educational component: exam component + hospital-administered course } \\
\text { - Distribution of guidelines } \\
\text { - Audit and feedback }\end{array}$ \\
\hline
\end{tabular}


- Multiple intervention study: 1 control group (group 1), 1 continuing medical education group (CME; group 2), 1 CME + quality assurance group (QA; group 3)

- Comparator: no intervention vs. CME only vs. CME + QA

\begin{tabular}{ll}
\hline Outcomes & Appropriateness of prophylaxis not assessed \\
- & Received prophylaxis: $51 \%$ (group 1), 49\% (group 2), 55\% (group 3) \\
- PE/DVT occurrence not assessed
\end{tabular}

Notes

Funding sources: Quote: "This research was supported by grant HL 35862 from the National Heart, Lung, and Blood Institute."

\section{Risk of bias}

Bias Authors' judgement Support for judgement

Random sequence genera- Unclear risk tion (selection bias)
Quote: "Hospitals were assigned to one of three groups, each consisting of five hospitals. Group assignments were made by means of lists of physicians' admitting privileges at each hospital so as to minimize the probability that individual physicians who practice in multiple hospitals would practice in more than one intervention group." (Page 670, column 1, paragraph 2)

Not adequately described.

Allocation concealment Unclear risk There was no mention of allocation concealment.
(selection bias)

\begin{tabular}{|c|c|c|}
\hline $\begin{array}{l}\text { Blinding of participants } \\
\text { and personnel (perfor- } \\
\text { mance bias) }\end{array}$ & Unclear risk & $\begin{array}{l}\text { Quote: "Although some physicians may have become aware that this study } \\
\text { was being undertaken, we made no general announcements to the medical } \\
\text { staff of our presence or purpose." (Page } 670 \text {, column 1, paragraph } 3 \text { ) }\end{array}$ \\
\hline
\end{tabular}

There was no mention of blinding of participants and personnel.

\begin{tabular}{lll}
\hline Blinding of outcome as- & Unclear risk & There was no mention of blinding of outcome assessment. \\
sessment (detection bias)
\end{tabular}

sessment (detection bias)

All outcomes
There was no mention of incomplete outcome data.

Incomplete outcome data Unclear risk

(attrition bias)

All outcomes

Selective reporting (re- Unclear risk No clinical or safety outcomes reported.
porting bias)

Other bias High risk

\begin{abstract}
Data were presented for each of the groups to which participants were randomized, and reports were free of suggestion of selective reporting of comparisons of intervention arms.

Unclear risk for recruitment bias: Quote: "Group assignments were made by means of lists of physicians' admitting privileges at each hospital so as to minimize the probability that individual physicians who practiced in multiple hospitals would practice in more than one intervention group." (Page 670, column 1, paragraph 2)

High risk for baseline imbalances: major imbalances in Table 2/3. Quote: "The sociodemographic and hospital-related characteristics of the study patients were similar both before and after the educational interventions as well as among patients in the three intervention groups (Table 2). Risk factors for venous thromboembolism in this selected population, shown in Table 3, were generally similar among study groups." (Page 672, column 1, paragraph 2)
\end{abstract}


High risk for incorrect analysis: possible clustering of participants within the same hospitals was not taken into account in the analysis. Also, there was no mention of sample size calculation. Quote: "Differences in the use of adequate methods of prophylaxis in hospitals with and without interventions were analysed by means of logistic regression modelling with adjustment for relevant risk factors, selected patient characteristics, and the dual sampling rates employed in large and small hospitals." (Page 671, column 2, paragraph 5)

Low risk of bias for other items listed as potential sources of bias.

\section{Cavalcanti 2016}

\begin{tabular}{|c|c|}
\hline Methods & $\begin{array}{l}\text { - } \mathrm{RCT} \\
\text { - Cluster } \\
\text { - Unit of randomization: intensive care units (ICU) } \\
\text { - Unit of analysis: patients/patient-days } \\
\text { - Study period: } 2013 \text { to } 2014\end{array}$ \\
\hline Participants & $\begin{array}{l}\text { - } \text { Brazil } \\
\text { - Number of centers not reported } \\
\text { - } 118 \text { intensive care units } \\
\text { - } \text { Inclusion criteria: patients from adult ICUs from all Brazilian regions } \\
\text { - Exclusion criteria: pediatric and cardiac ICUs, step-down units, ICUs that already used checklists, ICUs } \\
\text { whose leadership did not or would not implement multidisciplinary daily rounds, patients with a high } \\
\text { probability of an anticipated early death (between the } 48 \text { th and } 72 \text { nd hours of ICU stay), patients with } \\
\text { a suspected or confirmed diagnosis of brain death or those receiving exclusive palliative care } \\
\text { - N included: } 6877 \text { (phase } 1 \text {, observational study), } 6761 \text { (phase 2, cluster RCT): } 3434 \text { (control), } 3327 \text { (in- } \\
\text { tervention) } \\
\text { - Age (mean (SD)): control } 60 \text { ( } 18.8 \text { ), intervention } 59.1 \text { (19.2) } \\
\text { - Male \%: } 53.6 \text { (control), } 54.8 \text { (intervention) } \\
\text { - Control group: concurrent with intervention group; observed for months; same type of patients (ICU/ } \\
\text { hospital) as intervention group }\end{array}$ \\
\hline Interventions & $\begin{array}{l}\text { - Aimed at team } \\
\text { - Use of multifaceted intervention } \\
\text { - Daily multidisciplinary rounds to include the use of a checklist and discussion of goals of care, re- } \\
\text { minder via SMS messages one to three times a week to ensure follow-through with checklist adher- } \\
\text { ence and goals of care that targeted a broad spectrum of care processes including thromboprophy- } \\
\text { laxis } \\
\text { - The checklist was developed based on the clinical practice guideline development cycle } \\
\text { - Comparator: routine care and no pre-intervention training vs. intervention }\end{array}$ \\
\hline
\end{tabular}

Outcomes

- Appropriateness of prophylaxis not assessed

- Received prophylaxis: $75 \%$ (control), $74.8 \%$ (intervention)

- All-cause mortality (within 60 days): $34.8 \%$ (control), 32.9\% (intervention)

- PE/DVT occurrence not assessed

Notes

Additional data were obtained from original investigators.

Funding sources: Quote: "This study was conducted as part of the Program to Support Institutional Development of Universal Health System (PROADI) from the Brazilian Ministry of Health. It was funded 
mainly by the Brazilian Health Surveillance Agency (ANVISA), PROADI, and Brazilian Development Bank

(BNDES). D'Or Institute for Research and Education also contributed with additional funding."

\section{Risk of bias}

Bias Authors' judgement Support for judgement

Random sequence genera- Low risk tion (selection bias)

Quote: "A statistician from Research Institute HCor generated the randomization list with random permuted blocks of 4 units using an appropriate statistical package. Stratification was performed according to the median in-hospital mortality determined in the observational phase." (Page 1481, column 2, paragraph 3)

Quote: "To avoid selection bias, written consent was obtained at the cluster level from the director of each institution. The funders had no role in the analysis or publication decision. Nevertheless, the funders and ICU leaders requested an intervention period not longer than 6 months so that ICUs randomized to the control group would also receive the intervention in a timely fashion." (Page 1481, column 1, paragraph 4)

Allocation concealment Low risk
(selection bias)

Quote: "To ensure allocation concealment, the statistician who prepared the list received only the identification code of the unit and was not aware of the identity of the ICU. The allocation list was then sent to the research manager, who informed the ICUs about their randomization status in January 2014." (Page 1481, column 2, paragraph 3)

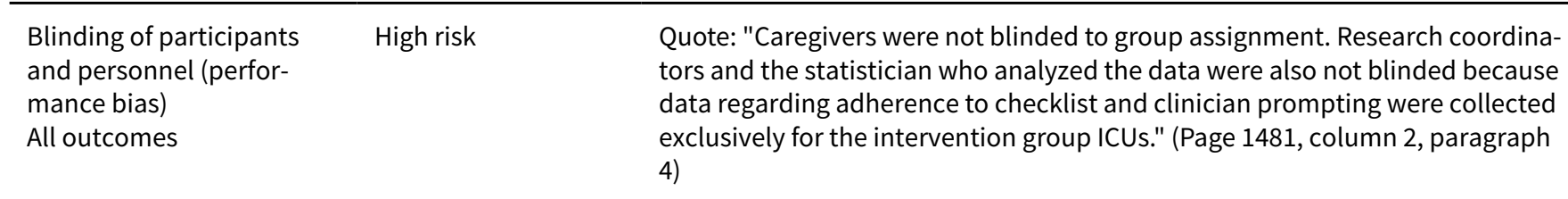

Blinding of outcome as- High risk
sessment (detection bias) All outcomes

Quote: "Caregivers were not blinded to group assignment. Research coordinators and the statistician who analyzed the data were also not blinded because data regarding adherence to checklist and clinician prompting were collected exclusively for the intervention group ICUs." (Page 1481, column 2, paragraph 4)

Incomplete outcome data Unclear risk
(attrition bias)
All outcomes

Quote: "The primary outcome was available for 6877 patients (100\%) in the observational phase and 6758 patients (99.9\%) in the randomized phase, although all patients were included in the primary outcome analyses. Responses to the SAQ were obtained from $6656(85.3 \%)$ staff members in the observational phase and $6375(78.8 \%)$ in the randomized phase, with response rates $75 \%$ or greater for $99.2 \%$ and $92.4 \%$ of ICUs, respectively, in both phases." (Page 1484 , column 2, paragraph 1)

\begin{tabular}{|c|c|c|}
\hline $\begin{array}{l}\text { Selective reporting (re- } \\
\text { porting bias) }\end{array}$ & Unclear risk & $\begin{array}{l}\text { They did not assess all clinical and safety outcomes (occurrence of VTE and } \\
\text { bleeding). }\end{array}$ \\
\hline Other bias & Low risk & $\begin{array}{l}\text { Low risk for baseline imbalances: Quote: "The units of randomization were the } \\
\text { ICUs. A statistician from Research Institute HCor generated the randomiza- } \\
\text { tion list with random permuted blocks of } 4 \text { units using an appropriate statis- } \\
\text { tical package. Stratification was performed according to the median in-hospi- } \\
\text { tal mortality determined in the observational phase. To ensure allocation con- } \\
\text { cealment, the statistician who prepared the list received only the identifica- } \\
\text { tion code of the unit and was not aware of the identity of the ICU. The alloca- } \\
\text { tion list was then sent to the research manager, who informed the ICUs about } \\
\text { their randomization status in January 2014." (Page 1481, column 2, paragraph } \\
\text { 3). Characteristics of the ICUs were mostly similar between groups. }\end{array}$ \\
\hline
\end{tabular}

Interventions for implementation of thromboprophylaxis in hospitalized patients at risk for venous thromboembolism (Review) Copyright $\odot 2018$ The Cochrane Collaboration. Published by John Wiley \& Sons, Ltd. 
Low risk for incorrect analysis: clustering was taken into account in analysis and in sample size calculation. Quote: "According to the sample size calculation, with 102 ICUs and an average of 50 patients per unit, the study had $90 \%$ power with a type I error rate of $5 \%$ to detect an absolute reduction in in-hospital mortality of $6 \%$ (from $30 \%$ in the control group to $24 \%$ in the intervention group), considering a coefficient of variation K of 0.25 ." (Page 1483, column 1, paragraph 4). Quote: "Because ICUs were randomized rather than patients and we measured outcomes at the patient level, the analyses were adjusted for clustering of the data." (Page 1483, column 1, paragraph 5)

Low risk of bias for other items listed as potential sources of bias.

\section{Chapman 2011}

\begin{tabular}{ll}
\hline Methods & RCT \\
& - Non-cluster \\
- Unit of randomization: participants \\
- Study period not reported
\end{tabular}

\section{Participants}

- Australia

- Number of centers not reported

- Depatments were not clearly reported (medical admissions)

- Medical patients

- Inclusion criteria: not clearly reported. Daily medical admissions were screened in order and consent was sought until work load saturation was reached

- Exclusion criteria: participants were excluded if they refused consent; if they were unable to consent and if their next-of-kin were unavailable.

- $\quad \mathrm{N}$ included: 359 participants

- N analyzed (estimation): 172 (control), 182 (intervention)

- Age: not reported

- Male \%: not reported

- Control group: not described. Not known if the control group was concurrent with the intervention group; if participants were observed for the same number of months; or if they included the same type of participants as intervention group

- Did not report who the intervention was aimed at

- Use of reminders: human alerts

- A trained nurse assessed participants and if necessary requested prophylaxis or ceased prophylaxis to reflect the guidelines. The type of guidelines (local, consensus, international) was not stated

- Comparator: standard care vs. intervention

Outcomes

- Appropriateness of prophylaxis assessed but not described (prophylaxis consistent with guidelines). Modality of prophylaxis and types of guidelines not reported

- Received appropriate prophylaxis: 66\% (control), 81\% (intervention)

- Symptomatic VTE (timing of assessment $=3$ months): control $=5(2.9 \%, 95 \% \mathrm{Cl}, 1.05$ to 6.73$)$ and intervention $=1(0.55 \%, 95 \% \mathrm{Cl} 0.0$ to 3.38$)$

- Method of VTE diagnosis not reported

Notes

This study was a conference abstract and was not published in a full manuscript. Original investigators were contacted, but they were unable to provide the requested data. However, we were able to extrapolate missing data. 
Funding sources: Quote: "This investigator initiated trial was supported with a research and education grant awarded by Sanofi-Aventis Australia Pty Ltd."

\section{Risk of bias}

\begin{tabular}{lll}
\hline Bias & Authors' judgement & Support for judgement \\
\hline $\begin{array}{ll}\text { Random sequence genera- } \\
\text { tion (selection bias) }\end{array}$ & Unclear risk & $\begin{array}{l}\text { Quote: "Subjects were randomised to either standard care or intervention: a } \\
\text { trained nurse for VTE and bleeding risk assessed patients and if necessary re- } \\
\end{array}$ \\
& $\begin{array}{l}\text { quested prophylaxis or ceased prophylaxis to reflect the guidelines." (Abstract } \\
\text { - Paragraph 2) }\end{array}$
\end{tabular}

Allocation concealment Unclear risk There was no mention of allocation concealment.

(selection bias)

Blinding of participants Unclear risk There was no mention of blinding of participants and personnel.
and personnel (perfor-

mance bias)

All outcomes

\begin{tabular}{|c|c|c|}
\hline $\begin{array}{l}\text { Blinding of outcome as- } \\
\text { sessment (detection bias) } \\
\text { All outcomes }\end{array}$ & Unclear risk & There was no mention of blinding of outcome assessment. \\
\hline $\begin{array}{l}\text { Incomplete outcome data } \\
\text { (attrition bias) } \\
\text { All outcomes }\end{array}$ & Unclear risk & There was no mention of incomplete outcome data. \\
\hline $\begin{array}{l}\text { Selective reporting (re- } \\
\text { porting bias) }\end{array}$ & Unclear risk & No safety outcomes reported \\
\hline Other bias & Unclear risk & $\begin{array}{l}\text { The study has not been published in a full manuscript form yet; some informa- } \\
\text { tion was missing. The occurrence of symptomatic VTE was assessed, but the } \\
\text { diagnostic modality was not stated. The objective was to assess the feasibili- } \\
\text { ty of a RCT to validate the guidelines, and probably to increase conformation } \\
\text { with current VTE prophylaxis guidelines, but the actual modality (pharmaco- } \\
\text { logic vs. mechanical) of prophylaxis was not stated. The sample size and analy- } \\
\text { sis were not described. }\end{array}$ \\
\hline
\end{tabular}

Dexter 2001

\begin{tabular}{ll}
\hline Methods & RCT \\
- Cluster \\
- Unit of randomization: medical teams \\
- Unit of analysis: patient \\
- Study period: 1997 to 1998 \\
\hline Participants \\
- USA \\
- 1 center \\
- Mepartment: general medical patients \\
- Inclusion criteria: all patients admitted to the general medicine service of Wishard Memorial Hospital \\
- Exclusion criteria: physicians who were in both the intervention group and the control group during \\
\end{tabular}


Dexter 2001 (Continued)

- N included: 5070 hospitalizations (control), 4995 hospitalizations (intervention): 664 participants (intervention), 662 participants (control)

- Age (mean): 53.2 (all). No description per group

- Male \%: 50 (all). No description per group

- Control group: concurrent with intervention group, observed for 1 year and 6 months; same types of participants (department/hospital) as intervention group; pre-existing intervention: alerts after admission

- Aimed at doctors and medical students
- Use of reminders: electronic alert
- Reminder generated when patient's electronic medical recorder included at least 1 indication for one
of the selective preventative therapies, no evidence of contraindications to therapies, and no active
orders for the therapy. Physicians could accept or reject reminders to one or two by stroke on the
computer
- Comparator: no intervention (computer does not display the reminder) vs. intervention

- Appropriateness of prophylaxis not defined but assessed (received prophylaxis for eligible partici-
pants), reminders recommended therapy and were generated only when the patient's electronic med-
ical record included: 1) at least one indication for one of the selected preventive therapies, 2) no evi-
dent contraindication to the therapy, and 3) no active orders for the therapy).
- Received appropriate prophylaxis: $17.5 \%$ (control), $34.3 \%$ (intervention)
- DVT/PE occurrence not assessed

Notes Additional data were obtained from original investigators.

Funding sources: Quote: "Supported by a grant (HS07719) from the Agency for Healthcare Research and Quality and a grant (N01-LM-6-3546) from the National Library of Medicine."

\section{Risk of bias}

\begin{tabular}{lll}
\hline Bias & Authors' judgement & Support for judgement \\
\hline $\begin{array}{ll}\text { Random sequence genera- } \\
\text { tion (selection bias) }\end{array}$ & Low risk & $\begin{array}{l}\text { Quote: "Using a blinded system of coin randomization, one of the investiga- } \\
\text { tors randomly designated four of the general medicine teams as intervention } \\
\text { teams and four as control teams." (Page 965, column 2, paragraph 4) } \\
\end{array}$ \\
& $\begin{array}{l}\text { The sequence was as required } \\
\end{array}$
\end{tabular}

\begin{tabular}{|c|c|c|}
\hline $\begin{array}{l}\text { Allocation concealment } \\
\text { (selection bias) }\end{array}$ & Unclear risk & $\begin{array}{l}\text { Quote: "Using a blinded system of coin randomization, one of the investiga- } \\
\text { tors randomly designated four of the general medicine teams as intervention } \\
\text { teams and four as control teams." (Page } 965 \text {, column } 2 \text {, paragraph } 4 \text { ) }\end{array}$ \\
\hline
\end{tabular}

\begin{tabular}{|c|c|c|}
\hline $\begin{array}{l}\text { Blinding of participants } \\
\text { and personnel (perfor- } \\
\text { mance bias) } \\
\text { All outcomes }\end{array}$ & High risk & $\begin{array}{l}\text { Quote: "All physicians, medical students, and patients associated with a team } \\
\text { were assigned that team's intervention status. The same investigator also } \\
\text { randomly assigned physicians to teams insofar as practical constraints al- } \\
\text { lowed (e.g., avoiding assignments that might lead to two consecutive nights of } \\
\text { overnight on-call duty). When physicians returned for multiple rotations dur- } \\
\text { ing the study period, we attempted to maintain their original intervention sta- } \\
\text { tus by assigning them to teams with the same status; most medical students } \\
\text { had only one rotation at the hospital during the study period." (Page 966, col- } \\
\text { umn 1, paragraph 1) }\end{array}$ \\
\hline
\end{tabular}

\begin{tabular}{|c|c|c|}
\hline $\begin{array}{l}\text { Blinding of outcome as- } \\
\text { sessment (detection bias) } \\
\text { All outcomes }\end{array}$ & Unclear risk & $\begin{array}{l}\text { No mention of blinding outcome assessors. However, primary outcomes were } \\
\text { rates at which the various therapies were ordered making bias unlikely. Quote: } \\
\text { "The primary outcomes of interest were the rates at which the various pre- } \\
\text { ventative therapies were ordered. These rates were obtained from routinely } \\
\text { stored data." (Page 966, column 1, paragraph 2) }\end{array}$ \\
\hline
\end{tabular}


Dexter 2001 (Continued)

$\begin{aligned} & \text { Incomplete outcome data Unclear risk } \\ & \text { (attrition bias) }\end{aligned} \quad \begin{aligned} & \text { There was no mention of the completeness of follow-up or of missing outcome } \\ & \text { data. }\end{aligned}$
(attrition bias) data.

All outcomes

Selective reporting (re- Unclear risk No clinical or safety outcomes reported
porting bias)

Other bias Unclear risk

\begin{abstract}
The physicians and students who rotated from intervention to control or vice versa might have diluted the effect of the intervention: Quote: "The organization of the teams of the general-medicine ward has been described previously; at present there are eight independent teams whose staff members (physicians and students) rotate approximately monthly." (Page 965, column 2, paragraph 3)
\end{abstract}

Unclear risk for recruitment bias: Quote: "All physicians, medical students, and patients associated with a team were assigned that team's intervention status. The same investigator also randomly assigned physicians to teams insofar as practical constraints allowed (e.g. avoiding assignments that might lead to two consecutive nights of overnight on-call duty). When physicians returned for multiple rotations during the study period, we attempted to maintain their original intervention status by assigning them to teams with the same status; most medical students had only one rotation at the hospital during the study period." (Page 966, column 1, paragraph 1). Quote: "During the 18 months of the study, a total of 202 physicians rotated an average of 2.1 times onto the inpatient service: 96 of these physicians ( 47.5 percent) were assigned only to intervention teams, 78 (38.6 percent) were assigned only to control teams, and 28 (13.9 percent) were assigned at different times to intervention teams and control teams." (Page 967, column 1, paragraph 2). While there was some risk for recruitment bias there was an attempt to mitigate this issue. Due to the nature of the intervention, it was unlikely that physicians were aware of an ongoing study. The risk of bias was unclear.

Unclear risk for baseline imbalances: There was no descriptive comparison of patient characteristics between clusters. Clusters were Internal Medicine teams at the same hospital, so likely the baseline characteristics are similar. Patients were admitted to the general medicine wards with the use of a system that distributed admissions equally among the teams, solely on the basis of the order in which patients required hospitalization. Patients automatically assumed the intervention status of the team to which they were assigned on admission and retained that status for the duration of their hospitalization. Previous studies involving inpatients have shown no material differences in clinical status among patients assigned to different teams

Unclear risk for incorrect analysis: not clearly stated that the clustering was taken into account in analysis. Quote: "The unit of analysis for all models was the individual hospital admission. We used a generalized-estimating equation method for all estimates of effect. We used a compound symmetry structure, which assumes that patients are independent of each other and that hospitalizations for a particular patient have a fixed correlation that does not vary over time." (Page 966, column 2, paragraph 4)

Low risk of bias for other items listed as potential sources of bias.

\begin{tabular}{ll}
\hline Methods & RCT \\
& $\cdot$ Cluster \\
& $\cdot$ Unit of randomization: internal medical ward
\end{tabular}


Fontaine 2006 (Continued)

- Unit of analysis: patients (by physicians)

- Study period not reported

\begin{tabular}{|c|c|}
\hline Participants & $\begin{array}{l}\text { - France } \\
\text { - } 30 \text { centers } \\
\text { - } \text { Departments: internal medicine } \\
\text { - Medical patients } \\
\text { - Inclusion criteria: all inpatients on internal medical ward } \\
\text { - } \text { Exclusion criteria: admitted or discharged on the day of survey and those receiving curative anti-co- } \\
\text { agulant treatment } \\
\text { - } \mathrm{N} \text { screened: } 939 \text { (baseline survey); } 502 \text { (group 1), } 437 \text { (group 2); } 863 \text { (postintervention survey): } 445 \\
\text { (group 3), } 418 \text { (group 4) } \\
\text { - N included: } 397 \text { (group 1), } 353 \text { (group 2), } 359 \text { (group 3), } 360 \text { (group 4) } \\
\text { - Age (median): } 75 \text { (group 1), } 71 \text { (group 2), } 74 \text { (group 3), } 70 \text { (group 4) } \\
\text { - Male \%: } 51 \text { (group 1), } 49 \text { (group 2), } 52 \text { (group 3), } 51 \text { (group 4) } \\
\text { - Control group: controlled before-after study; control group concurrent with intervention group; ob- } \\
\text { served for } 1 \text { day; same types of participants as intervention group }\end{array}$ \\
\hline Interventions & $\begin{array}{l}\text { - Aimed at doctors } \\
\text { - Use of reminders: preprinted orders } \\
\text { - All physicians in intervention group were required to use specific anticoagulant prescription forms } \\
\text { featuring the recommended prescription criteria } \\
\text { - } 4 \text { groups: baseline control (group 1), baseline intervention (group 2), post-intervention control (group } \\
\text { 3), post-intervention intervention (group 4). } \\
\text { - In January, baseline survey was performed. Intervention was implemented over the next } 3 \text { months, } \\
\text { and the post-intervention survey was carried out in April. } \\
\text { - Comparator: no intervention (usual practices) vs. intervention; baseline vs. post-intervention }\end{array}$ \\
\hline Outcomes & $\begin{array}{l}\text { - Appropriateness of prophylaxis not defined (but described as 'under treatment' and 'over treatment') } \\
\text { - Received prophylaxis: } 38 \% \text { (group 1), } 40 \% \text { (group 2), 36\% (group 3), 32\% (group 4) } \\
\text { - PE/DVT occurrence not assessed }\end{array}$ \\
\hline
\end{tabular}

Notes

Funding sources: Quote: "This study was endorsed as a collective project by the Collegial Federation of Internal Medicine departments and supported by the Department of Evaluation of Assistance PubliqueHopitaux de Paris."

\section{Risk of bias}

Bias Authors' judgement Support for judgement

Random sequence genera- Unclear risk tion (selection bias)
Quote: "The study took place during one rotation period of residents, and included three parts: (i) in January, a 1-day baseline survey was performed in 30 Internal Medicine departments of Assistance Publique-Hôpitaux de Paris; (ii) over the following 3-month period Internal Medicine departments were randomized into two groups: all practitioners in wards allocated to the intervention group were required to systematically use specific anticoagulant prescription forms that featured the recommended prescription criteria, whilst doctors in the control group continued prescribing according to their usual practices and (iii) a 1-day postintervention survey was repeated in April." (page 370, column 2, paragraph 2)

Allocation concealment $\quad$ Unclear risk
(selection bias)


Fontaine 2006 (Continued)

Blinding of participants and personnel (perfor-

Unclear risk

There was no mention of blinding of participants and personnel. mance bias)

All outcomes

$\begin{array}{ll}\text { Blinding of outcome as- } & \text { Unclear risk }\end{array}$ There was no mention of blinding of outcome assessment.

All outcomes

Incomplete outcome data Unclear risk $\quad$ There was no mention of attrition or missing outcome data.
(attrition bias)

All outcomes

Selective reporting (re- Unclear risk No clinical or safety outcomes reported
porting bias)

\begin{tabular}{|c|c|c|}
\hline Other bias & Unclear risk & $\begin{array}{l}\text { Unclear risk for baseline imbalances: very limited analysis of baseline charac- } \\
\text { teristics in each cluster group. See Table } 1 .\end{array}$ \\
\hline
\end{tabular}

Unclear risk for incorrect analysis: Quote: "Data were analysed with Stata 8.0, using appropriate multilevel survey analysis procedures to take into account possible associations between prescription decisions for patients treated by the same practitioner." (page 371, column 1, paragraph 1). No description of the analysis procedures and mention of the sample size calculation.

Low risk of bias for other items listed as potential sources of bias.

\section{Garcia 2009}

\begin{tabular}{ll}
\hline Methods & Quasi-RCT \\
- & Cluster \\
& (the other two teams served as the control group) \\
- Unit of randomization: teams (internal medicine) \\
- Unit of analysis: participants \\
- Study period: 2006 \\
- USA \\
- 1 center \\
- Departments: general internal medicine service \\
- Medical patients \\
- Inclusion criteria: patients admitted to the general internal medicine teams, Monday to Friday, at risk \\
- for VTE (score greater than or equal to 4) \\
- Exclusion criteria: patients on anticoagulant a/c already \\
- N screened: 216 (control), 160 (intervention) \\
- Age (range, mean): control = 20 to 95 (58), intervention = 28 to 97 (61) \\
- Male \%: 46 (control), 57 (intervention) \\
- Control group: concurrent with intervention group; observed for 4 months; same types of participants \\
(department/hospital) as intervention group
\end{tabular}

Interventions

- Aimed at doctors

- Use of reminders: human alerts 
Garcia 2009 (Continued)

- Pharmacist used history and physical exam available to determine VTE risk score. Pharmacist determined if at-risk patient had been ordered VTE prophylaxis. Pharmacist notified admitting physician

- Comparator: no intervention (usual care) vs. intervention

Outcomes

- Appropriateness of prophylaxis assessed (If one of the following strategies was initiated within 36 hours of hospital admission: $5000 \mathrm{U}$ heparin twice a day, enoxaparin $40 \mathrm{mg} / \mathrm{d}$, fondaparinux $2.5 \mathrm{mg}$ or SCDs)

- Received appropriate prophylaxis: $61 \%$ (control), $73 \%$ (intervention)

- PE/DVT occurrence not assessed

Notes

This study was classified as a quasi-RCT for the following reasons: 1) method of sequence generation was not stated; and 2) it might be difficult to randomly assigned a small number of participants (4 teams) into 2 groups.

Funding sources: no mention of funding source

\section{Risk of bias}

\begin{tabular}{lll}
\hline Bias & Authors' judgement & Support for judgement \\
\hline $\begin{array}{l}\text { Random sequence genera- } \\
\text { tion (selection bias) }\end{array}$ & Unclear risk & $\begin{array}{l}\text { Quote: "Two of the teams were randomly assigned to be in the intervention } \\
\text { group (the other two teams served as the control group) for the duration of the } \\
\text { study." (Page 542, column 1, paragraph 3) }\end{array}$ \\
\hline
\end{tabular}

Allocation concealment $\quad$ Unclear risk
(selection bias)

\begin{tabular}{|c|c|c|}
\hline $\begin{array}{l}\text { Blinding of participants } \\
\text { and personnel (perfor- } \\
\text { mance bias) } \\
\text { All outcomes }\end{array}$ & High risk & $\begin{array}{l}\text { Quote: "Once an at-risk patient was identified, the pharmacist determined if } \\
\text { VTE prophylaxis had been ordered. For each such patient, the pharmacist noti- } \\
\text { fied the admitting physician on the team about the patient's VTE risk and read } \\
\text { a standardized script informing the doctor of the patients' VTE risk, but no spe- } \\
\text { cific therapy was recommended." (Page 542, column 2, paragraph 1) }\end{array}$ \\
\hline
\end{tabular}

Quote: "For the patients admitted to the two teams designated as the control groups, a record of names and medical record numbers was collected by the pharmacists (using the same method as described above), but no attempt was made to alter the usual care received by these patients." (Page 542, column 2, paragraph 2)

There could not have been blinding of all participants and personnel because live pharmacists spoke to the physicians.

\begin{tabular}{|c|c|c|}
\hline $\begin{array}{l}\text { Blinding of outcome as- } \\
\text { sessment (detection bias) } \\
\text { All outcomes }\end{array}$ & Unclear risk & There was no mention of blinding of outcome assessment. \\
\hline $\begin{array}{l}\text { Incomplete outcome data } \\
\text { (attrition bias) } \\
\text { All outcomes }\end{array}$ & Unclear risk & There was no mention of attrition or missing outcome data. \\
\hline $\begin{array}{l}\text { Selective reporting (re- } \\
\text { porting bias) }\end{array}$ & Unclear risk & No clinical or safety outcomes reported \\
\hline Other bias & High risk & $\begin{array}{l}\text { Unclear risk for baseline imbalances: Very limited analysis of baseline charac- } \\
\text { teristics and some differences between each cluster group. See Table } 1 . \\
\text { High risk for incorrect analysis: Quote: "We estimated that } 300 \text { patients would } \\
\text { be needed to have power of } 90 \% \text { (two-sided alpha of } 5 \% \text { ) to detect an increase } \\
\text { in appropriate VTE prophylaxis from } 40 \% \text { in the control group to } 60 \% \text { in the in- } \\
\text { tervention group." (Page } 542 \text {, column 2, paragraph 4) }\end{array}$ \\
\hline
\end{tabular}


Garcia 2009 (Continued)

Quote: "Our comparison between intervention and control groups was done by the t-test for continuous outcomes, and by the Fisher's exact test for binary/categorical variables." (Page 543, column 1, paragraph 1). Clustering was not taken into account in the analysis and in sample size calculation.

Low risk of bias for other items listed as potential sources of bias.

Hinchey 2010

$\begin{array}{ll}\text { Methods } & \text { Quasi-RCT } \\ \text { - Cluster } & \text { Randomization method: hospitals were randomized to either control or intervention group. The study } \\ & \text { was designed to be a group-randomized controlled trial but because of randomization difficulties it } \\ & \text { was a quasi-experimental study. } \\ \text { - Unit of randomization: site (hospital) } \\ \text { - Unit of analysis: site (hospital) } \\ \text { - Study period: } 2001 \text { to } 2004\end{array}$

\begin{tabular}{|c|c|}
\hline Participants & $\begin{array}{l}\text { - USA } \\
\text { - } 16 \text { centers (sites) } \\
\text { - Departments: neurology } \\
\text { - Inhospital stroke care patients } \\
\text { - Inclusion criteria: acute ischemic stroke patients, over } 18 \text { years old, seen by neurology, and not hospi- } \\
\text { tal-to-hospital transfers, patients transferred from the emergency room of another hospital and those } \\
\text { transferred from adult homes, nursing homes, rehab units, etc. } \\
\text { - Exclusion criteria: patients with a discharge diagnosis of transient ischemic attack (TIA) and those } \\
\text { - } \text { admitted to an acute care unit outside hospital and then transferred } \\
\text { - Age (mean): } 71 \text { (control), } 69 \text { (intervention) } \\
\text { - Male \%: } 49.4 \text { (control), } 50.7 \text { (intervention) } \\
\text { - Control group: concurrent with intervention group; observed for months; same type of sites as inter- } \\
\text { vention group }\end{array}$ \\
\hline Interventions & $\begin{array}{l}\text { - Aimed at doctors } \\
\text { - Use of multifaceted interventions } \\
\text { - Reminders (standard orders, pathways, protocols, standardized dysphagia screens, atrial fibrillation } \\
\text { reminder stickers), written information, face-to-face interview, audit and feedback } \\
\text { - Comparator: control group (audit, feedback, and benchmark information) vs. intervention group (au- } \\
\text { dit, feedback, and benchmark information plus a multifaceted intervention) }\end{array}$ \\
\hline Outcomes & $\begin{array}{l}\text { - Appropriateness of prophylaxis not assessed } \\
\text { - Received prophylaxis: raw data not available } \\
\text { - PE/DVT occurrence not assessed }\end{array}$ \\
\hline Notes & $\begin{array}{l}\text { Due to missing outcome raw data, this study was not include in our quantitative analysis. } \\
\text { Funding sources: Quote: "Supported by grant number National Institute of Health K23NS002163, the } \\
\text { American Academy of Neurology (AAN), the American Heart Association/American Stroke Association } \\
\text { (AHA/ASA), and an unrestricted educational grant from Boehringer Ingelheim Pharmaceuticals Inc, } \\
\text { Ridgefield, Connecticut. The content is solely the responsibility of the authors and does not represent } \\
\text { any official views of the NIH, AAN, AHA/ASA, or Boehringer Ingelheim." }\end{array}$ \\
\hline
\end{tabular}

\section{Risk of bias}

Interventions for implementation of thromboprophylaxis in hospitalized patients at risk for venous thromboembolism (Review) 
Hinchey 2010 (Continued)

\section{Bias Authors' judgement Support for judgement}

Random sequence genera- High risk tion (selection bias)
Quote: "This was designed to be a group-randomized controlled trial but because of randomization difficulties this is a quasi-experimental study. The site is the unit of intervention and analysis. To control for potential sources of bias such as differential maturation, selection, and contamination, hospitals were paired on baseline dysphagia measure adherence rates and the stage of their QI infrastructure and then randomized to either a control group that received audit, feedback, and benchmark information only or to an intervention group that received audit, feedback, and benchmark information plus a multifaceted intervention designed specifically for each site." (Page 131, column 2, paragraph 6)

Quote: "Of the 7 remaining site PIs in the intervention group, one had a conflict with the scheduled intervention meeting and was switched to the control group. Thus, the site from the control group with the most similar dysphagia adherence rate and QI infrastructure stage to this PI's site was switched to the experimental group. These changes, which occurred before the intervention phase of the study, resulted in group assignments not being randomized." (Page 132, column 2, paragraph 1)

Randomization was violated and there were some imbalances between groups.

Allocation concealment $\quad$ Unclear risk
(selection bias)

Blinding of participants Unclear risk There was no mention of blinding of outcome assessment.

and personnel (perfor-

mance bias)

All outcomes

Blinding of outcome as- Unclear risk There was no mention of blinding of outcome assessment.

sessment (detection bias)

All outcomes

\section{Incomplete outcome data High risk} (attrition bias)

All outcomes

\begin{abstract}
Quote: "Two hospitals led by one principal investigator (PI) and randomized to the intervention group dropped out of the project just after randomization because of financial constraints in ongoing data collection. They had collected a total of 150 cases or $6.5 \%$ of the total baseline data, which were excluded from the analysis." (Page 132, column 1, paragraph 3). Two hospitals out of 13 $(15.38 \%)$ dropped out of the study; this rate is high and there was no mention of other missing outcome data.
\end{abstract}

\begin{tabular}{|c|c|c|}
\hline $\begin{array}{l}\text { Selective reporting (re- } \\
\text { porting bias) }\end{array}$ & High risk & $\begin{array}{l}\text { Raw data were not available in primary and secondary analysis. All } 6 / 6 \text { inter- } \\
\text { vention sites reported outcomes in post hoc analysis, whereas only } 6 / 7 \text { control } \\
\text { sites did; and there was no explanation. }\end{array}$ \\
\hline
\end{tabular}

No clinical or safety outcomes reported

Other bias High risk

\begin{abstract}
The pairing for randomization based on dysphagia measure adherence might not necessarily be concordant with VTE prophylaxis: Quote: "We chose to pair hospitals by their dysphagia adherence because the measure had the most variation in adherence and room for improvement among the sites. This may be able to control for other, immeasurable hospital variations, which could affect the results. All control hospitals had access to the same data analyses given to the intervention group." (Page 132, column 1, paragraph 1)

Unclear risk for baseline imbalances: Quote: "Baseline differences (intervention $v$ control) for patient and hospital characteristics of the 13 sites are shown
\end{abstract}


in Table 2. There were no significant hospital characteristic differences between the intervention and control sites. For patient characteristic data, patients admitted to the control hospitals were on average older, and more likely to be white and discharged to a skilled nursing facility." (Page 132, column 1, paragraph 1)

High risk for loss of clusters: Quote: "Two hospitals led by one principal investigator $(\mathrm{PI})$ and randomized to the intervention group dropped out of the project just after randomization because of financial constraints in ongoing data collection." (Page 132, column 1, paragraph 3)

Low risk for incorrect analysis: clustering was taken into account in sample size calculation and in analysis: Quote: "To determine sample size based on a group-randomized design, we used the actual variation associated with patient counts per hospital, and the variability in the hospital adherence rates across hospitals, based on 5 months of data." (Page 132, column 2, paragraph 3)

Quote: "Because patients cluster within a hospital, we controlled for clustering within sites using the generalized linear mixed model incorporating correlations using the Glimmix procedure for each PM." (Page 133, column 1, paragraph 2)

Low risk of bias for other items listed as potential sources of bias

\section{Kucher 2005}

\begin{tabular}{ll}
\hline Methods & Quasi-RCT \\
- & Non-cluster \\
- Randomization method: patients with even medical number assigned to intervention group and pa- \\
tients with odd number assigned to control group \\
- Unit of randomization: individual participants \\
- Unit of analysis: participants \\
- Study period: 2000 to 2004 \\
- USA \\
Participants 1 center \\
- Departments: medical and surgical services excluding neurology, newborn, and neonatal ICU \\
- Medical, surgical and ER/trauma patients \\
- Inclusion criteria: 18 years or older, increased risk of VTE, from medical and surgical services \\
- Exclusion criteria: patients from department of neurology, newborn service, and neonatal ICU, patient \\
- receiving mechanical or pharmacologic prophylaxis \\
- Age (range, median): 18 to 97,62 (control), 18 to 99,63 (intervention) \\
- Male \%: 47.7 (control), 46.5 (intervention) \\
- Control group: concurrent with intervention; control group observed for 3 years and 5 months; same \\
types of participants (department/hospital) as intervention group; pre-existing intervention: distrib- \\
ution of guidelines
\end{tabular}

Interventions

- Aimed at doctors

- Use of reminders: electronic alert

- Computer program that identified patients at risk for VTE, if patient at risk then computer reviews orders to identify current medications and then alerts responsible physician to patient's risk of DVT. $M D$ required to acknowledge the alteration then withheld or ordered prophylaxis 
Kucher 2005 (Continued)

- Comparator: no intervention (no specific prompt was provided to use guidelines for the prevention of venous thromboembolism) vs. intervention (computer alert)

\begin{tabular}{|c|c|}
\hline Outcomes & $\begin{array}{l}\text { - } \text { Appropriateness of prophylaxis not assessed } \\
\text { - } \text { Received prophylaxis: } 14.5 \% \text { (control), } 33.5 \% \text { (intervention) } \\
\text { - Symptomatic VTE (timing of assessment (TOA) = } 90 \text { days): } 8.2 \% \text { (control), } 4.9 \% \text { (intervention) } \\
\text { - Symptomatic VTE (TOA = } 30 \text { days): } 5.7 \% \text { (control), } 3.3 \% \text { (intervention) } \\
\text { - Symptomatic DVT (TOA = } 90 \text { days): } 2.8 \% \text { (control), } 1.2 \% \text { (intervention) } \\
\text { - Symptomatic DVT (TOA = } 30 \text { days): } 2 \% \text { (control), } 0.8 \% \text { (intervention) } \\
\text { - Symptomatic proximal DVT (TOA = } 90 \text { days): } 1.8 \% \text { (control), } 0.8 \% \text { (intervention) } \\
\text { - Symptomatic proximal DVT (TOA = } 30 \text { days): } 1.4 \% \text { (control), } 0.6 \% \text { (intervention) } \\
\text { - Symptomatic distal DVT (TOA = } 90 \text { days): } 1 \% \text { (control), } 0.4 \% \text { (intervention) } \\
\text { - Symptomatic distal DVT (TOA = } 30 \text { days): } 0.6 \% \text { (control), } 0.2 \% \text { (intervention) } \\
\text { - Symptomatic PE (TOA = } 90 \text { days): } 2.8 \% \text { (control), } 1.1 \% \text { (intervention) } \\
\text { - Symptomatic PE (TOA = } 30 \text { days): } 1.7 \% \text { (control), } 0.8 \% \text { (intervention) } \\
\text { - Symptomatic upper limb DVT (TOA = } 90 \text { days): } 2.6 \% \text { (control), } 2.5 \% \text { (intervention) } \\
\text { - Symptomatic upper limb DVT (TOA = } 30 \text { days): } 2 \% \text { (control), } 1.6 \% \text { (intervention) } \\
\text { - Major bleeding (TOA = } 30 \text { days): } 1.5 \% \text { (control), } 1.5 \% \text { (intervention) } \\
\text { - Minor bleeding (TOA = } 30 \text { days): } 7 \% \text { (control), } 6.5 \% \text { (intervention) } \\
\text { - All-cause mortality (TOA = } 90 \text { days): } 22.3 \% \text { (control), } 22.5 \% \text { (intervention) } \\
\text { - All-cause mortality (TOA = } 30 \text { days): } 12.5 \% \text { (control), } 13.9 \% \text { (intervention) } \\
\text { - Method of VTE diagnosis: venography }\end{array}$ \\
\hline
\end{tabular}

Notes

This study was classified as a quasi-RCT because of the non-random component in the sequence generation method.

Funding sources: No clear mention of sources of funding but Dr Goldhaber reported having received clinical research support from Bristol-Myers Squibb and GlaxoSmithKline and having served as a consultant for Sanofi-Aventis, Pfizer, and AstraZeneca.

\section{Risk of bias}

\section{Bias Authors' judgement Support for judgement}

Random sequence genera- High risk tion (selection bias)
Quote: "Patients with even medical-record numbers were assigned to the intervention group, and those with odd medical-record numbers were assigned to the control group, without further stratification." (Page 971, column 1, paragraph 4)

Allocation concealment Unclear risk
(selection bias)

Quote: "Patients with even medical record numbers were assigned to the intervention group, and those with odd medical-record numbers were assigned to the control group, without further stratification." (Page 971, column 1, paragraph 4)

There was no mention of allocation concealment.

Quote: "Physicians responsible for patients in the control group were not aware that these patients were being followed for clinical events." (Page 971, column 2, paragraph 1)

Unclear, considering the fact that physicians for the most part were responsible for participants in both groups.

\begin{tabular}{|c|c|c|}
\hline $\begin{array}{l}\text { Blinding of participants } \\
\text { and personnel (perfor- } \\
\text { mance bias) }\end{array}$ & Low risk & $\begin{array}{l}\text { Quote: "We conducted a 90-day follow-up of all study patients, reviewing their } \\
\text { medical records in the patient database of Brigham and Women's Hospital. } \\
\text { Clinical events were identified with the use of information from the index hos- }\end{array}$ \\
\hline
\end{tabular}

Interventions for implementation of thromboprophylaxis in hospitalized patients at risk for venous thromboembolism (Review) 
Kucher 2005 (Continued)

summaries, physician's notes, blood-test results, vascular-laboratory reports, nuclear-medicine reports, and radiology reports. In addition, the Social Security Death Index was used to identify patients who died during the 90-day period." (Page 971, column 2, paragraph 3).

Follow-up data were collected from routine medical data.

Blinding of outcome as- $\quad$ Low risk
sessment (detection bias)

Quote: "Three investigators who were unaware of patients' group assignments All outcomes adjudicated all endpoints." (Page 972, column 1, paragraph 2)

There was no description of the blinding of outcome assessment.

Incomplete outcome data Low risk
(attrition bias)

Quote: "Overall, 2361 patients (94.2 percent) had follow-up data beyond the All outcomes index hospitalization, and 145 patients (5.8 percent) were lost to follow-up. Of the patients lost to follow-up, 78 were in the intervention group and 67 were in the control group ( $\mathrm{P}=0.39)$." (Page 971, column 2, paragraph 4)

The rate of incomplete outcome data was low.

\begin{tabular}{ll}
\hline $\begin{array}{l}\text { Selective reporting (re- } \\
\text { porting bias) }\end{array}$ & High risk \\
& $\begin{array}{l}\text { Quote: "Safety endpoints included total mortality at } 30 \text { days and the rate of } \\
\text { hemorrhagic events at } 90 \text { days." (Page } 972, \text { column 1, paragraph 1) }\end{array}$ \\
& $\begin{array}{l}\text { All clinical and safety outcomes were assessed, but the rate of hemorrhagic } \\
\text { events at } 90 \text { days was not presented as stated. }\end{array}$
\end{tabular}

Other bias Low risk There were no other sources of bias for items listed as potential other sources
of bias.

\section{Labarere 2007}

\begin{tabular}{|c|c|}
\hline Methods & $\begin{array}{l}\text { - } \text { RCT } \\
\text { - } \text { Cluster } \\
\text { - Unit of randomization: acute care departments } \\
\text { - Unit of analysis: participants } \\
\text { - Study period: } 2003 \text { to } 2004\end{array}$ \\
\hline Participants & $\begin{array}{l}\text { - France } \\
\text { - } 50 \text { centers } \\
\text { - Departments: post-acute care departments (medical) } \\
\text { - Medical patients } \\
\text { - Inclusion criteria: } 65 \text { years or older, present } \\
\text { - Exclusion criteria: positive diagnosis of DVT or PE at admission or if required, long-term anticoagula- } \\
\text { tion therapy with heparin or vitamin K antagonist for reasons other than VTE prophylaxis } \\
\text { - N screened: } 659 \text { (group 1), } 475 \text { (group 2) } \\
\text { - N included: } 497 \text { (group 1), } 315 \text { (group 2) } \\
\text { - Age (median): } 83 \text { (group 1), } 81 \text { (group 2) } \\
\text { - Male \%: } 31.6 \text { (control), } 38.4 \text { (intervention) } \\
\text { - Control group: concurrent with intervention, control group observed for } 1 \text { day; control groups were } \\
\text { from other hospitals; pre-existing interventions: development and distribution of guidelines, educa- } \\
\text { tion (aimed at physicians only) }\end{array}$ \\
\hline Interventions & $\begin{array}{l}\text { - Aimed at doctors and nurses } \\
\text { - Use of multifaceted intervention } \\
\text { - Educational component: } 1 \text { hour on-site educational session re: prophylaxis against VTE, pocket size } \\
\text { card of guidelines, posters, mailed data re: prophylaxis use in the department }\end{array}$ \\
\hline
\end{tabular}


Labarere 2007 (Continued)

- Development and distribution of guidelines

- Audit and feedback

- Comparator: group $1=$ intervention targeted at physicians only vs. group $2=$ intervention targeted at physicians and nurses

\begin{tabular}{ll}
\hline Outcomes & Appropriateness of prophylaxis not assessed \\
- Received prophylaxis: $48 \%$ (group 1), $55 \%$ (group 2) \\
- Asymptomatic DVT: $13 \%$ (group 1), 15\% (group 2) \\
- Asymptomatic proximal DVT: $4 \%$ (group 1), $4 \%$ (group 2) \\
- Asymptomatic distal DVT: $9 \%$ (group 1), 1\% (group 2) \\
- Thrombocytopaenia: $0.2 \%$ (group 1), 0\% (group 2) \\
- Method of VTE diagnosis: Doppler ultrasound \\
Timing of outcome assessment unclear \\
Funding sources: Quote: "This research was funded by a grant from the French Ministry of Health (Pro- \\
gramme Hospitalier de Recherche Clinique). Ultrasound systems were provided by Sonosite France. \\
The funding sources had no role in the study design; the collection, analysis or interpretation of the da- \\
ta; or the decision to submit the manuscript for publication."
\end{tabular}

\section{Risk of bias}

Bias Authors' judgement Support for judgement

Random sequence genera- Low risk tion (selection bias)

Quote: "Departments were randomly assigned to a guideline implementation intervention that targeted both physicians and nurses, or physicians only. Randomization was not stratified and was performed by our statistician using a computer generated sequence with a one-to-one allocation ratio in order to obtain comparison groups of equal sample sizes." (Page 302, column 2, paragraph 2)

\begin{tabular}{lll}
\hline $\begin{array}{l}\text { Allocation concealment } \\
\text { (selection bias) }\end{array}$ & Low risk & $\begin{array}{l}\text { Quote: "Allocation sequence was concealed until interventions were as- } \\
\text { signed." (Page 302, column 2, paragraph 2) }\end{array}$ \\
\hline $\begin{array}{l}\text { Blinding of participants } \\
\text { and personnel (perfor- } \\
\text { mance bias) }\end{array}$ & High risk & $\begin{array}{l}\text { Quote: "Given the nature of the intervention, physicians and nurses could not } \\
\text { be blinded to intervention." (Page 302, column 2, paragraph 4) }\end{array}$ \\
All outcomes &
\end{tabular}

Blinding of outcome as- Unclear risk Quote: "Trained physicians, who were members of the research team, collectsessment (detection bias) ed data on risk factors for deep vein thrombosis and prophylaxis using a stanAll outcomes dardized data abstract form." (Page 303, column 1, paragraph 2)

Quote: "Compression ultrasonography was performed by registered vascular medicine physicians who were unaware of both risk factors and thromboprophylaxis." (Page 303, column 1, paragraph 3)

There was no description of the blinding of outcome assessment other than compression ultrasonography.

$\begin{array}{ll}\begin{array}{l}\text { Incomplete outcome data } \\ \text { (attrition bias) }\end{array} & \text { High risk } \\ \text { All outcomes } & \begin{array}{l}\text { Quote: "Eleven patients were excluded from multivariable analysis because of } \\ \text { missing values." (Table 3, page 307) }\end{array} \\ & \begin{array}{l}\text { There was no description of the degree of completeness of the study and the } \\ \text { missing outcomes. }\end{array}\end{array}$


Labarere 2007 (Continued)

Selective reporting (reporting bias)

Low risk

No major selective reporting noticed: bleeding complications were reported. However, major and minor bleeding complications rates were not reported separately. Timing of outcome assessment was not clearly reported.

Other bias High risk

Unclear risk of recruitment bias: There do not seem to be any individuals recruited after randomization. However, it was possible that doctors worked in more than one unit and were in both the control and intervention populations. This was not addressed.

Low risk for baseline imbalances: Quote: "The patients allocated to the intervention targeted at physicians only tended to be older and were more likely to be female and to have chronic heart failure and inflammatory disorders, while relatively more patients allocated to the intervention targeted at both physicians and nurses had recent major surgery (Table 2)." . (Page 304, column 1, paragraph 1).These differences were adjusted for in the analysis.

High risk for loss of clusters: Quote: "Of 53 facilities approached, three declined to participate and 50 were randomized (Fig. 1). Of these, eight facilities dropped out of the study before intervention implementation and data collection, all citing nursing staff shortage. They were withdrawn from the study and the analysis was based on 24 facilities allocated to the intervention targeted at physicians only and 18 facilities allocated to the intervention targeted at both physicians and nurses (Table 1)." (Page 303, column 2, paragraph 4)

Low risk for incorrect analysis: clustering was taken into account in the sample size calculation and in analysis. Quote: "Based on the findings of a previous study, we assumed an intra cluster correlation of $r=0.20$, a mean number of 20 patients enrolled per department, and a $30 \%$ rate of physical prophylactic measures for the intervention that targeted physicians only. Under these assumptions, we anticipated a power of $80 \%$ to detect a difference of $20 \%$ in rates between the two groups with a $=0.05$ with 25 departments for each intervention group." (Page 303, column 2, paragraph 1)

Quote: "To account for patient clustering within departments, we used random intercept logistic regression with the two levels defined by patient and department". (Page 303, column 2, paragraph 3)

Low risk of bias for other items listed as potential sources of bias

\section{Overhage 1996}

\begin{tabular}{ll}
\hline Methods & RCT \\
- Cluster \\
- Unit of randomization: services \\
- Unit of analysis: participants \\
- Study period: 1992 to 1993 \\
\hline Participants & USA \\
- 1 center & Departments: medicine services \\
- Medical patients \\
- Inclusion criteria: patients admitted to general medicine ward during 6-month study period for whom \\
the computer generated at least 1 preventative care recommendation \\
- Exclusion criteria: patient was admitted before study began, patient was discharged after study end- \\
ed, patient had already been hospitalized once during the study, patient remained in the hospital less \\
than 18 hours \\
- N included: 801 (control), 821 (intervention)
\end{tabular}


- Age (mean (SD)): control = 51 (18), intervention = 51 (18)

- Male \%: 50 (control), 50 (intervention)

- Control group: concurrent with intervention group. Control group observed for 6 months; same types of participants (department/hospital) as intervention group

\begin{tabular}{ll}
\hline Interventions & Aimed at doctors \\
- Use of reminders: electronic alert \\
- Computer reminder program analyzed electronic medical records, reminders appeared on printed \\
daily reports and at work station when entering order, suggestions for orders provided \\
- Comparator: physicians who received the intervention (electronic alert) vs. controls (reminders were \\
not printed or displayed) \\
\hline - Appropriateness of prophylaxis not assessed \\
- Received prophylaxis: $35.7 \%$ (control), 43.3\% (intervention) \\
- PE/DVT occurrence not assessed
\end{tabular}

Notes

Funding sources: Quote: "This work was supported by grants HS 05626 and HS 07719-013 from the Agency for Health Care Policy and Research, Rockville, Md."

\section{Risk of bias}

Bias Authors' judgement Support for judgement

Random sequence genera- Unclear risk tion (selection bias)
Quote: "Before each 6-week rotation, the chief medical resident constructed teams of faculty, house staff and students bases on scheduling issues, clinical skills, and personalities. The study biostatistician then randomly assigned the teams to services. Patients were assigned intervention or control status based on the service to which they were admitted." (Page 1552, column 2, paragraph 2)

They did not provide details on how the 6 services were randomized.

Allocation concealment Unclear risk
(selection bias)

\begin{tabular}{|c|c|c|}
\hline $\begin{array}{l}\text { Blinding of participants } \\
\text { and personnel (perfor- } \\
\text { mance bias) } \\
\text { All outcomes }\end{array}$ & Unclear risk & $\begin{array}{l}\text { Quote: "In addition, to structuring call schedules to maintain 'blinding', the } \\
\text { computer would not print or display reminders for control physicians at any } \\
\text { time." (Page 1553, column 1, paragraph 5). There was no clear mention of } \\
\text { blinding of all participants and personnel. }\end{array}$ \\
\hline
\end{tabular}

\begin{tabular}{lll}
\hline $\begin{array}{l}\text { Blinding of outcome as- } \\
\text { sessment (detection bias) }\end{array}$ & High risk & $\begin{array}{l}\text { Quote: "The study biostatistician then randomly assigned the teams to ser- } \\
\text { vices. Patients were assigned intervention or control status based on the ser- } \\
\text { All outcomes }\end{array}$ \\
\hline
\end{tabular}
vice to which they were admitted." (Page 1552, column 2, paragraph 2)

Incomplete outcome data Unclear risk (attrition bias)

All outcomes

\begin{tabular}{ll}
\hline $\begin{array}{l}\text { Selective reporting (re- } \\
\text { porting bias) }\end{array}$ & Unclear risk \\
\hline Other bias & Unclear risk
\end{tabular}

\section{There was no mention of the completeness of follow-up or of incomplete out- come data.}

No clinical or safety outcomes reported

\begin{abstract}
Low risk for baseline imbalances: Quote: "No differences were seen between the intervention and control patients for demographic characteristics or the most common primary admitting diagnoses (Table 2)." (Page 1552, column 1, paragraph 4)

Unclear risk for incorrect analysis: clustering was taken into account in the analysis. But, there was no mention of sample size calculation. Quote: "Be-
\end{abstract}


cause compliance rates for different preventive care measures were correlated within each physician team, we analyzed the results for all preventive care measures combined and then for each measure separately using the Kleinman beta binomial model. For all comparisons, we defined a 2-tailed P value of .05 or less as significant." (Page 1553, column 2, paragraph 4)

Low risk of bias for other items listed as potential sources of bias

\begin{tabular}{|c|c|}
\hline Methods & $\begin{array}{l}\text { - } \mathrm{RCT} \\
\text { - Cluster } \\
\text { - Unit of randomization: hospitals } \\
\text { - Unit of analysis: participants } \\
\text { - Study period: } 2009\end{array}$ \\
\hline Participants & $\begin{array}{l}\text { - } \text { Canada } \\
\text { - } 6 \text { centers } \\
\text { - Departments: medical wards excluding cardiology, intensive care, and other medical subspecialties } \\
\text { - Medical patients } \\
\text { - Inclusion criteria: patients } \geq 18 \text { years of age and admitted to the service of general internal medicine } \\
\text { during the study period } \\
\text { - Exclusion criteria: patients who were receiving therapeutic anticoagulation or having a length of stay } \\
\text { less than } 24 \text { hours, patients admitted under cardiology, intensive care, or other medical subspecialties } \\
\text { - services } \\
\text { - N included: } 1457 \text { (control), } 1154 \text { (intervention) } \\
\text { - } \text { Age (range, median): } 18 \text { to } 102,72 \text { (control), } 18 \text { to } 100,72 \text { (intervention) } \\
\text { - Control group: concurrent with intervention group; observed for months; same type of partici- } \\
\text { pants/departments as intervention group }\end{array}$ \\
\hline Interventions & $\begin{array}{l}\text { - Aimed at medical wards } \\
\text { - Use of multifaceted intervention } \\
\text { - Education sessions, standardized risk assessment algorithm and physicians' orders, audit, and feed- } \\
\text { back } \\
\text { - Comparator: no intervention (no active or passive knowledge-translation strategies to improve } \\
\text { thromboprophylaxis) vs. intervention }\end{array}$ \\
\hline Outcomes & $\begin{array}{l}\text { - Appropriateness of prophylaxis assessed (If a physician's order for the correct type and dose of throm- } \\
\text { boprophylaxis prescribed within the first } 24 \text { hours of admission, taking into account the individual } \\
\text { patient's thrombosis and bleeding risks) } \\
\text { - Received prophylaxis: } 30 \% \text { (control), } 32 \% \text { (intervention) } \\
\text { - Received appropriate prophylaxis: } 20 \% \text { (control), } 23 \% \text { (intervention) } \\
\text { - PE/DVT occurrence not assessed }\end{array}$ \\
\hline
\end{tabular}

Funding sources: Quote: "This study was supported by a Collaborative Research Grant from the Canadian Medical Protective Association awarded to MP, as well as a Team Grant awarded to Dr. Jeffrey Weitz from the Canadian Institutes of Health Research (CIHR). JDD is leading a component of the Team Grant aimed at promoting knowledge translation of research related to venous thromboembolism (CTP79846). MP received funding from the Thrombosis Interest Group of Canada, and a McMaster University Department of Medicine Internal Career Award. FAS holds a Career Investigator Award from the Heart and Stroke Foundation. LT is a clinical trials mentor for the Canadian Institutes of Health Research. DJC holds a Research Chair with the Canadian Institutes of Health Research." 
Pai 2013 (Continued)

Risk of bias

\begin{tabular}{|c|c|c|}
\hline Bias & Authors' judgement & Support for judgement \\
\hline $\begin{array}{l}\text { Random sequence genera- } \\
\text { tion (selection bias) }\end{array}$ & Low risk & $\begin{array}{l}\text { Quote: "To ensure balance between the intervention and control groups, } \\
\text { we used a stratified randomization strategy, based on the Ontario Ministry } \\
\text { of Health and Longterm Care's Group A/B/C classification of hospitals. Each } \\
\text { group included one hospital from Group A (academic hospitals), one hospi- } \\
\text { tal from Group B (community hospitals having greater than } 100 \text { beds), and } \\
\text { one hospital from Group C (community hospitals having fewer than } 100 \text { beds). } \\
\text { Both Group A hospitals had a consultative thromboembolism service. None } \\
\text { of the hospitals used medical patient admission order sets. Randomization of } \\
\text { clusters, using a random number table, was concealed, with a } 1: 1 \text { allocation } \\
\text { sequence within strata. The allocation sequence was generated by the study } \\
\text { statistician." (Page 2, column 2, paragraph 3) }\end{array}$ \\
\hline
\end{tabular}

Allocation concealment Unclear risk Quote: "Hospitals were the unit of randomization, and each hospital repre(selection bias) sented a cluster." (Page 2, column 2, paragraph 3)

Quote: "Randomization of clusters, using a random number table, was concealed, with a 1:1 allocation sequence within strata. The allocation sequence was generated by the study statistician." (Page 2, column 2, paragraph 3)

There was no description of the concealment.

\begin{tabular}{|c|c|c|}
\hline $\begin{array}{l}\text { Blinding of participants } \\
\text { and personnel (perfor- } \\
\text { mance bias) }\end{array}$ & High risk & $\begin{array}{l}\text { Quote: "This study was not blinded." (Page 4, column 1, paragraph 2) } \\
\text { Results might have been influenced by the lack of blinding. }\end{array}$ \\
\hline
\end{tabular}

All outcomes

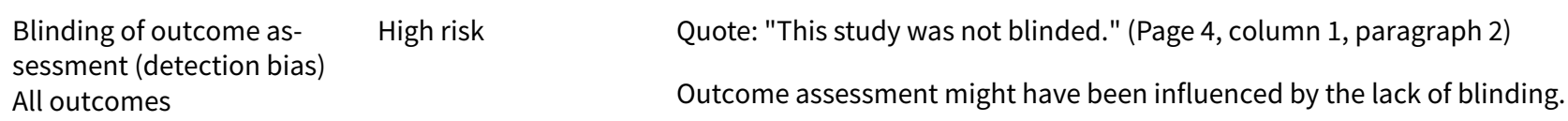

Incomplete outcome data Low risk No incomplete data
(attrition bias)
All outcomes

Selective reporting (re- Unclear risk No clinical or safety outcomes reported
porting bias)

\begin{tabular}{ll}
\hline Other bias & Low risk \\
& $\begin{array}{l}\text { only the first admission was included." (Page 3, column 2, paragraph 1) }\end{array}$
\end{tabular}

Low risk for baseline imbalances: Quote: "The intervention and control groups were comparable. However, some baseline differences were noted. Specifically, there was a higher prevalence of acute respiratory disease (16\% versus 9\%) and sepsis (13\% versus $8 \%$ ) in the intervention group, and a higher prevalence of cancer in the control group (12\% versus $8 \%)$. There was a higher prevalence of patients at risk for bleeding in the intervention group (10\% versus $6 \%$ ), as well as a higher prevalence of patients at risk for VTE without risk of bleeding (38\% versus 32\%). Clusters were comparable for baseline characteristics. Table 4 outlines the prophylaxis options prescribed in the intervention and control group hospitals." (Page 6, column 1, paragraph 1)

Quote: "The VTE risk profiles of patients at intervention and control hospitals were comparable (see Tables 2, 3)." (Page 6, column 1, paragraph 2)

Low risk for incorrect analysis: Quote: "As this was a pilot trial, the goal was to generate crude estimates of feasibility and data to calculate an intraclass cor- 
Pai 2013 (Continued)

relation coefficient (ICC) for use in future studies. Thus, the sample size in SENTRY was not adjusted for clustering." (Page 5, column 1, paragraph 1). Quote:

"A logistic model using the generalized estimating equation (GEE) method was used to account for this clustering effect, incorporating both within-hospital and between-hospital variations. An ICC and variance inflation factor (VIF) were also calculated to assess the impact of the clustering effect." (Page 5, column 2, paragraph 1). Clustering was taken into account in the analysis, but not in sample size calculation.

Low risk of bias for other items listed as potential sources of bias

\section{Piazza 2009}

\begin{tabular}{|c|c|}
\hline Methods & $\begin{array}{l}\text { - RCT } \\
\text { - Non-cluster } \\
\text { - Unit of randomization: participant } \\
\text { - Unit of analysis: participant } \\
\text { - Study period: } 2006 \text { to } 2007\end{array}$ \\
\hline Participants & $\begin{array}{l}\text { - USA } \\
\text { - } 25 \text { centers } \\
\text { - Departments: medical and surgical services excluding neurology, newborn, neonatal ICU, and reha- } \\
\text { bilitation units } \\
\text { - Medical and surgical patients } \\
\text { - Inclusion criteria: at least } 18 \text { years old, medical or surgical services, high risk of VTE, not receiving any } \\
\text { VTE prophylaxis } \\
\text { - Exclusion criteria: patients on neurology services, newborn service, neonatal ICU, rehabilitation units, } \\
\text { patients not at high risk of developing VTE } \\
\text { - N included: } 1255 \text { (control), } 1238 \text { (intervention) } \\
\text { - Age (range, mean (SD)): control = } 19 \text { to } 103,68.28 \text { (14.99), intervention = } 20 \text { to } 100,69.3 \text { (15.46) } \\
\text { - Male \%: } 53.4 \text { (control), } 54.5 \text { (intervention) } \\
\text { - Control group: concurrent with intervention group, observed over the same time as intervention } \\
\text { group; same types of participants (department/hospital) as intervention group }\end{array}$ \\
\hline Interventions & $\begin{array}{l}\text { - Aimed at doctors } \\
\text { - Use of reminders: human alert } \\
\text { - Responsible physicians alerted by another staff member if his or her patient was at high risk for VTE, } \\
\text { and that VTE prophylaxis was recommended, based on point scale of DVT risk factors } \\
\text { - Comparator: doctors were either alerted or not alerted }\end{array}$ \\
\hline Outcomes & $\begin{array}{l}\text { - Appropriateness of prophylaxis not assessed } \\
\text { - Received prophylaxis: } 20.6 \% \text { (control), } 46 \% \text { (intervention) } \\
\text { - Symptomatic VTE (within } 90 \text { days): } 3.4 \% \text { (control), } 2.7 \% \text { (intervention) } \\
\text { - Symptomatic DVT (within } 90 \text { days): } 2 \% \text { (control), } 1.6 \% \text { (intervention) } \\
\text { - Symptomatic proximal DVT (within } 90 \text { days): } 1 \% \text { (control), } 0.3 \% \text { (intervention) } \\
\text { - Symptomatic PE (within } 90 \text { days): } 0.7 \% \text { (control), } 0.4 \% \text { (intervention) } \\
\text { - Symptomatic DVT + PE (within } 90 \text { days): } 0.6 \% \text { (control), } 0.6 \% \text { (intervention) } \\
\text { - Major bleeding (within } 30 \text { days): } 2.3 \% \text { (control), } 2.1 \% \text { (intervention) } \\
\text { - All-cause mortality (within } 90 \text { days): } 16.9 \% \text { (control), } 17.6 \% \text { (intervention) } \\
\text { - Method of VTE diagnosis: Doppler ultrasound, venography, ventilation-perfusion scan }\end{array}$ \\
\hline
\end{tabular}


Piazza 2009 (Continued)

Notes
Funding sources: Quote: "This investigator-initiated study was funded in part by an unrestricted research grant from Sanofi-Aventis, and Dr Piazza is supported by a Research Career Development Award (K12 HL083786) from the National Heart, Lung, and Blood Institute (NHLBI)."

\section{Risk of bias}

\begin{tabular}{lll}
\hline Bias & Authors' judgement & Support for judgement \\
\hline $\begin{array}{l}\text { Random sequence genera- } \\
\text { tion (selection bias) }\end{array}$ & Unclear risk & $\begin{array}{l}\text { Quote: "Randomization envelopes containing the statement 'alert' (interven- } \\
\text { tion group) or 'no alert' (control group) were provided by the Harvard Clinical } \\
\text { Research Institute to randomize eligible patients." (Page 2197, column 2, para- } \\
\text { graph 4) }\end{array}$ \\
& &
\end{tabular}

Allocation concealment $\quad$ Unclear risk $\quad$ No information on whether the envelopes were sealed or opaque, etc.
(selection bias)
(selection bias)

\begin{tabular}{|c|c|c|}
\hline $\begin{array}{l}\text { Blinding of participants } \\
\text { and personnel (perfor- } \\
\text { mance bias) }\end{array}$ & Unclear risk & $\begin{array}{l}\text { Quote: "All end points were adjudicated by investigators who were unawa } \\
\text { the patients' group assignments." (Page } 2198 \text {, column 1, paragraph 2) }\end{array}$ \\
\hline All outcomes & & There was no mention of the blinding of all participants and personnel. \\
\hline
\end{tabular}

\begin{tabular}{|c|c|c|}
\hline $\begin{array}{l}\text { Blinding of outcome as- } \\
\text { sessment (detection bias) } \\
\text { All outcomes }\end{array}$ & Low risk & $\begin{array}{l}\text { Quote: "All endpoints were adjudicated by investigators who were unaware of } \\
\text { the patients' group assignments." (Page 2198, column 1, paragraph 2) }\end{array}$ \\
\hline
\end{tabular}

\begin{tabular}{ll}
\hline $\begin{array}{l}\text { Incomplete outcome data } \\
\text { (attrition bias) }\end{array}$ & Low risk \\
All outcomes & tion." (Page 2197, column 2, paragraph 6)
\end{tabular}

Selective reporting (re- Low risk
porting bias)

\section{All relevant outcomes (clinical and safety outcomes) were assessed. (Page 2198, Table 1-2; page 2199, Table 3)}

Other bias Unclear risk

\begin{abstract}
Quote: "Because most physicians treated both intervention and control patients, it is possible that receiving a physician alert for patients in the intervention group also affected the use of prophylaxis in the control group." (Page 2200 , column 2, paragraph 2). There was a possible dependence between physicians in the intervention and the control group.
\end{abstract}

Quote: "The intervention and control groups were similar with regard to baseline characteristics, except that patients randomized to a physician alert were more likely to be $>75$ years ( $42.5 \%$ versus $37.8 \%$; $P=0.02$; Table 1 )." (Page 2198 , column 2, paragraph 2)

Quote: "One study center that enrolled 178 patients violated the study protocol and paged house officers rather than the attending physicians." (Page 2197, column 2, paragraph 4)

Low risk of bias for other items listed as potential sources of bias

Roy 2016

\begin{tabular}{ll}
\hline Methods & RCT \\
- Cluster \\
- Unit of randomization: centers (hospitals) \\
- Unit of analysis: participants \\
- Study period: 2009 to 2010
\end{tabular}


Roy 2016 (Continued)

- Farticipants
- 27 centers
- Departments: emergency
- ER patients
- Inclusion criteria: patients over 40 years old, presenting to the emergency department for acute med-
ical illness and requiring hospitalization in a medical ward
- Exclusion criteria: patients who were hospitalized for less than 48 hours; if VTE or PE was diagnosed
within 48 hours following admission, and if they received a therapeutic dosage of anticoagulants for
another reason than an acute VTE
- N included: 1686 (observational period), 18691 (intervention period): 6992 (control), 8359 (interven-
tion)
- Age (range, median): 58 to 82,73 (control), 59 to 83,74 (intervention)
- Male \%: 50.6 (control), 49.5 (intervention)
(hospital/ER)

- Use of multifaceted intervention that included an alert component

- Educational lectures, posters and pocket cards, computerized clinical decision support systems and computerized reminders

- Comparator: no intervention vs. intervention

Outcomes

Notes
- Appropriateness of prophylaxis assessed (thromboprophylaxis was considered adequate if: i) for highrisk patients with thromboprophylaxis recommended as per the guidelines, antithrombotic treatment was initiated before Day 5 and administered at the correct dosage for at least 5 days, or ii) for low-risk patients with no indication or those with contra-indication for anticoagulant treatment, antithrombotic treatment was not administered)

- Received prophylaxis: $44.1 \%$ (control), $48.2 \%$ (intervention)

- Received appropriate prophylaxis: $15.6 \%$ (control), $17.6 \%$ (intervention)

- Symptomatic VTE (within 3 months): $1.9 \%$ (control), $1.9 \%$ (intervention)

- Symptomatic DVT (within 3 months): $0.5 \%$ (control), $0.6 \%$ (intervention)

- Symptomatic proximal DVT (within 3 months): $0.3 \%$ (control), $0.3 \%$ (intervention)

- Symptomatic distal DVT (within 3 months): $0.2 \%$ (control), $0.3 \%$ (intervention)

- Symptomatic PE (within 3 months): 0.5\% (control), 0.4\% (intervention)

- Symptomatic fatal PE (within 3 months): $0.07 \%$ (control), $0.04 \%$ (intervention)

- Major bleeding (within 3 months): $1.3 \%$ (control), 1.2\% (intervention)

- All-cause mortality (within 3 months): $11.1 \%$ (control), $11.3 \%$ (intervention)

- Unexplained sudden death (within 3 months): $0.9 \%$ (control), $0.9 \%$ (intervention)

- Method of VTE diagnosis: venography, ultrasonography, pulmonary angiography, computed tomography, and ventilation-perfusion scan

Funding sources: Quote: "The study was supported by two grants from the French Ministry of Health (PHRC 2008 and 2011: 21-09), and received further financial aid from Bayer HealthCare SAS, France and Sanofi SAS, France. The funders had no role in study design, data collection and analysis, decision to publish, or preparation of the manuscript."

\section{Risk of bias}

\begin{tabular}{lll}
\hline Bias & Authors' judgement & Support for judgement \\
\hline $\begin{array}{ll}\text { Random sequence genera- } \\
\text { tion (selection bias) }\end{array}$ & Low risk & $\begin{array}{l}\text { Quote: "A random number table was used to assign hospitals to either the in- } \\
\text { tervention or standard practice group (control group). Randomization was } \\
\text { stratified in order to include the same number of academic hospitals and cen- } \\
\text { ters using a computerized medical file in each group." (Page 3, paragraph 6) }\end{array}$
\end{tabular}


Roy 2016 (Continued)

Allocation concealment Unclear risk Quote: "No intervention was performed in the centers allocated to the control (selection bias) group. The principal investigators were instructed to continue their practice as usual." (Page 4, paragraph 5)

\begin{tabular}{|c|c|c|}
\hline $\begin{array}{l}\text { Blinding of participants } \\
\text { and personnel (perfor- } \\
\text { mance bias) }\end{array}$ & High risk & $\begin{array}{l}\text { Quote: "Physicians were aware of an ongoing study of thromboprophylaxis } \\
\text { and may have improved their baseline practice (Hawthorne effect)." (Page 11, } \\
\text { paragraph 5) }\end{array}$ \\
\hline
\end{tabular}

Blinding of outcome as- Low risk sessment (detection bias) All outcomes
Quote: "An independent adjudication committee, blinded to the group allocation, performed a chart review and analyzed all suspected outcome events." (Page 5, paragraph 2)

Quote: "The statistician was blinded to the randomization group and center names." (Page 5, paragraph 8)

Incomplete outcome data Low risk Accounted for all missing data. See figure 1. (Page 7, paragraph 1)

(attrition bias)

All outcomes

Selective reporting (re- High risk
porting bias)

Selective reporting (re- High risk

Accounted for all missing data. See figure 1. (Page 7, paragraph 1)

Quote: "In patients for whom prophylaxis was recommended but with contraindication to antithrombotic treatment, a mechanical prophylaxis method was recommended, namely by means of compression stockings or intermittent pneumatic compression devices." (Page 3, paragraph 8)

Quote: "Secondly, we focused our analysis on antithrombotic treatment and did not assess mechanical thromboprophylaxis." (Page 11, paragraph 5)

Analysis did not account for mechanical prophylaxis in analysis as stated, but patients who could not receive regular prophylaxis were put on mechanical prophylaxis.

Other bias Unclear risk

\begin{abstract}
Unclear risk for recruitment bias: There did not seem to be any individuals recruited after randomization. However, it was possible that MDs worked in more than one unit and were in both the control and intervention populations. This was not addressed.
\end{abstract}

Low risk for baseline imbalances: Quote: "All data regarding demographic characteristics, past medical history and co-morbidities, medication on admission, main acute medical condition (principal reason for hospitalization), procedures performed during hospitalization, and length of hospital stay has been provided in Table 2 and S1 Table" (Page 6, paragraph 8)

Low risk for incorrect analysis: clustering was taken into account in analysis and in sample size calculation. Quote: "With the study design assuming 30 participating centers divided into two groups of 15 , an intra-cluster correlation of 0.01 , a $5 \%$ combined rate of VTE or major bleedings in the control group, a total of 16,170 patients with 8085 in each group were required to detect a $1.5 \%$ absolute difference between the two groups, with $3.5 \%$ in the intervention group, at a power of $80 \%$ and significance level of 5\%." (Page 5, paragraph 6). Quote: "We estimated the odds ratio in mixed-effects logistic regression, adjusting for significant patient- and center-level confounders and taking into account the dependence between patients from the same hospital, also known as the clustering effect." (Page 5, paragraph 8)

Low risk of bias for other items listed as potential sources of bias.

a/c: anticoagulant

$\mathrm{Cl}$ : confidence interval

CME: continuing medical education

Interventions for implementation of thromboprophylaxis in hospitalized patients at risk for venous thromboembolism (Review) 
DVT: deep vein thrombosis

ER: emergency room

GEE: generalized estimating equation

ICC: intraclass correlation

ICU: intensive care unit

MD: medical doctor

$\mathrm{N}$ : number

PE: pulmonary embolism

$\mathrm{PI}$ : principal investigator

QA: quality assurance

QI: quality improvement

QRT: quasi-randomized controlled trial

RCT: randomized controlled trial

SAQ: Safety Attitudes Questionnaire

SCD: Sequential compression device

SD: standard deviation

TIA: transient ischemic attack

TOA: timing of assessment

U: unit

VIF: variance inflation factor

VTE: venous thromboembolism

Characteristics of excluded studies [ordered by study ID]

\begin{tabular}{ll}
\hline Study & Reason for exclusion \\
\hline Marini 2014 & $\begin{array}{l}\text { The intervention did not aim to increase the use of prophylaxis, decrease the proportion of sympto- } \\
\text { matic VTE, or decrease the proportion of asymptomatic VTE. }\end{array}$ \\
\hline Nendaz 2010 & Non-randomized controlled trial (controlled before-and-after study design). \\
\hline Piazza 2013 & The intervention was directed to outpatients. \\
\hline
\end{tabular}

VTE: venous thromboembolism

DATA AND ANALYSES

Comparison 1. Alerts versus standard care

\begin{tabular}{llllll}
\hline Outcome or subgroup title & $\begin{array}{l}\text { No. of } \\
\text { studies }\end{array}$ & $\begin{array}{l}\text { No. of } \\
\text { partici- } \\
\text { pants }\end{array}$ & Statistical method & Effect size \\
\hline 1 Received prophylaxis & 3 & 5057 & Risk Difference (M-H, Random, 95\% Cl) & $0.21[0.15,0.27]$ \\
\hline 2 Received appropriate prophylaxis & 3 & 1820 & Risk Difference (M-H, Random, 95\% Cl) & $0.16[0.12,0.20]$ \\
\hline 3 Symptomatic VTE & 3 & 5353 & Risk Ratio (M-H, Random, 95\% Cl) & $0.64[0.47,0.86]$ \\
\hline
\end{tabular}


Analysis 1.1. Comparison 1 Alerts versus standard care, Outcome 1 Received prophylaxis.

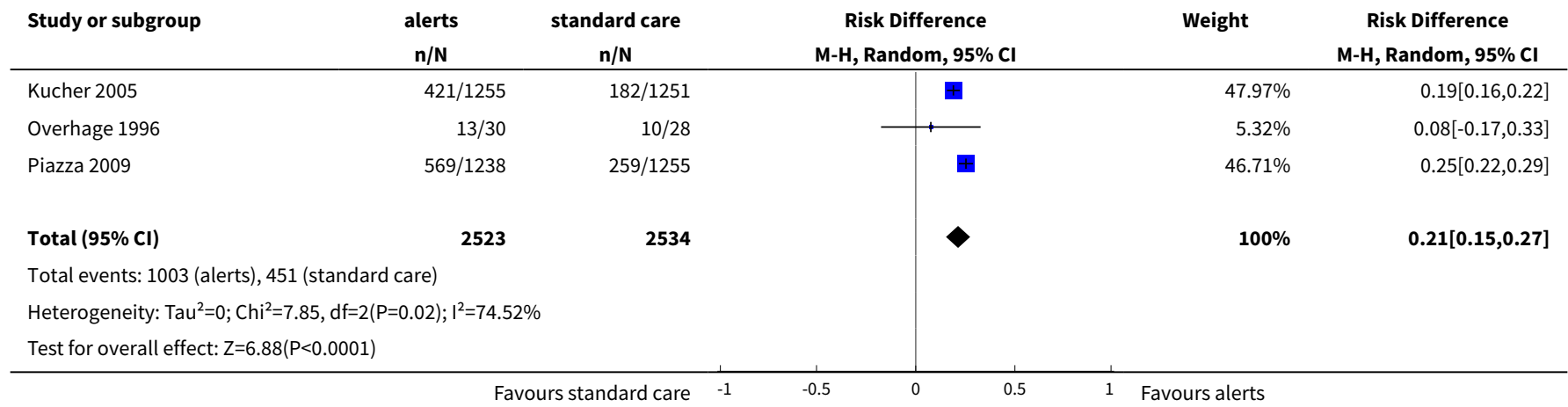

Analysis 1.2. Comparison 1 Alerts versus standard care, Outcome 2 Received appropriate prophylaxis.

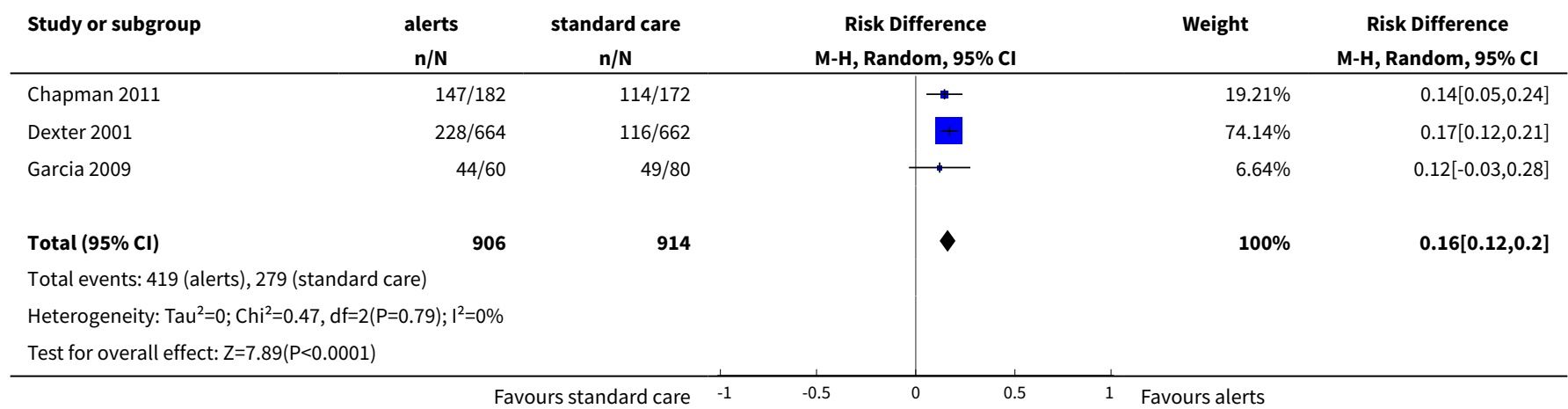

Analysis 1.3. Comparison 1 Alerts versus standard care, Outcome 3 Symptomatic VTE.

\begin{tabular}{|c|c|c|c|c|c|}
\hline Study or subgroup & $\begin{array}{c}\text { alerts } \\
\mathrm{n} / \mathrm{N}\end{array}$ & $\begin{array}{c}\text { standard care } \\
n / N \\
\end{array}$ & $\begin{array}{c}\text { Risk Ratio } \\
\text { M-H, Random, } 95 \% \text { Cl }\end{array}$ & Weight & $\begin{array}{c}\text { Risk Ratio } \\
\text { M-H, Random, } 95 \% \mathrm{Cl}\end{array}$ \\
\hline Chapman 2011 & $1 / 182$ & $5 / 172$ & \begin{tabular}{l|l}
1 & \\
\end{tabular} & $1.97 \%$ & $0.19[0.02,1.6]$ \\
\hline Kucher 2005 & $61 / 1255$ & $103 / 1251$ & $\theta$ & $62.84 \%$ & $0.59[0.43,0.8]$ \\
\hline Piazza 2009 & $32 / 1238$ & $41 / 1255$ & $\rightarrow$ & $35.19 \%$ & $0.79[0.5,1.25]$ \\
\hline Total $(95 \% \mathrm{Cl})$ & 2675 & 2678 & $>$ & $100 \%$ & $0.64[0.47,0.86]$ \\
\hline \multicolumn{6}{|c|}{ Heterogeneity: $\mathrm{Tau}^{2}=0.01 ; \mathrm{Chi}^{2}=2.35, \mathrm{df}=2(\mathrm{P}=0.31) ; \mathrm{I}^{2}=14.91 \%$} \\
\hline \multicolumn{6}{|c|}{ Test for overall effect: $Z=2.9(P=0)$} \\
\hline
\end{tabular}


Comparison 2. Multifaceted interventions versus standard care or another intervention

\begin{tabular}{|c|c|c|c|c|}
\hline Outcome or subgroup title & $\begin{array}{l}\text { No. of } \\
\text { studies }\end{array}$ & $\begin{array}{l}\text { No. of } \\
\text { partici- } \\
\text { pants }\end{array}$ & Statistical method & Effect size \\
\hline 1 Received prophylaxis (unadjusted) & 5 & 26330 & $\begin{array}{l}\text { Risk Difference }(\mathrm{M}-\mathrm{H} \text {, Random, } \\
95 \% \mathrm{Cl})\end{array}$ & $\begin{array}{l}0.03[0.00 \\
0.05]\end{array}$ \\
\hline 2 Received prophylaxis (adjusted) & 5 & 9198 & $\begin{array}{l}\text { Risk Difference (M-H, Random, } \\
95 \% \mathrm{Cl})\end{array}$ & $\begin{array}{l}0.04[0.02 \\
0.06]\end{array}$ \\
\hline $\begin{array}{l}3 \text { Received prophylaxis (adjusted) sensitivity } \\
\text { analysis: applied lowest ICC from other trials }\end{array}$ & 5 & 9089 & $\begin{array}{l}\text { Risk Difference (M-H, Random, } \\
95 \% \mathrm{Cl})\end{array}$ & $\begin{array}{l}0.04[0.02 \\
0.06]\end{array}$ \\
\hline $\begin{array}{l}4 \text { Received prophylaxis (adjusted) sensitivity } \\
\text { analysis: applied mean ICC from other trials }\end{array}$ & 5 & 8491 & $\begin{array}{l}\text { Risk Difference (M-H, Random, } \\
95 \% \mathrm{Cl})\end{array}$ & $\begin{array}{l}0.03[0.01 \\
0.06]\end{array}$ \\
\hline $\begin{array}{l}5 \text { Received prophylaxis (adjusted) sensitivity } \\
\text { analysis: applied highest ICC from trials }\end{array}$ & 5 & 8440 & $\begin{array}{l}\text { Risk Difference (M-H, Random, } \\
95 \% \mathrm{Cl})\end{array}$ & $\begin{array}{l}0.04[0.01 \\
0.06]\end{array}$ \\
\hline
\end{tabular}

Analysis 2.1. Comparison 2 Multifaceted interventions versus standard care or another intervention, Outcome 1 Received prophylaxis (unadjusted).

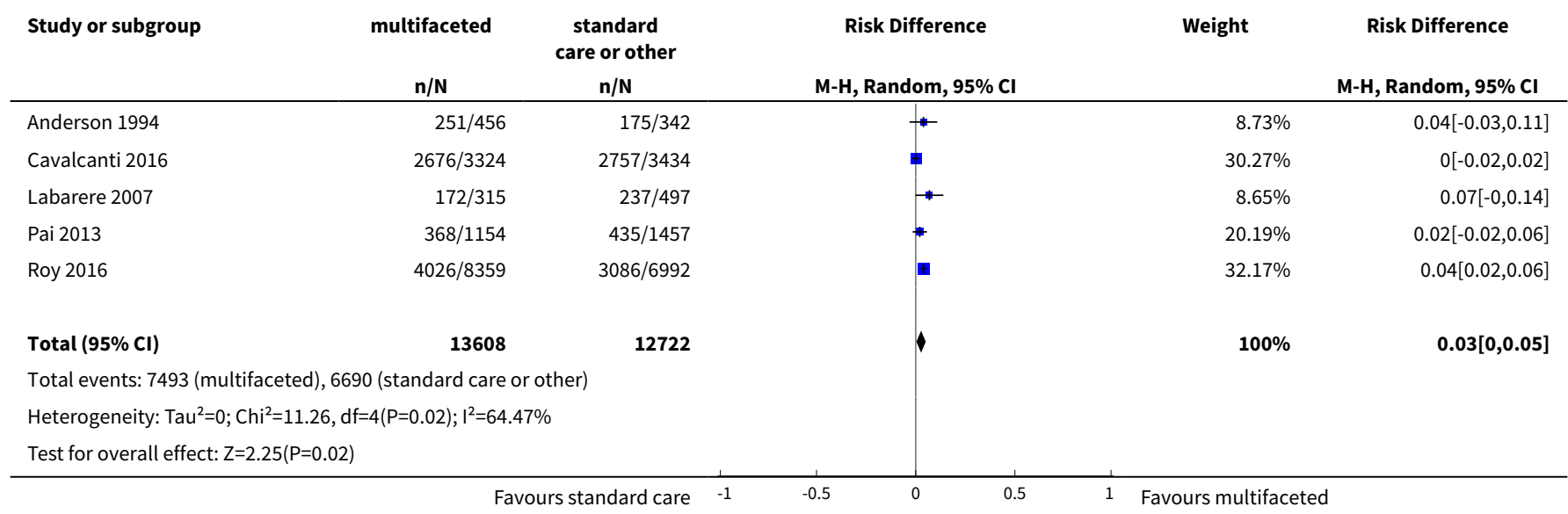

Analysis 2.2. Comparison 2 Multifaceted interventions versus standard care or another intervention, Outcome 2 Received prophylaxis (adjusted).

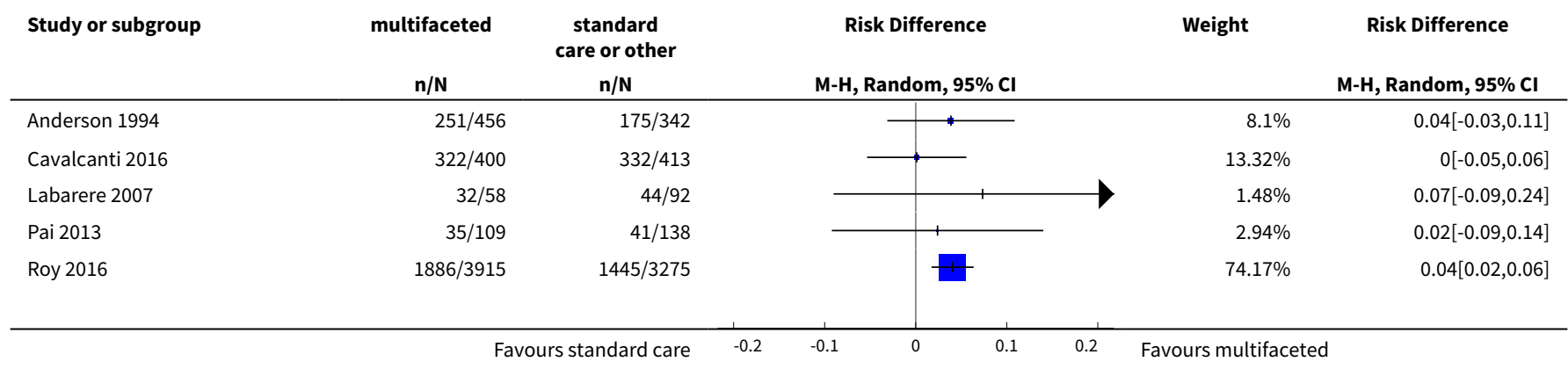




\begin{tabular}{|c|c|c|c|c|c|}
\hline \multirow[t]{2}{*}{ Study or subgroup } & multifaceted & $\begin{array}{l}\text { standard } \\
\text { care or other }\end{array}$ & Risk Difference & \multirow[t]{2}{*}{ Weight } & Risk Difference \\
\hline & $\mathrm{n} / \mathbf{N}$ & $n / N$ & M-H, Random, 95\% Cl & & M-H, Random, 95\% Cl \\
\hline Total $(95 \% \mathrm{Cl})$ & 4938 & 4260 & & $100 \%$ & $0.04[0.02,0.06]$ \\
\hline \multicolumn{6}{|c|}{ Total events: 2526 (multifaceted), 2037 (standard care or other) } \\
\hline \multicolumn{6}{|c|}{ Heterogeneity: Tau $^{2}=0 ; \mathrm{Chi}^{2}=1.99, \mathrm{df}=4(\mathrm{P}=0.74) ; \mathrm{I}^{2}=0 \%$} \\
\hline Test for overall effect & & & & & \\
\hline
\end{tabular}

Analysis 2.3. Comparison 2 Multifaceted interventions versus standard care or another intervention, Outcome 3 Received prophylaxis (adjusted) sensitivity analysis: applied lowest ICC from other trials.

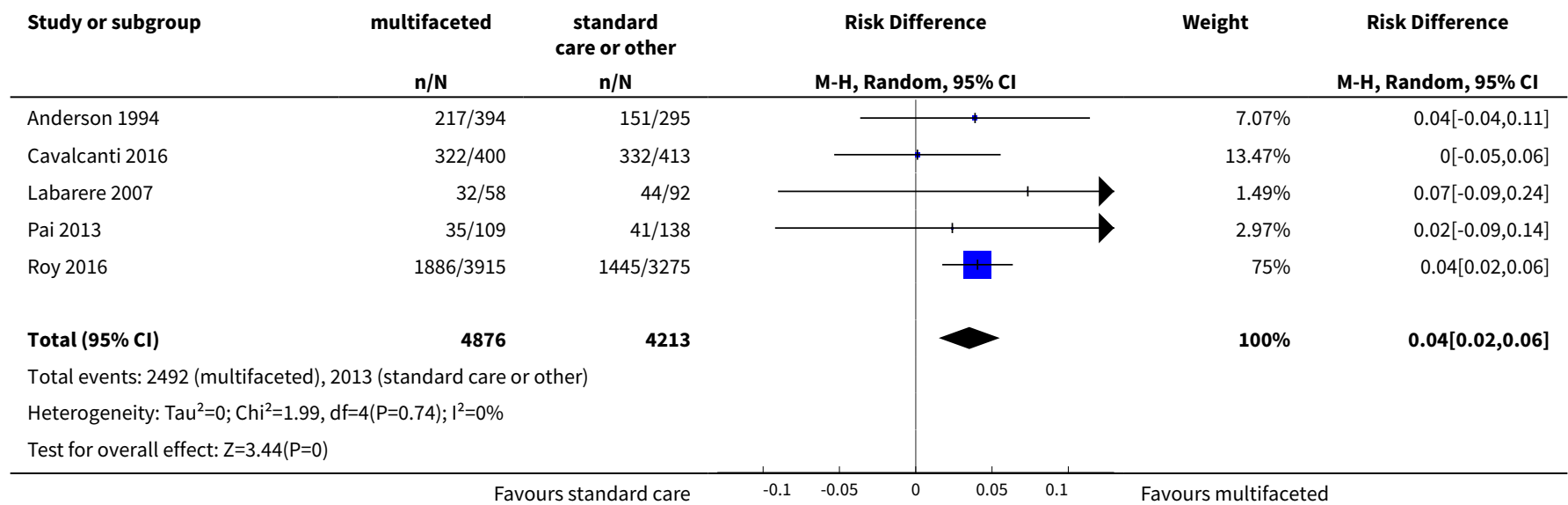

Analysis 2.4. Comparison 2 Multifaceted interventions versus standard care or another intervention, Outcome 4 Received prophylaxis (adjusted) sensitivity analysis: applied mean ICC from other trials.

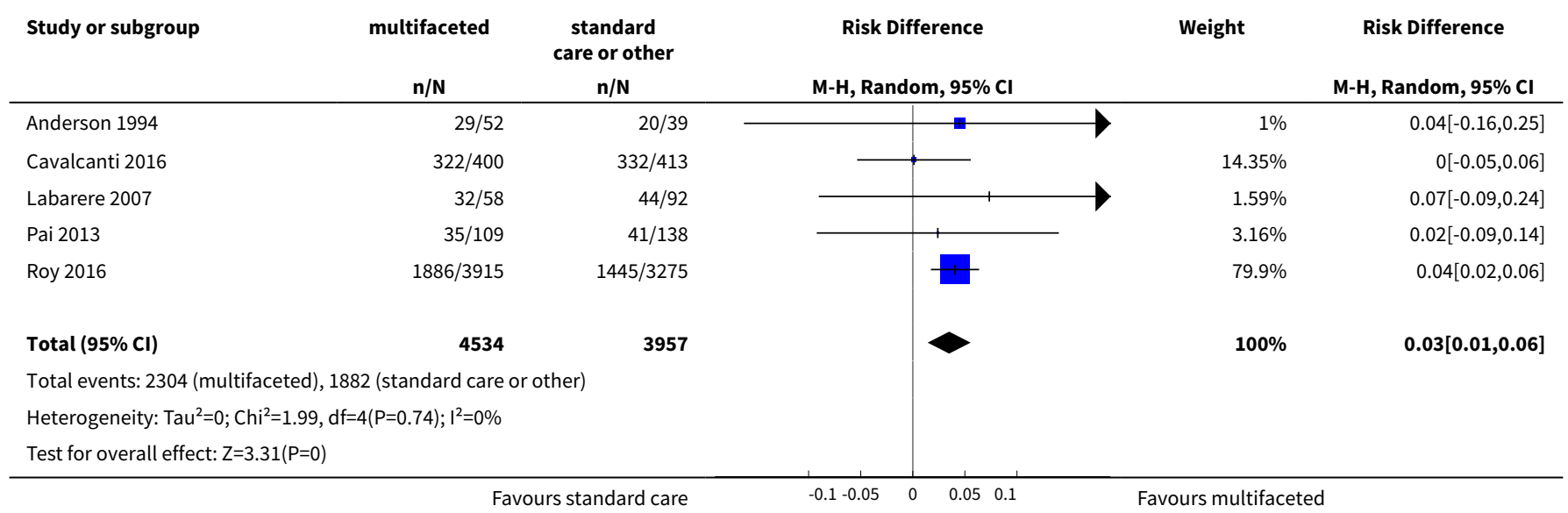


Analysis 2.5. Comparison 2 Multifaceted interventions versus standard care or another intervention, Outcome 5 Received prophylaxis (adjusted) sensitivity analysis: applied highest ICC from trials.

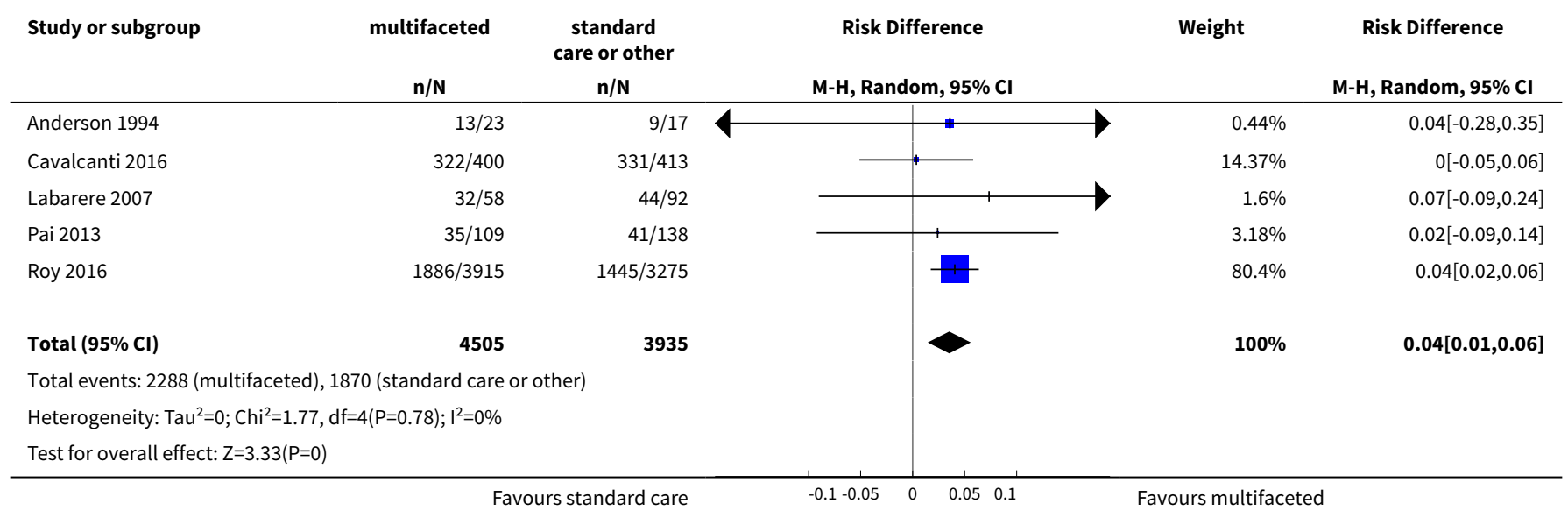

ADDITIONAL TABLES

Table 1. Quantitative risk of bias score for sensitivity analysis

\begin{tabular}{|c|c|c|}
\hline \multicolumn{3}{|c|}{ Quantitative risk of bias score for sensitivity analysis } \\
\hline Trial & $\begin{array}{l}\text { Summary ROB } \\
\text { Score }\end{array}$ & Overall ROB \\
\hline Anderson 1994 & -1 & Unclear \\
\hline Cavalcanti 2016 & +1 & Unclear \\
\hline Chapman 2011 & 0 & Unclear \\
\hline Dexter 2001 & 0 & Unclear \\
\hline Fontaine 2006 & 0 & Unclear \\
\hline Garcia 2009 & -2 & High \\
\hline Hinchey 2010 & -4 & High \\
\hline Kucher 2005 & +2 & Low \\
\hline Labarere 2007 & 0 & Unclear \\
\hline Overhage 1996 & -1 & Unclear \\
\hline Pai 2013 & +1 & Unclear \\
\hline Piazza 2009 & +3 & Low \\
\hline Roy 2016 & +1 & Unclear \\
\hline
\end{tabular}

ROB: risk of bias 
Table 2. Primary outcome - unadjusted/adjusted meta-analysis and sensitivity analysis

\begin{tabular}{lllll}
\hline Intervention & Outcome & $\begin{array}{l}\text { Risk Difference (RD) (95\% } \\
\text { CI) }\end{array}$ & $\begin{array}{l}\text { I' Statis- } \\
\text { tic for RD }\end{array}$ & Relative Risk (RR) (95\% CI) \\
\hline Multifaceted unadjusted & Received prophylaxis & $0.03(0.00$ to 0.05$)$ & $64 \%$ & 1.07 (1.00 to 1.14) \\
\hline Multifaceted adjusted & Received prophylaxis & $0.04(0.02$ to 0.06$)$ & $0 \%$ & $1.06(1.02$ to 1.11$)$ \\
\hline Multifaceted lowest ICC & Received prophylaxis & $0.04(0.02$ to 0.06$)$ & $0 \%$ & $1.06(1.02$ to 1.11$)$ \\
\hline Multifaceted mean ICC & Received prophylaxis & $0.04(0.01$ to 0.06$)$ & $0 \%$ & $1.06(1.01$ to 1.11$)$ \\
\hline Multifaceted highest ICC & Received prophylaxis & $0.04(0.01$ to 0.06$)$ & $0 \%$ & $1.06(1.01$ to 1.11$)$
\end{tabular}

ICCs were available for 4/5 (Cavalcanti $2016=0.13$, Labarere $2007=0.24$, Pai $2013=0.022$, Roy $2016=0.002$ ) trials included in this meta-analysis. ICC's were not available for Anderson 1994.

In this table adjustment for the cluster design effect was performed via reported ICCs. No ICC was applied to the one trial that did not report an ICC (Anderson 1994). We performed a sensitivity analysis using the lowest reported ICC (0.002), the mean reported ICC (0.0985), and the highest reported ICC (0.24) for the trial that did not report an ICC (Anderson 1994). All trials in the meta-analysis were clustered designs.

ICC: intracluster correlation

Anderson 1994; Cavalcanti 2016; Labarere 2007; Pai 2013; Roy 2016

Table 3. Alerts

\begin{tabular}{|c|c|c|c|c|c|}
\hline Outcomes & $\begin{array}{l}\text { Number } \\
\text { of studies }\end{array}$ & $\begin{array}{l}\text { Risk Dif- } \\
\text { ference } \\
\text { (RD) }\end{array}$ & $\begin{array}{l}95 \% \text { Confidence inter- } \\
\text { val }\end{array}$ & $\begin{array}{l}\text { Events, inter- } \\
\text { vention }\end{array}$ & $\begin{array}{l}\text { Events, con- } \\
\text { trol }\end{array}$ \\
\hline Received prophylaxis & 3 & 0.21 & $(0.15$ to 0.27$)$ & $1003 / 2523$ & $451 / 2534$ \\
\hline Received appropriate prophylaxis & 3 & 0.16 & $(0.12$ to 0.20$)$ & $419 / 906$ & $279 / 914$ \\
\hline Venous thromboembolism outcomes & $\begin{array}{l}\text { Number } \\
\text { of studies }\end{array}$ & $\begin{array}{l}\text { Risk Ra- } \\
\text { tio (RR) }\end{array}$ & $\begin{array}{l}95 \% \text { Confidence inter- } \\
\text { val }\end{array}$ & $\begin{array}{l}\text { Events, inter- } \\
\text { vention }\end{array}$ & $\begin{array}{l}\text { Events, con- } \\
\text { trol }\end{array}$ \\
\hline Symptomatic VTE & 3 & 0.64 & $(0.47$ to 0.86$)$ & $94 / 2675$ & $149 / 2678$ \\
\hline \multirow[t]{2}{*}{ Symptomatic DVT } & 2 & $0.43^{a}$ & $(0.23$ to 0.78$)$ & $15 / 1255$ & $35 / 1251$ \\
\hline & & $0.80^{\mathrm{b}}$ & (0.44 to 1.46$)$ & $19 / 1238$ & $24 / 1255$ \\
\hline \multirow[t]{2}{*}{ Symptomatic PE } & 2 & $0.40^{a}$ & $(0.22$ to 0.74$)$ & $14 / 1255$ & $35 / 1251$ \\
\hline & & $0.63^{b}$ & (0.21 to 1.93$)$ & $5 / 1238$ & $8 / 1255$ \\
\hline Asymptomatic VTE & - & - & - & - & - \\
\hline Asymptomatic DVT & - & - & - & - & - \\
\hline Asymptomatic PE & - & - & - & - & - \\
\hline
\end{tabular}


Table 3. Alerts (Continued)

\begin{tabular}{|c|c|c|c|c|c|}
\hline Mortality & $\begin{array}{l}\text { Number } \\
\text { of studies }\end{array}$ & $\begin{array}{l}\text { Risk Ra- } \\
\text { tio (RR) }\end{array}$ & $\begin{array}{l}\text { 95\% Confidence inter- } \\
\text { val }\end{array}$ & $\begin{array}{l}\text { Events, inter- } \\
\text { vention }\end{array}$ & $\begin{array}{l}\text { Events, con- } \\
\text { trol }\end{array}$ \\
\hline \multirow[t]{2}{*}{ All-cause mortality } & 2 & $1.01^{a}$ & (0.87 to 1.17 ) & $282 / 1255$ & $279 / 1251$ \\
\hline & & $1.04^{b}$ & (0.88 to 1.24$)$ & $215 / 1238$ & $209 / 1255$ \\
\hline Sudden death & - & - & - & - & - \\
\hline Safety outcomes & $\begin{array}{l}\text { Number } \\
\text { of studies }\end{array}$ & $\begin{array}{l}\text { Risk Ra- } \\
\text { tio (RR) }\end{array}$ & $\begin{array}{l}\text { 95\% Confidence inter- } \\
\text { val }\end{array}$ & $\begin{array}{l}\text { Events, inter- } \\
\text { vention }\end{array}$ & $\begin{array}{l}\text { Events, con- } \\
\text { trol }\end{array}$ \\
\hline \multirow[t]{2}{*}{ Major bleeding } & 2 & $1.00^{a}$ & (0.53 to 1.87 ) & $19 / 1255$ & $19 / 1251$ \\
\hline & & $0.91^{b}$ & (0.53 to 1.54$)$ & $25 / 1238$ & $28 / 1255$ \\
\hline Minor bleeding & 1 & $0.92^{a}$ & (0.69 to 1.23 ) & $81 / 1255$ & $88 / 1251$ \\
\hline Thrombocytopenia & - & - & - & - & - \\
\hline
\end{tabular}

DVT: deep vein thrombosis

PE: pulmonary embolism

VTE: venous thromboembolism

Chapman 2011; Dexter 2001; Garcia 2009; Kucher 2005; Piazza 2009; Overhage 1996

Table 4. Computer alerts

\begin{tabular}{|c|c|c|c|c|c|}
\hline Outcomes & $\begin{array}{l}\text { Number } \\
\text { of studies }\end{array}$ & $\begin{array}{l}\text { Risk Differ- } \\
\text { ence (RD) }\end{array}$ & 95\% Confidence interval & $\begin{array}{l}\text { Events, inter- } \\
\text { vention }\end{array}$ & $\begin{array}{l}\text { Events, con- } \\
\text { trol }\end{array}$ \\
\hline \multirow[t]{2}{*}{ Received prophylaxis } & 2 & $0.19 a$ & $(0.16$ to 0.22$)$ & $421 / 1255$ & $182 / 1251$ \\
\hline & & $0.08^{b}$ & $(-0.17$ to 0.33$)$ & $13 / 30$ & $10 / 28$ \\
\hline Received appropriate prophylaxis & 1 & $0.17 \mathrm{c}$ & $(0.12$ to 0.21$)$ & $228 / 664$ & $116 / 662$ \\
\hline Venous thromboembolism outcomes & $\begin{array}{l}\text { Number } \\
\text { of studies }\end{array}$ & $\begin{array}{l}\text { Risk Ratio } \\
\text { (RR) }\end{array}$ & 95\% Confidence interval & $\begin{array}{l}\text { Events, inter- } \\
\text { vention }\end{array}$ & $\begin{array}{l}\text { Events, con- } \\
\text { trol }\end{array}$ \\
\hline Symptomatic VTE & 1 & $0.59 a$ & (0.43 to 0.80$)$ & $61 / 1255$ & $103 / 1251$ \\
\hline Symptomatic DVT & 1 & $0.43^{a}$ & (0.23 to 0.78$)$ & $15 / 1255$ & $35 / 1251$ \\
\hline Symptomatic PE & 1 & $0.40^{a}$ & (0.22 to 0.74$)$ & $14 / 1255$ & $35 / 1251$ \\
\hline Asymptomatic VTE & - & - & - & - & - \\
\hline Asymptomatic DVT & - & - & - & - & - \\
\hline Asymptomatic PE & - & - & - & - & - \\
\hline
\end{tabular}


Table 4. Computer alerts (Continued)

\begin{tabular}{|c|c|c|c|c|c|}
\hline Mortality & $\begin{array}{l}\text { Number } \\
\text { of studies }\end{array}$ & $\begin{array}{l}\text { Risk Ratio } \\
\text { (RR) }\end{array}$ & $95 \%$ Confidence interval & $\begin{array}{l}\text { Events, inter- } \\
\text { vention }\end{array}$ & $\begin{array}{l}\text { Events, con- } \\
\text { trol }\end{array}$ \\
\hline All-cause mortality & 1 & $1.01^{\mathrm{a}}$ & (0.87 to 1.17$)$ & $282 / 1255$ & $279 / 1251$ \\
\hline Sudden death & - & - & - & - & - \\
\hline Safety outcomes & $\begin{array}{l}\text { Number } \\
\text { of studies }\end{array}$ & $\begin{array}{l}\text { Risk Ratio } \\
\text { (RR) }\end{array}$ & $95 \%$ Confidence interval & $\begin{array}{l}\text { Events, inter- } \\
\text { vention }\end{array}$ & $\begin{array}{l}\text { Events, con- } \\
\text { trol }\end{array}$ \\
\hline Major bleeding & 1 & $1.00^{\mathrm{a}}$ & (0.53 to 1.87 ) & $19 / 1255$ & $19 / 1251$ \\
\hline Minor bleeding & 1 & $0.92^{a}$ & (0.69 to 1.23 ) & $81 / 1255$ & $88 / 1251$ \\
\hline Thrombocytopenia & - & - & - & - & - \\
\hline
\end{tabular}

DVT: deep vein thrombosis

PE: pulmonary embolism

VTE: venous thromboembolism

Dexter 2001; Kucher 2005; Overhage 1996

Table 5. Human alerts

\begin{tabular}{|c|c|c|c|c|c|}
\hline Outcomes & $\begin{array}{l}\text { Number } \\
\text { of studies }\end{array}$ & $\begin{array}{l}\text { Risk Dif- } \\
\text { ference } \\
\text { (RD) }\end{array}$ & $\begin{array}{l}95 \% \text { Confidence inter- } \\
\text { val }\end{array}$ & $\begin{array}{l}\text { Events, inter- } \\
\text { vention }\end{array}$ & $\begin{array}{l}\text { Events, } \\
\text { control }\end{array}$ \\
\hline Received prophylaxis & 1 & $0.25^{a}$ & $(0.22$ to 0.29$)$ & $569 / 1238$ & $259 / 1255$ \\
\hline \multirow[t]{2}{*}{ Received appropriate prophylaxis } & 2 & $0.14^{b}$ & $(0.05$ to 0.24$)$ & $147 / 182$ & $114 / 172$ \\
\hline & & $0.12^{\mathrm{C}}$ & $(-0.03$ to 0.28$)$ & $44 / 60$ & $49 / 80$ \\
\hline Venous thromboembolism outcomes & $\begin{array}{l}\text { Number } \\
\text { of studies }\end{array}$ & $\begin{array}{l}\text { Risk Ra- } \\
\text { tio (RR) }\end{array}$ & $\begin{array}{l}95 \% \text { Confidence inter- } \\
\text { val }\end{array}$ & $\begin{array}{l}\text { Events, inter- } \\
\text { vention }\end{array}$ & $\begin{array}{l}\text { Events, } \\
\text { control }\end{array}$ \\
\hline \multirow[t]{2}{*}{ Symptomatic VTE } & 2 & $0.79^{a}$ & $(0.50$ to 1.25$)$ & $32 / 1238$ & $41 / 1255$ \\
\hline & & $0.19 \mathrm{~b}$ & (0.02 to 1.60$)$ & $1 / 182$ & $5 / 172$ \\
\hline Symptomatic DVT & 1 & $0.80^{a}$ & (0.44 to 1.46$)$ & $19 / 1238$ & $24 / 1255$ \\
\hline Symptomatic PE & 1 & $0.63^{a}$ & (0.21 to 1.93$)$ & $5 / 1238$ & $8 / 1255$ \\
\hline Asymptomatic VTE & - & - & - & - & - \\
\hline Asymptomatic DVT & - & - & - & - & - \\
\hline Asymptomatic PE & - & - & - & - & - \\
\hline Mortality & $\begin{array}{l}\text { Number } \\
\text { of studies }\end{array}$ & $\begin{array}{l}\text { Risk Ra- } \\
\text { tio (RR) }\end{array}$ & $\begin{array}{l}95 \% \text { Confidence inter- } \\
\text { val }\end{array}$ & $\begin{array}{l}\text { Events, inter- } \\
\text { vention }\end{array}$ & $\begin{array}{l}\text { Events, } \\
\text { control }\end{array}$ \\
\hline
\end{tabular}


Table 5. Human alerts

(Continued)

\begin{tabular}{|c|c|c|c|c|c|}
\hline All-cause mortality & 1 & $1.04^{a}$ & (0.88 to 1.24$)$ & $215 / 1238$ & $209 / 1255$ \\
\hline Sudden death & - & - & - & - & - \\
\hline Safety outcomes & $\begin{array}{l}\text { Number } \\
\text { of studies }\end{array}$ & $\begin{array}{l}\text { Risk Ra- } \\
\text { tio (RR) }\end{array}$ & $\begin{array}{l}95 \% \text { Confidence inter- } \\
\text { val }\end{array}$ & $\begin{array}{l}\text { Events, inter- } \\
\text { vention }\end{array}$ & $\begin{array}{l}\text { Events, } \\
\text { control }\end{array}$ \\
\hline Major bleeding & 1 & $0.91^{a}$ & (0.53 to 1.54$)$ & $25 / 1238$ & $28 / 1255$ \\
\hline Minor bleeding & - & - & - & - & - \\
\hline Thrombocytopenia & - & - & - & - & - \\
\hline
\end{tabular}

DVT: deep vein thrombosis

PE: pulmonary embolism

VTE: venous thromboembolism

Chapman 2011; Garcia 2009; Piazza 2009

Table 6. Multifaceted interventions

\begin{tabular}{|c|c|c|c|c|c|}
\hline Outcomes & $\begin{array}{l}\text { Number } \\
\text { of studies }\end{array}$ & $\begin{array}{l}\text { Risk Dif- } \\
\text { ference } \\
\text { (RD) }\end{array}$ & $\begin{array}{l}95 \% \text { Confidence inter- } \\
\text { val }\end{array}$ & $\begin{array}{l}\text { Events, inter- } \\
\text { vention }\end{array}$ & $\begin{array}{l}\text { Events, con- } \\
\text { trol }\end{array}$ \\
\hline Received prophylaxis & 5 & 0.03 & (0.00 to 0.05$)$ & $7306 / 13611$ & $6509 / 12722$ \\
\hline \multirow[t]{2}{*}{ Received appropriate prophylaxis } & \multirow[t]{2}{*}{2} & $0.03^{a}$ & $(-0.00$ to 0.06$)$ & $263 / 1154$ & $290 / 1457$ \\
\hline & & $0.02^{b}$ & (0.01 to 0.03$)$ & $1474 / 8359$ & $1094 / 6992$ \\
\hline Venous thromboembolism outcomes & $\begin{array}{l}\text { Number } \\
\text { of studies }\end{array}$ & $\begin{array}{l}\text { Risk Ra- } \\
\text { tio (RR) }\end{array}$ & $\begin{array}{l}95 \% \text { Confidence inter- } \\
\text { val }\end{array}$ & $\begin{array}{l}\text { Events, inter- } \\
\text { vention }\end{array}$ & $\begin{array}{l}\text { Events, con- } \\
\text { trol }\end{array}$ \\
\hline Symptomatic VTE & 1 & $0.97 \mathrm{~b}$ & (0.77 to 1.23$)$ & $150 / 8068$ & $128 / 6692$ \\
\hline Symptomatic DVT & 1 & $1.17^{b}$ & (0.76 to 1.81$)$ & $48 / 8068$ & $34 / 6692$ \\
\hline Symptomatic PE & 1 & $0.71^{b}$ & (0.44 to 1.15$)$ & $31 / 8068$ & $36 / 6692$ \\
\hline Asymptomatic VTE & - & - & - & - & - \\
\hline Asymptomatic DVT & 1 & $1.21 \mathrm{c}$ & (0.86 to 1.70$)$ & $49 / 315$ & $64 / 497$ \\
\hline Asymptomatic PE & - & - & - & - & - \\
\hline Mortality & $\begin{array}{l}\text { Number } \\
\text { of studies }\end{array}$ & $\begin{array}{l}\text { Risk Ra- } \\
\text { tio (RR) }\end{array}$ & $\begin{array}{l}95 \% \text { Confidence inter- } \\
\text { val }\end{array}$ & $\begin{array}{l}\text { Events, inter- } \\
\text { vention }\end{array}$ & $\begin{array}{l}\text { Events, con- } \\
\text { trol }\end{array}$ \\
\hline \multirow[t]{2}{*}{ All-cause mortality } & \multirow[t]{2}{*}{2} & $1.02^{b}$ & (0.93 to 1.12 ) & $940 / 8298$ & $764 / 6884$ \\
\hline & & $0.95^{d}$ & (0.88 to 1.01$)$ & $1096 / 3327$ & $1196 / 3434$ \\
\hline
\end{tabular}


Table 6. Multifaceted interventions (Continued)

\begin{tabular}{|c|c|c|c|c|c|}
\hline Sudden death & 1 & $1.01^{b}$ & (0.72 to 1.43 ) & $72 / 8298$ & $59 / 6884$ \\
\hline Safety outcomes & $\begin{array}{l}\text { Number } \\
\text { of studies }\end{array}$ & $\begin{array}{l}\text { Risk Ra- } \\
\text { tio (RR) }\end{array}$ & $\begin{array}{l}\text { 95\% Confidence inter- } \\
\text { val }\end{array}$ & $\begin{array}{l}\text { Events, inter- } \\
\text { vention }\end{array}$ & $\begin{array}{l}\text { Events, con- } \\
\text { trol }\end{array}$ \\
\hline Major bleeding & 1 & $0.96^{b}$ & (0.72 to 1.28$)$ & $100 / 8068$ & $86 / 6692$ \\
\hline Minor bleeding & - & - & - & - & - \\
\hline Thrombocytopenia & 1 & $0.53^{c}$ & (0.02 to 12.86$)$ & $0 / 315$ & $1 / 497$ \\
\hline
\end{tabular}

aPai 2013; bRoy 2016; CLabarere 2007; dCavalcanti 2016

DVT: deep vein thrombosis

PE: pulmonary embolism

VTE: venous thromboembolism

Anderson 1994 CME + QA Group; Cavalcanti 2016; Hinchey 2010; Labarere 2007; Pai 2013; Roy 2016

Table 7. Educational interventions

\begin{tabular}{|c|c|c|c|c|c|}
\hline Outcomes & $\begin{array}{l}\text { Number of } \\
\text { studies }\end{array}$ & $\begin{array}{l}\text { Risk Differ- } \\
\text { ence (RD) }\end{array}$ & $\begin{array}{l}95 \% \text { Confidence } \\
\text { interval }\end{array}$ & $\begin{array}{l}\text { Events, inter- } \\
\text { vention }\end{array}$ & $\begin{array}{l}\text { Events, } \\
\text { control }\end{array}$ \\
\hline Received prophylaxis & 1 & -0.02 & $(-0.09$ to 0.05$)$ & $252 / 513$ & $175 / 342$ \\
\hline Received appropriate prophylaxis & - & - & - & - & - \\
\hline Venous thromboembolism outcomes & $\begin{array}{l}\text { Number of } \\
\text { studies }\end{array}$ & $\begin{array}{l}\text { Risk Ratio } \\
\text { (RR) }\end{array}$ & $\begin{array}{l}95 \% \text { Confidence } \\
\text { interval }\end{array}$ & $\begin{array}{l}\text { Events, inter- } \\
\text { vention }\end{array}$ & $\begin{array}{l}\text { Events, } \\
\text { control }\end{array}$ \\
\hline Symptomatic VTE & - & - & - & - & - \\
\hline Symptomatic DVT & - & - & - & - & - \\
\hline Symptomatic PE & - & - & - & - & - \\
\hline Asymptomatic DVT & - & - & - & - & - \\
\hline Asymptomatic PE & - & - & - & - & - \\
\hline Mortality & $\begin{array}{l}\text { Number of } \\
\text { studies }\end{array}$ & $\begin{array}{l}\text { Risk Ratio } \\
\text { (RR) }\end{array}$ & $\begin{array}{l}95 \% \text { Confidence } \\
\text { interval }\end{array}$ & $\begin{array}{l}\text { Events, inter- } \\
\text { vention }\end{array}$ & $\begin{array}{l}\text { Events, } \\
\text { control }\end{array}$ \\
\hline All-cause mortality & - & - & - & - & - \\
\hline Sudden death & - & - & - & - & - \\
\hline Safety outcomes & $\begin{array}{l}\text { Number of } \\
\text { studies }\end{array}$ & $\begin{array}{l}\text { Risk Ratio } \\
\text { (RR) }\end{array}$ & $\begin{array}{l}95 \% \text { Confidence } \\
\text { interval }\end{array}$ & $\begin{array}{l}\text { Events, inter- } \\
\text { vention }\end{array}$ & $\begin{array}{l}\text { Events, } \\
\text { control }\end{array}$ \\
\hline Major bleeding & - & - & - & - & - \\
\hline Minor bleeding & - & - & - & - & - \\
\hline Thrombocytopenia & - & - & - & - & - \\
\hline
\end{tabular}


Table 7. Educational interventions (Continued)

\author{
Anderson 1994 CME group
}

DVT: deep vein thrombosis

PE: pulmonary embolism

VTE: venous thromboembolism

\title{
Table 8. Preprinted orders
}

\begin{tabular}{|c|c|c|c|c|c|}
\hline Outcomes & $\begin{array}{l}\text { Number of } \\
\text { studies }\end{array}$ & $\begin{array}{l}\text { Risk Differ- } \\
\text { ence (RD) }\end{array}$ & $\begin{array}{l}95 \% \text { Confidence } \\
\text { interval }\end{array}$ & $\begin{array}{l}\text { Events, inter- } \\
\text { vention }\end{array}$ & $\begin{array}{l}\text { Events, } \\
\text { control }\end{array}$ \\
\hline Received prophylaxis & 1 & -0.05 & $(-0.12$ to 0.02$)$ & $115 / 360$ & $133 / 359$ \\
\hline Received appropriate prophylaxis & - & - & - & - & - \\
\hline Venous thromboembolism outcomes & $\begin{array}{l}\text { Number of } \\
\text { studies }\end{array}$ & $\begin{array}{l}\text { Risk Ratio } \\
\text { (RR) }\end{array}$ & $\begin{array}{l}95 \% \text { Confidence } \\
\text { interval }\end{array}$ & $\begin{array}{l}\text { Events, inter- } \\
\text { vention }\end{array}$ & $\begin{array}{l}\text { Events, } \\
\text { control }\end{array}$ \\
\hline Symptomatic VTE & - & - & - & - & - \\
\hline Symptomatic DVT & - & - & - & - & - \\
\hline Symptomatic PE & - & - & - & - & - \\
\hline Asymptomatic VTE & - & - & - & - & - \\
\hline Asymptomatic DVT & - & - & - & - & - \\
\hline Asymptomatic PE & - & - & - & - & - \\
\hline Mortality & $\begin{array}{l}\text { Number of } \\
\text { studies }\end{array}$ & $\begin{array}{l}\text { Risk Ratio } \\
\text { (RR) }\end{array}$ & $\begin{array}{l}95 \% \text { Confidence } \\
\text { interval }\end{array}$ & $\begin{array}{l}\text { Events, inter- } \\
\text { vention }\end{array}$ & $\begin{array}{l}\text { Events, } \\
\text { control }\end{array}$ \\
\hline All-cause mortality & - & - & - & - & - \\
\hline Sudden death & - & - & - & - & - \\
\hline Safety outcomes & $\begin{array}{l}\text { Number of } \\
\text { studies }\end{array}$ & $\begin{array}{l}\text { Risk Ratio } \\
\text { (RR) }\end{array}$ & $\begin{array}{l}95 \% \text { Confidence } \\
\text { interval }\end{array}$ & $\begin{array}{l}\text { Events, inter- } \\
\text { vention }\end{array}$ & $\begin{array}{l}\text { Events, } \\
\text { control }\end{array}$ \\
\hline Major bleeding & - & - & - & - & - \\
\hline Minor bleeding & - & - & - & - & - \\
\hline Thrombocytopenia & - & - & - & - & - \\
\hline Fontaine 2006 & & & & & \\
\hline
\end{tabular}

DVT: deep vein thrombosis

PE: pulmonary embolism

VTE: venous thromboembolism 


\section{A P P E N D I CES}

\section{Appendix 1. MEDLINE Ovid and Cochrane search strategy}

1. $\exp$ Thrombosis/pc

2. exp Embolism/pc

3. (thrombosis or thrombotic or thrombus or thrombi or thromboembol ${ }^{\star}$ ).tw.

4. (emboli* or embolus).tw.

6. clot?.tw.

7. (DVT or VTE or PE).tw.

8. or/1-7

9. exp Anticoagulants/

10. anticoagulant ${ }^{\star}$. tw.

11. (hydroxycoumarins or acenocoumarol or acenocoumar* or minisintrom or nicoumalone or s?nc?umar or sintrom or s?nthrom* or ancrod or ancrod or arvin or venacil or agkistrodon or arwinor or (blood adj3 coagulat* adj3 inhibit*) or "citric acid" or uralyt or dalteparin or tedelparin or fr-860 or fr860 or dalteparin or kabi2165 or kabi-2165 or fragmin* or "dermatan sulfate" or chondroitin or dextran or dextrans or hemodex or promit or macrodex or saviosol or rheodextran or polyglucin or hyskon or rheomacrodex or infukoll or rheopolyglucin or rheoisodex or rondex or dic?umarol or dicoumarin or bishydroxycoumarin or edetic or tetracemate or calcitetracemate or edta or ethylenedinitrilotetraacetic or edetate or (calcium adj3 tetacine) or versenate or coprin or edathamil or versene or dinitrilotetraacetate or "chelaton 3" or enoxaparin* or pk10169 or "pk 10169" or emt-967 or emt96* or clexane or lovenox or emt-966 or (ethyl adj3 biscoumacetate) or ethyldicoumarol or pelentan or tromexan or carbethoxydicoumarol or foy or gabexate or heparin ${ }^{\star}$ or at?eroid* or liquaemin or nadroparin* or fraxiparin* or cy-216 or cy216 or "pentosan sulfuric polyester" or "pentosan sulphuric polyester" or ((polysulfate or polysulphate) adj sodium adj pentosan ${ }^{\star}$ ) or ((sulfuric or sulphuric) adj polyester adj pentosan*) or fibrocid or ((hoe or bay or hoe-bay) adj "946") or ((pentosan* or polypentose or xylan) adj (sulphate or sulfate or sp54 or sp-54 or polysulfate* or polysulphate*)) or pz68 or pz-68 or elmiron or hemoclar or phenindione or pindione or phenyline or fenilin or phenylindanedione or dindevan or phenprocoumon or falithrom or phenprogramma or phenprocoumalol or marcumar or phenylpropylhydroxycumarinum or phenprocoumarol or liquamar or marcoumar or "protein c" or "protein s" or warfarin marevan or coumadin* or warfant or aldocumar or tedicumar or "beta 2-glycoprotein $\mathrm{i}$ " or apo-h or anticardiolipin or "apoliprotein h" or ec-vmfa or "endothelial cell viability maintaining factor" or "beta(2)gpi").tw.

12. exp Stockings, Compression/

13. exp Intermittent Pneumatic Compression Devices/

14. ((compression* or thromboembolism-deterrent or anti-embolism or TED) adj3 (stocking* or hose or hosiery or device*)).tw.

15. (prophylaxis or prophylactic).tw.

16. pc.fs.

17. (prevent ${ }^{\star}$ or reduce or reduction or diminish or decrease ${ }^{\star}$ or inhibit $\left.{ }^{\star}\right)$.tw.

18. or/9-17

19. exp Medical Order Entry Systems/

20. exp Reminder Systems/

21. exp Drug Therapy, Computer-Assisted/

22. (("computeri?ed physician" or system) adj5 "order entry").tw.

23. CPOE.tw.

24. ((computeri?ed or automat ${ }^{\star}$ or medicat ${ }^{\star}$ or electronic $\left.{ }^{\star}\right)$ adj5 $\left(\right.$ alert $^{\star}$ or reminder $\left.\left.^{\star}\right)\right)$.tw.

25. sticker?.tw.

26. prescription aid?.tw.

27. exp Decision Support Systems, Clinical/

28. decision support.tw.

29. CDS.tw.

30. e-iatrogenesis.tw.

31. alert fatigue.tw.

32. electronic tool?.tw.

33. exp Guideline/

34. exp Guidelines as Topic/

35. exp Guideline Adherence/

36. exp Clinical Protocols/

37. protocol $^{\star}$.tw.

38. guideline*.tw.

39. adhere ${ }^{\star}$. tw.

40. (comply or compliance).tw.

41. or/19-40

42. exp Inpatients/ or exp Hospitalization/ or exp Hospitals/

43. (inpatient* or "in?patient*").tw.

44. exp Adolescent, Hospitalized/ or exp Child, Hospitalized/

45. (hospitali? $\mathrm{e}^{\star}$ or hospitali?ation).tw. 
46. (admitted adj3 (hospital or patient $\left.\left.{ }^{\star}\right)\right)$.tw.

47. ("high risk" or "at risk").tw.

48. or/42-47

49. thromboprophyla*.mp.

50.8 and 18 and 41 and 48

51.48 and 49

52.50 or 51

53. limit 52 to $y r=" 1980$-Current"

\section{Appendix 2. Embase Ovid search strategy}

1. exp thrombosis prevention/

2. exp embolism prevention/

3. (thrombosis or thrombotic or thrombus or thrombi or thromboembol*).tw.

4. (emboli* or embolus).tw.

5. (phlebothrombo* or phlebitis).tw.

6. exp blood clotting/

7. clot.tw.

8. (DVT or VTE or PE).ti,ab.

9. or/1-8

10. exp *anticoagulant agent/

11. anticoagulant ${ }^{\star}$.tw.

12. (hydroxycoumarins or acenocoumarol or acenocoumar ${ }^{\star}$ or minisintrom or nicoumalone or s?nc?umar or sintrom or s?nthrom* or ancrod or ancrod or arvin or venacil or agkistrodon or arwinor or (blood adj3 coagulat* adj3 inhibit*) or "citric acid" or uralyt or dalteparin or tedelparin or fr-860 or fr860 or dalteparin or kabi2165 or kabi-2165 or fragmin* or "dermatan sulfate" or chondroitin or dextran or dextrans or hemodex or promit or macrodex or saviosol or rheodextran or polyglucin or hyskon or rheomacrodex or infukoll or rheopolyglucin or rheoisodex or rondex or dic?umarol or dicoumarin or bishydroxycoumarin or edetic or tetracemate or calcitetracemate or edta or ethylenedinitrilotetraacetic or edetate or (calcium adj3 tetacine) or versenate or coprin or edathamil or versene or dinitrilotetraacetate or "chelaton 3" or enoxaparin* or pk10169 or "pk 10169" or emt-967 or emt96* or clexane or lovenox or emt-966 or (ethyl adj3 biscoumacetate) or ethyldicoumarol or pelentan or tromexan or carbethoxydicoumarol or foy or gabexate or heparin* or at?eroid* or liquaemin or nadroparin* or fraxiparin* or cy-216 or cy216 or "pentosan sulfuric polyester" or "pentosan sulphuric polyester" or ((polysulfate or polysulphate) adj sodium adj pentosan*) or ((sulfuric or sulphuric) adj polyester adj pentosan*) or fibrocid or ((hoe or bay or hoe-bay) adj "946") or ((pentosan* or polypentose or xylan) adj (sulphate or sulfate or sp54 or sp-54 or polysulfate* or polysulphate*)) or pz68 or pz-68 or elmiron or hemoclar or phenindione or pindione or phenyline or fenilin or phenylindanedione or dindevan or phenprocoumon or falithrom or phenprogramma or phenprocoumalol or marcumar or phenylpropylhydroxycumarinum or phenprocoumarol or liquamar or marcoumar or "protein c" or "protein s" or warfarin marevan or coumadin* or warfant or aldocumar or tedicumar or "beta 2-glycoprotein $\mathrm{i}$ " or apo-h or anticardiolipin or "apoliprotein $\mathrm{h}$ " or ec-vmfa or "endothelial cell viability maintaining factor" or "beta(2)gpi").tw.

13. exp compression stocking/

14. ((compression* or thromboembolism-deterrent or anti-embolism or TED) adj3 (stocking* or hose or hosiery)).tw.

15. (prophylaxis or prophylactic).tw.

16. pc.fs.

17. (prevent ${ }^{\star}$ or reduce or reduction or diminish or decrease ${ }^{\star}$ or inhibit $\left.{ }^{\star}\right)$.tw.

18. or $/ 10-17$

19. exp hospital information system/

20. exp reminder system/

21. exp computer assisted drug therapy/

22. (("computeri?ed physician" or system) adj5 "order entry").tw.

23. CPOE.tw.

24. ((computeri?ed or automat ${ }^{\star}$ or medicat $^{\star}$ or electronic $\left.{ }^{\star}\right)$ adj5 (alert ${ }^{\star}$ or reminder $\left.\left.^{\star}\right)\right)$.tw.

25. sticker*.tw.

26. prescription aid*.tw.

27. exp decision support system/

28. "decision support".tw.

29. CDS.tw.

30. e-iatrogenesis.tw.

31. alert fatigue.tw.

32. electronic tool ${ }^{*}$.tw.

33. exp practice guideline/

34. exp clinical protocol/

35. (protocol ${ }^{\star}$ or guideline ${ }^{\star}$ or adhere $\left.{ }^{\star}\right)$.tw.

36. (comply or compliance).tw.

37. or/19-36 
38. exp hospital patient/ or exp hospitalization/ or ( ${ }^{*} \exp { }^{*}$ hospital/ and exp patient/)

39. (inpatient* or "in?patient").tw.

40. (hospitali? $\mathrm{e}^{\star}$ or hospitali?ation).tw.

41. (admitted adj3 (hospital or patient $\left.{ }^{\star}\right)$ ).tw.

42. ("high risk" or "at risk").tw.

43. or/38-42

44. thromboprophyla*.mp.

45. 9 and 18 and 37 and 43

46.43 and 44

47.45 or 46

48. limit 47 to $y r=" 1980$-Current"

\section{Appendix 3. BIOSIS previews Ovid search strategy}

1. (thrombosis or thrombotic or thrombus or thrombi or thromboembol $\left.{ }^{\star}\right)$.mp.

2. (emboli* or embolus).mp.

3. (phlebothrombo* or phlebitis).mp.

4. clot $^{\star} . \mathrm{mp}$.

5. (DVT or VTE or PE).tw.

6. or/1-5

7. anticoagulant ${ }^{\star} . \mathrm{mp}$.

8. (hydroxycoumarins or acenocoumarol or acenocoumar ${ }^{\star}$ or minisintrom or nicoumalone or s?nc?umar or sintrom or s?nthrom* or ancrod or ancrod or arvin or venacil or agkistrodon or arwinor or (blood adj3 coagulat* adj3 inhibit*) or "citric acid" or uralyt or dalteparin or tedelparin or fr-860 or fr860 or dalteparin or kabi2165 or kabi-2165 or fragmin* or "dermatan sulfate" or chondroitin or dextran or dextrans or hemodex or promit or macrodex or saviosol or rheodextran or polyglucin or hyskon or rheomacrodex or infukoll or rheopolyglucin or rheoisodex or rondex or dic?umarol or dicoumarin or bishydroxycoumarin or edetic or tetracemate or calcitetracemate or edta or ethylenedinitrilotetraacetic or edetate or (calcium adj3 tetacine) or versenate or coprin or edathamil or versene or dinitrilotetraacetate or "chelaton 3" or enoxaparin* or pk10169 or "pk 10169" or emt-967 or emt96* or clexane or lovenox or emt-966 or (ethyl adj3 biscoumacetate) or ethyldicoumarol or pelentan or tromexan or carbethoxydicoumarol or foy or gabexate or heparin ${ }^{\star}$ or at?eroid ${ }^{\star}$ or liquaemin or nadroparin* or fraxiparin* or cy-216 or cy216 or "pentosan sulfuric polyester" or "pentosan sulphuric polyester" or ((polysulfate or polysulphate) adj sodium adj pentosan ${ }^{\star}$ ) or ((sulfuric or sulphuric) adj polyester adj pentosan*) or fibrocid or ((hoe or bay or hoe-bay) adj "946") or ((pentosan* or polypentose or xylan) adj (sulphate or sulfate or sp54 or sp-54 or polysulfate* or polysulphate*)) or pz68 or pz-68 or elmiron or hemoclar or phenindione or pindione or phenyline or fenilin or phenylindanedione or dindevan or phenprocoumon or falithrom or phenprogramma or phenprocoumalol or marcumar or phenylpropylhydroxycumarinum or phenprocoumarol or liquamar or marcoumar or "protein c" or "protein s" or warfarin marevan or coumadin* or warfant or aldocumar or tedicumar or "beta 2-glycoprotein i" or apo-h or anticardiolipin or "apoliprotein $\mathrm{h}$ " or ec-vmfa or "endothelial cell viability maintaining factor" or "beta(2)gpi").tw.

9. ((compression* or thromboembolism-deterrent or anti-embolism or TED) adj3 (stocking* or hose or hosiery)).mp.

10. (prophylaxis or prophylactic).mp.

11. prevent $^{\star}$ or reduce or reduction or diminish or decrease ${ }^{\star}$ or inhibit $\left.{ }^{\star}\right) . \mathrm{mp}$.

12. or/7-11

13. (("computeri?ed physician" or system) adj5 "order entry").tw.

14. CPOE.tw.

15. ((computeri?ed or automat ${ }^{\star}$ or medicat $^{\star}$ or electronic $\left.{ }^{\star}\right)$ adj5 $\left(\right.$ alert $^{\star}$ or reminder $\left.\left.^{\star}\right)\right)$.tw.

16. sticker*.tw.

17. prescription aid*.tw.

18. "decision support".tw.

19. CDS.tw.

20. e-iatrogenesis.tw.

21. alert fatigue.tw.

22. electronic tool ${ }^{\star}$.tw.

23. (guideline ${ }^{\star}$ or protocol$^{\star}$ or adhere $\left.{ }^{\star}\right)$.tw.

24. (comply or compliance).tw.

25. or/13-24

26. (inpatient* or "in?patient").tw.

27. (hospitali? $\mathrm{e}^{\star}$ or hospitali?ation).tw.

28. (admit* adj3 (hospital or patient*)).tw.

29. ("high risk" or "at risk").tw.

30. or/26-29

31. thromboprophyla*.mp.

32.6 and 12 and 25 and 30

33. 30 and 31

34.32 or 33 


\section{Appendix 4. CINAHL search strategy}

\section{S46 S44 OR S45}

S45 S42 AND S43

S44 S8 AND S15 AND S32 AND S42

S43TI thromboprophyla* OR AB thromboprophyla*

S42 S33 OR S34 OR S35 OR S36 OR S37 OR S38 OR S39 OR S40 OR S41

S41TI ("high risk" OR "at risk") OR AB ("high risk" OR "at risk")

S40TI (admitted N3 (hospital or patient*)) OR AB (admitted N3 (hospital or patient $\left.{ }^{\star}\right)$ )

S39TI (hospitali? $e^{\star}$ OR hospitali?ation) OR AB (hospitali?e* OR hospitali?ation)

S38(MH "Child, Hospitalized")

S37(MH "Adolescent, Hospitalized")

S36TI (inpatient* OR in?patient ${ }^{\star}$ ) OR AB (inpatient* OR in?patient ${ }^{\star}$ )

S35(MH "Hospitals+")

S34(MH "Hospitalization+")

S33(MH "Inpatients")

S32 S16 OR S17 OR S18 OR S19 OR S20 OR S21 OR S22 OR S23 OR S24 OR S25 OR S26 OR S27 OR S28 OR S29 OR S30 OR S31

S31TI (protocol* or guideline* OR adhere*) OR AB (protocol ${ }^{\star}$ or guideline* OR adhere*)

S30(MH "Practice Guidelines")

S29TI electronic tool ${ }^{*}$ OR AB electronic tool ${ }^{*}$

S28TI alert fatigue OR AB alert fatigue

$\mathrm{S} 27 \mathrm{TI}$ e-iatrogenesis OR AB e-iatrogenesis

S26TI CDS OR AB CDS

S25TI decision support* OR AB decision support*

S24(MH "Decision Support Systems, Clinical")

S23TI prescription aid $^{\star}$ OR AB prescription aid*

S22TI sticker* OR AB sticker*

S21TI ((computeri?ed or automat* or medicat ${ }^{\star}$ or electronic $\left.{ }^{\star}\right)$ N5 (alert* or reminder $\left.{ }^{\star}\right)$ ) OR AB ((computeri?ed or automat* or medicat ${ }^{\star}$ or electronic ${ }^{\star}$ ) N5 (alert* or reminder $\left.{ }^{\star}\right)$ )

S20TI CPOE OR AB CPOE

S19TI (("computeri?ed physician" or system) N5 "order entry") OR AB (("computeri?ed physician" or system) N5 "order entry")

S18(MH "Drug Therapy, Computer Assisted")

S17(MH "Reminder Systems")

S16(MH "Electronic Order Entry")

S15 S9 OR S10 OR S11 OR S12 OR S13 OR S14

S14TI (prevent* or reduce or reduction or diminish or decrease* or inhibit ${ }^{\star}$ ) OR AB (prevent ${ }^{\star}$ or reduce or reduction or diminish or decrease* or inhibit*)

S13TI (prophylaxis or prophylactic) OR AB (prophylaxis or prophylactic)

S12TI ((compression* or thromboembolism-deterrent or anti-embolism or TED) N3 (stocking* or hose or hosiery or device*)) OR AB ((compression* or thromboembolism-deterrent or anti-embolism or TED) N3 (stocking ${ }^{\star}$ or hose or hosiery or device*))

S11(MH "Compression Garments")

S10TI anticoagulant* OR AB anticoagulant*

S9(MH "Anticoagulants+")

S8 S1 OR S2 OR S3 OR S4 OR S5 OR S6 OR S7

S7TX (DVT OR VTE OR PE) OR AB (DVT OR VTE OR PE)

S6TX (clot or clots) OR AB (clot or clots)

S5TX (phlebothrombo* or phlebitis) OR AB (phlebothrombo* or phlebitis)

S4TX (emboli* OR embolus) OR AB (emboli* or embolus)

S3TX (thrombosis or thrombotic or thrombus or thrombi or thromboembol*) OR AB (thrombosis or thrombotic or thrombus or thrombi or thromboembol $\left.{ }^{\star}\right)$

$\mathrm{S} 2$ (MH "Embolism+/PC")

S1(MH "Thrombosis+/PC")

\section{Appendix 5. WEB OF SCIENCE search strategy}

\#1 TS=(thrombosis or thrombotic or thrombus or thrombi or thromboembol* OR emboli* OR embolus OR phlebothrombo* or phlebitis OR clot OR DVT OR VTE OR PE)

\#2 TS=(anticoagulant* OR hydroxycoumarins or acenocoumarol or acenocoumar ${ }^{\star}$ or minisintrom or nicoumalone or s?nc?umar or sintrom or s?nthrom* or ancrod or ancrod or arvin or venacil or agkistrodon or arwinor or (blood NEAR/3 coagulat* NEAR/3 inhibit*) or "citric acid" or uralyt or dalteparin or tedelparin or fr-860 or fr860 or dalteparin or kabi2165 or kabi-2165 or fragmin* or "dermatan sulfate" or chondroitin or dextran or dextrans or hemodex or promit or macrodex or saviosol or rheodextran or polyglucin or hyskon or rheomacrodex or infukoll or rheopolyglucin or rheoisodex or rondex or dic?umarol or dicoumarin or bishydroxycoumarin or edetic or tetracemate or calcitetracemate or edta or ethylenedinitrilotetraacetic or edetate or (calcium NEAR/3 tetacine) or versenate or coprin or edathamil or 
versene or dinitrilotetraacetate or "chelaton 3" or enoxaparin* or pk10169 or "pk 10169" or emt-967 or emt96* or clexane or lovenox or emt-966 or (ethyl NEAR/3 biscoumacetate) or ethyldicoumarol or pelentan or tromexan or carbethoxydicoumarol or foy or gabexate or heparin* or at?eroid* or liquaemin or nadroparin* or fraxiparin* or cy-216 or cy216 or "pentosan sulfuric polyester" or "pentosan sulphuric polyester" or ((polysulfate or polysulphate) NEAR/1 sodium NEAR/1 pentosan*) or ((sulfuric or sulphuric) NEAR/1 polyester NEAR/1 pentosan*) or fibrocid or ((hoe or bay or hoe-bay) NEAR/1 "946") or ((pentosan* or polypentose or xylan) NEAR/1 (sulphate or sulfate or sp54 or sp-54 or polysulfate* or polysulphate*)) or pz68 or pz-68 or elmiron or hemoclar or phenindione or pindione or phenyline or fenilin or phenylindanedione or dindevan or phenprocoumon or falithrom or phenprogramma or phenprocoumalol or marcumar or phenylpropylhydroxycumarinum or phenprocoumarol or liquamar or marcoumar or "protein c" or "protein s" or warfarin marevan or coumadin* or warfant or aldocumar or tedicumar or "beta 2-glycoprotein i" or apo-h or anticardiolipin or "apoliprotein h" or ec-vmfa or "endothelial cell viability maintaining factor" or "beta(2)gpi" OR ((compression* or thromboembolism-deterrent or anti-embolism or TED) NEAR/3 (stocking ${ }^{\star}$ or hose or hosiery)) OR prophylaxis or prophylactic or prevent ${ }^{\star}$ or reduce or reduction or diminish or decrease ${ }^{\star}$ or inhibit $\left.{ }^{\star}\right)$

\#3 TS=((("computeri?ed physician" or system) NEAR/5 "order entry") OR CPOE OR ((computeri?ed or automat* or medicat* or electronic*) NEAR/5 (alert* or reminder $\left.{ }^{\star}\right)$ ) or sticker* OR "prescription aid" ${ }^{\star}$ OR "decision support" OR CDS OR e-iatrogenesis OR "alert fatigue" OR "electronic tool*" OR guideline* or protocol $^{\star}$ OR adhere* OR comply or compliance)

\#4 TS=(inpatient* OR "in-patient*" or hospitali?e* or hospitali?ation or (admitted NEAR/3 (hospital* or patient")) OR "high risk" or "at risk") \#5 TS=(thromboprophyla*)

\#6 \#4 AND \#3 AND \#2 AND \#1

\#7 \#5 AND \#4

\#8 \#7 OR \#6

\section{Appendix 6. LILACS Search Strategy}

((thrombosis or thrombotic or thrombus or thrombi or thromboembol* or phlebothrombo* or phlebitis or clot* or DVT or VTE) AND (prophylaxis or prophylactic or prevent ${ }^{\star}$ or reduce or reduction or diminish or decrease* or inhibit $\left.{ }^{\star}\right)$ ) OR thromboprophyla*

\section{Appendix 7. PubMed search strategy}

\#65,"Search \#64 NOT medline[sb]"

\#64,"Search \#62 OR \#63"

\#63,"Search \#60 AND \#61"

\#62,"Search \#15 AND \#27 AND \#52 AND \#60"

\#61,"Search thromboprophyla*[tw]"

\#60,"Search \#52 OR \#53 OR \#54 OR \#55 OR \#56 OR \#58 OR \#59"

\#59,"Search high risk[tw] or at risk[tw]"

\#58,"Search admitted[tw] AND (hospital[tw] or patient[tw] or patients[tw])"

\#56,"Search hospitalise ${ }^{\star}[\mathrm{tw}]$ or hospitalisation[tw] or hospitalize* $[\mathrm{tw}]$ or hospitalization[tw]"

\#55,"Search Adolescent, Hospitalized[Mesh] or Child, Hospitalized[Mesh]"

\#54,"Search inpatient[tw] or inpatients[tw] or in-patient[tw] or in-patients[tw]"

\#53,"Search Inpatients[Mesh] or Hospitalization[Mesh] or Hospitals[Mesh]"

\#52,"Search \#29 OR \#30 OR \#31 OR \#32 OR \#33 OR \#34 OR \#35 OR \#36 OR \#37 OR \#38 OR \#39 OR \#40 OR \#41 OR \#42 OR \#43 OR \#44 OR \#45 OR \#46 OR \#47 OR \#48 OR \#49 OR \#50 OR \#51"

\#51,"Search comply[tw] or compliance[tw]"

\#50,"Search adhere*[tw]"

\#49,"Search guideline ${ }^{\star}[\mathrm{tw}] "$

\#48,"Search protocol*[tw]"

\#47,"Search Clinical Protocols[Mesh]"

\#46,"Search Guideline Adherence[Mesh]"

\#45,"Search Guidelines as Topic[Mesh]"

\#44,"Search Guideine[Mesh] Schema: all"

\#43,"Search Guideine[Mesh]"

\#42,"Search electronic tool* [tw]"

\#41,"Search alert fatigue[tw]"

\#40,"Search e-iatrogenesis[tw]"

\#39,"Search CDS[tw]"

\#38,"Search decision support[tw]"

\#37,"Search "'Decision Support Systems, Clinical"'[Mesh]"

\#36,"Search prescription aid*[tw]"

\#35,"Search sticker ${ }^{\star}[\mathrm{tw}] "$

\#34,"Search ((computerised or computerized or automat ${ }^{\star}$ or medicat ${ }^{\star}$ or electronic $\left.{ }^{\star}\right)$ AND (alert* or reminder $\left.\left.^{\star}\right)\right)[$ tw]"

\#33,"Search CPOE[tw]"

\#32,"Search (("'computerised physician"'" or "'computerized physician"" or system) AND "'order entry"')[tw]"

\#31,"Search ""Drug Therapy, Computer-Assisted""[Mesh]"

\#30,"Search "'Reminder Systems"'[Mesh]"

Interventions for implementation of thromboprophylaxis in hospitalized patients at risk for venous thromboembolism (Review)

Copyright (c) 2018 The Cochrane Collaboration. Published by John Wiley \& Sons, Ltd. 
\#29,"Search "'Medical Order Entry Systems"" [Mesh]"

\#27,"Search \#16 OR \#17 OR \#19 OR \#21 OR \#23 OR \#24 OR \#25 OR \#26"

\#26,"Search prevent ${ }^{\star}[\mathrm{tw}]$ or reduce[tw] or reduction[tw] or diminish[tw] or decrease*[tw] or inhibit*[tw]"

\#25,"Search prophylaxis[tw] or prophylactic[tw]"

\#24,"Search ((compression* or thromboembolism-deterrent or anti-embolism or TED) AND (stocking* or hose or hosiery or device*))[tw]" \#23,"Search ""Intermittent Pneumatic Compression Devices"'[Mesh]"

\#21,"Search ""Stockings, Compression""[Mesh]"

\#19,"Search hydroxycoumarins[tw] or acenocoumarol[tw] or acenocoumar* [tw] or minisintrom[tw] or nicoumalone[tw] or syncumar[tw] or sintrom [tw] or sinthrom ${ }^{\star}[\mathrm{tw}]$ or synthrom ${ }^{*}[\mathrm{tw}]$ or ancrod[tw] or arvin[tw] or venacil[tw] or agkistrodon[tw] or arwinor[tw] or blood coagulation inhibitor[tw] or blood coagulation inhibitors[tw] or citric acid[tw] or uralyt[tw] or dalteparin[tw] or tedelparin[tw] or fr-860[tw] or fr860[tw] or dalteparin[tw] or kabi2165[tw] or kabi-2165[tw] or fragmin*[tw] or ""dermatan sulfate" "[tw] or chondroitin[tw] or dex$\operatorname{tran}[\mathrm{tw}]$ or dextrans[tw] or hemodex[tw] or promit[tw] or macrodex[tw] or saviosol[tw] or rheodextran[tw] or polyglucin[tw] or hyskon[tw] or rheomacrodex[tw] or infukoll[tw] or rheopolyglucin[tw] or rheoisodex[tw] or rondex[tw] or dicumarol[tw] or dicoumarol[tw] or dicoumarin[tw] or bishydroxycoumarin[tw] or edetic[tw] or tetracemate[tw] or calcitetracemate[tw] or edta[tw] or ethylenedinitrilotetraacetic [tw] or edetate[tw] or (calcium AND tetacine)[tw] or versenate[tw] or coprin[tw] or edathamil[tw] or versene[tw] or dinitrilotetraacetate[tw] or ""chelaton 3""[tw] or enoxaparin*[tw] or pk10169[tw] or ""pk 10169""[tw] or emt-967[tw] or emt96*[tw] or clexane[tw] or lovenox[tw] or emt-966[tw] or ""ethyl biscoumacetate""'[tw] or ethyldicoumarol[tw] or pelentan[tw] or tromexan[tw] or carbethoxydicoumarol[tw] or foy[tw] or gabexate[tw] or heparin* [tw] or ateroid*[tw] or atheroid*[tw] or liquaemin[tw] or nadroparin*[tw] or fraxiparin*[tw] or cy-216[tw] or cy216[tw] or ""pentosan sulfuric polyester""[tw] or ""pentosan sulphuric polyester""[tw] or ((polysulfate or polysulphate) AND sodium AND pentosan*) [tw] or ((sulfuric or sulphuric) AND polyester AND pentosan*)[tw] or fibrocid[tw] or ((hoe or bay or hoe-bay) AND "'946"')[tw] or ((pentosan* or polypentose or xylan) [tw] AND (sulphate or sulfate or sp54 or sp-54 or polysulfate* or polysulphate*))[tw] or pz68[tw] or pz-68[tw] or elmiron[tw] or hemoclar[tw] or phenindione[tw] or pindione[tw] or phenyline[tw] or fenilin[tw] or phenylindanedione [tw] or dindevan[tw] or phenprocoumon[tw] or falithrom[tw] or phenprogramma[tw] or phenprocoumalol[tw] or marcumar[tw] or phenylpropylhydroxycumarinum[tw] or phenprocoumarol[tw] or liquamar[tw] or marcoumar[tw] or ""protein c""[tw] or ""protein s""[tw] or ""warfarin marevan""'[tw] or coumadin*[tw] or warfant[tw] or aldocumar[tw] or tedicumar[tw] or ""beta 2-glycoprotein i""[tw] or apo-h[tw] or anticardiolipin[tw] or ""apoliprotein $\mathrm{h}$ "'[tw] or ec-vmfa[tw] or "'endothelial cell viability maintaining factor""[tw] or ""beta(2)gpi""[tw]"

$\# 17$, ,Search anticoagulant ${ }^{\star}[$ tw]"

\#16,"Search "'Anticoagulants" "[Mesh]"

\#15,"Search \#7 OR \#8 OR \#9 OR \#10 OR \#11 OR \#12 OR \#14"

\#14,"Search DVT[tiab] OR VTE[tiab] OR PE[tiab]"

\#12,"Search clot[tw]

\#11,"Search phlebothrombo*[tw] or phlebitis[tw]"

\#10,"Search emboli[tw] or embolus[tw]"

\#9,"Search thrombosis[tw] or thrombotic[tw] or thrombus[tw] or thrombi[tw] or thromboembol*[tw]"

\#8,"Search "'Embolism/prevention and control"'[Mesh]"

\#7,"Search ""Thrombosis/prevention and control""[Mesh]"

\section{Appendix 8. Clinicaltrials.gov search strategy}

thrombosis or thrombotic or thrombus or thrombi or thromboembol* or emboli* or embolus or phlebothrombo* or phlebitis or clot or clots or DVT or VTE or PE

\section{Appendix 9. Funnel Plots}

Figure 4; Figure 5; Figure 6; Figure 7; Figure 8

Appendix 10. Influence analysis

Influence analyses

\section{Alerts - Received prophylaxis}

\begin{tabular}{llll}
\hline Study omitted & RD estimate without study & 95\% Confidence interval \\
\hline Kucher 2005 & 0.21 & 0.06 & 0.36 \\
\hline Overhage 1996 & 0.22 & 0.16 & 0.28 \\
\hline
\end{tabular}


(Continued)

\begin{tabular}{lccc} 
Piazza 2009 & 0.19 & 0.16 & 0.22 \\
\hline Combined & 0.21 & 0.15 & 0.27 \\
\hline
\end{tabular}

\begin{tabular}{llll}
\hline \multicolumn{2}{l}{ Alerts - Received appropriate prophylaxis } & & \\
\hline Study omitted & RD estimate without study & $\mathbf{9 5 \%}$ Confidence interval \\
\hline Chapman 2011 & 0.16 & 0.12 & 0.21 \\
\hline Dexter 2001 & 0.14 & 0.06 & 0.22 \\
\hline Garcia 2009 & 0.16 & 0.12 & 0.20 \\
\hline Combined & 0.16 & 0.12 & 0.20 \\
\hline
\end{tabular}

\begin{tabular}{llll}
\hline Alerts - Symptomatic VTE & & & \\
\hline Study omitted & RR estimate without study & 95\% Confidence interval \\
\hline Chapman 2011 & 0.65 & 0.50 & 0.85 \\
\hline Kucher 2005 & 0.57 & 0.18 & 1.86 \\
\hline Piazza 2009 & 0.56 & 0.34 & 0.92 \\
\hline Combined & 0.64 & 0.47 & 0.86 \\
\hline
\end{tabular}

\section{Multifaceted interventions - Received prophylaxis (adjusted)}

\begin{tabular}{llll}
\hline Study omitted & RD estimate without study & 95\% Confidence interval \\
\hline Anderson 1994 & 0.04 & 0.01 & 0.06 \\
\hline Cavalcanti 2016 & 0.04 & 0.02 & 0.06 \\
\hline Labarere 2007 & 0.03 & 0.01 & 0.06 \\
\hline Pai 2013 & 0.04 & 0.02 & 0.06 \\
\hline Roy 2016 & 0.02 & -0.02 & 0.06 \\
\hline Combined & 0.04 & 0.02 & 0.06 \\
\hline
\end{tabular}

VTE: venous thromboembolism

\section{Appendix 11. Abbreviations}

CDSR: Cochrane Database of Systematic Rviews

CENTRAL: Cochrane Central Register of Controlled Trials 
$\mathrm{Cl}$ : confidence interval

CINAHL: Cumulative Index to Nursing and Allied Health Literature

CME: continuous medical education

Cochrane EPOC: Cochrane Effective Practice and Organisation of Care

CRT: cluster randomized controlled trial

DARE: Database of Abstracts of Reviews of Effects

DVT: deep vein thrombosis

GRADE: Grading of Recommendations Assessment, Development and Evaluation

$\mathrm{I}^{2}$ : statistical index of heterogeneity

ICC: intraclass correlation

LILACS: Latin American and Caribbean health sciences LIterature

MeSH: Medical Subject Headings

NHS EED: NHS Economic Evaluation Database

PE: pulmonary embolism

PICOS: patients, intervention, comparator, outcome, setting

QA: quality assurance

QRT: quasi-randomized controlled trial

RAP: received appropriate prophylaxis

$\mathrm{RCT}$ : randomized controlled trial

$\mathrm{RD}$ : risk difference

ROB: risk of bias

RP: received prophylaxis

RR: risk ratio

VTE: venous thromboembolism

\section{WHAT'S NEW}

\begin{tabular}{lll}
\hline Date & Event & Description \\
\hline 11 August 2017 & $\begin{array}{l}\text { New citation required but conclusions } \\
\text { have not changed }\end{array}$ & $\begin{array}{l}\text { focus of review changed from RCTs plus NRS to RCTs only; review } \\
\text { updated according to Cochrane current criteria, new authors } \\
\text { joined review team, no change to conclusions }\end{array}$ \\
\hline 7 January 2017 & New search has been performed & $\begin{array}{l}\text { searches rerun, five new studies included, three new studies ex- } \\
\text { cluded }\end{array}$ \\
\hline
\end{tabular}

\section{CONTRIBUTIONS OF AUTHORS}

1. Article reviewers: David Morrison (DM), Gisèle Diendéré (GD), Dr Susan Kahn (SK), Dr Adi J. Klil-Drori (AJK)

2. Resolving disputes: DM, GD, SK, AJK

3. Statistical expertise: Alexandre Piche (AP), Dr Kristian B Filion (KBF)

4. Content expertise: SK, KF, Dr Vicky Tagalakis (VT), Jessica Emed (JE), Dr André Roussin (AR), Dr William Geerts (WG)

5. Administrative coordination: DM

6. Literature searches: Martin Morris (MM), AJK, DM

7. Drafting the manuscript: DM, GD, SK

8. Revising the manuscript: DM, GD, SK, KBF, VT, JE, AR, AP, AJK, Dr James Douketis, (JD), MM, WG

\section{DECLARATIONS OF INTEREST}

The authors of this review did not receive any funding to undertake this review other than the peer-reviewed grant noted above. The authors report the following declarations of interest:

SK has received grant support from public granting agencies (CIHR) for research on the treatment of venous thrombosis. She participated in industry-sponsored advisory board meetings (Boehringer-Ingelheim, Servier Canada, one meeting for each entity), on the treatment of venous thrombosis and provided expert testimony for the Canadian Medical Protective Association. SK also reports that Sanofi Aventis has partnered with her institution to help create a center of excellence in thrombosis and anticoagulation.

DM: none known

GD: none known

AP: none known

Interventions for implementation of thromboprophylaxis in hospitalized patients at risk for venous thromboembolism (Review) 
KBF: none known

AJK: AJK's institution has received funds from the Young Investigator Award from the American Society of Clinical Oncology Conquer Cancer Foundation. AJK reports receiving payments from Bristol Myers Squibb for lectures.

JD: JD reports receiving funds from board memberships of Bayer, Boehringer-Ingelheim, Bristol-Myers-Squibb, Daiichi-Sankyo, Pfizer, and Sanofi; consultancy fees from Actelion, Janssen Research and Development; funds for speaking at educational activities; royalties from the Merck Manual, Up-to-Date; JD's institution has received a grant from Boehringer-Ingelheim.

JE: JE received an honorarium for participation in a single meeting (focus group) with LEO Pharma for work unrelated to the submitted review.

AR: AR reports board membership and consultancy activities for BMS, BI, Pfizer, and Bayer, and received payment for lectures from BMS, $\mathrm{BI}$, Bayer, and Pfizer not related to this review. AR also reports that his institution has received a CIHR grant for AIDS vascular research, and payment for development of educational presentations from BI, Bayer, BMS, and Pfizer for the preparation of university-accredited symposiums and slide kits.

VT: VT has received, and currently holds grant support from the CIHR for research in venous thrombosis; has engaged in lectures sponsored by companies that manufacture anticoagulants (Leo Pharma, Bristol Myer Squibb, and Pfizer); has received a grant from a manufacturer of an anticoagulant (Sanofi Aventis).

MM: reports receiving funds from American Academy of Clinical Toxicology for creation of search strategies for systematic reviews, and from International Team for Implantology for peer reviewing of search strategy.

WG: WG reports board membership (Canadian Patient Safety Institute (Safer Health Care Now) National lead for venous thromboembolism prevention), consultancy (Bayer Healthcare, Pfizer, Sanofi) and payment for lectures (Bayer Healthcare, Leo Pharma, Sanofi) and development of educational presentations (Bayer Healthcare, Leo Pharma). Other support has been received by his institution from Sanofi for clinical and quality of care outreach programs. WG reports that these relationships in no way impact on his involvement with this Cochrane review.

\section{SOURCES OF SUPPORT}

\section{Internal sources}

- Canadian Institutes for Health Research Knowledge Synthesis Grant (\#141001), Canada.

- Canadian Institutes for Health Research Foundation Grant (\#143346), Canada.

\section{External sources}

- Chief Scientist Office, Scottish Government Health Directorates, The Scottish Government, UK.

The Cochrane Vascular editorial base is supported by the Chief Scientist Office.

\section{DIFFERENCES BETWEEN PROTOCOLANDREVIEW}

Our previous review included both randomized trials and non-randomized studies (Kahn 2013). In this updated review, we decided to focus solely on randomized trials, as the risk of bias in the non-randomized studies included in our last review was high. Details of the non-randomized studies previously classed as included studies can be found in Kahn 2013. We had intended to address heterogeneity via subgroup analyses, but there were not enough trials in the meta-analysis in question to examine subgroup effects. We also had intended to assess publication bias via funnel plots and cumulative meta-analysis but there were not enough trials in each meta-analysis to meaningfully interpret these analyses. However, we presented the funnel plots for all analyses except the sensitivity analyses in Appendix 9 , for the sake of completeness.

We split the primary outcome 'Increase in the proportion of participants who received prophylaxis or received appropriate prophylaxis' into a primary outcome (Increase in the proportion of participants who received prophylaxis) and secondary outcome (Increase in the proportion of participants who received appropriate prophylaxis). We added the secondary outcomes 'decrease in the proportion of participants who developed any (i.e. symptomatic or asymptomatic) VTE (all VTE, any, proximal, or distal DVT, PE, fatal PE)' and decrease in the number of deaths (all-cause mortality, sudden death)'. We assessed the certainty of the evidence according to the GRADE approach.

\section{INDEX TERMS}

\section{Medical Subject Headings (MeSH)}

*Hospitalization; Anticoagulants [therapeutic use]; Australia; Europe; Hospitals; North America; Postoperative Complications [epidemiology] [prevention \& control]; Pulmonary Embolism [epidemiology] [prevention \& control]; Randomized Controlled Trials as Topic; Venous Thromboembolism [epidemiology] [ ${ }^{\star}$ prevention \& control]; Venous Thrombosis [epidemiology] [prevention \& control]

\section{MeSH check words}

Adult; Humans 